\title{
IntechOpen
}

\section{Mitochondria and Brain Disorders}

\author{
Edited by Stavros Baloyannis
}

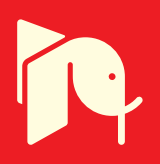





\section{Mitochondria and Brain Disorders}

Edited by Stavros Baloyannis 

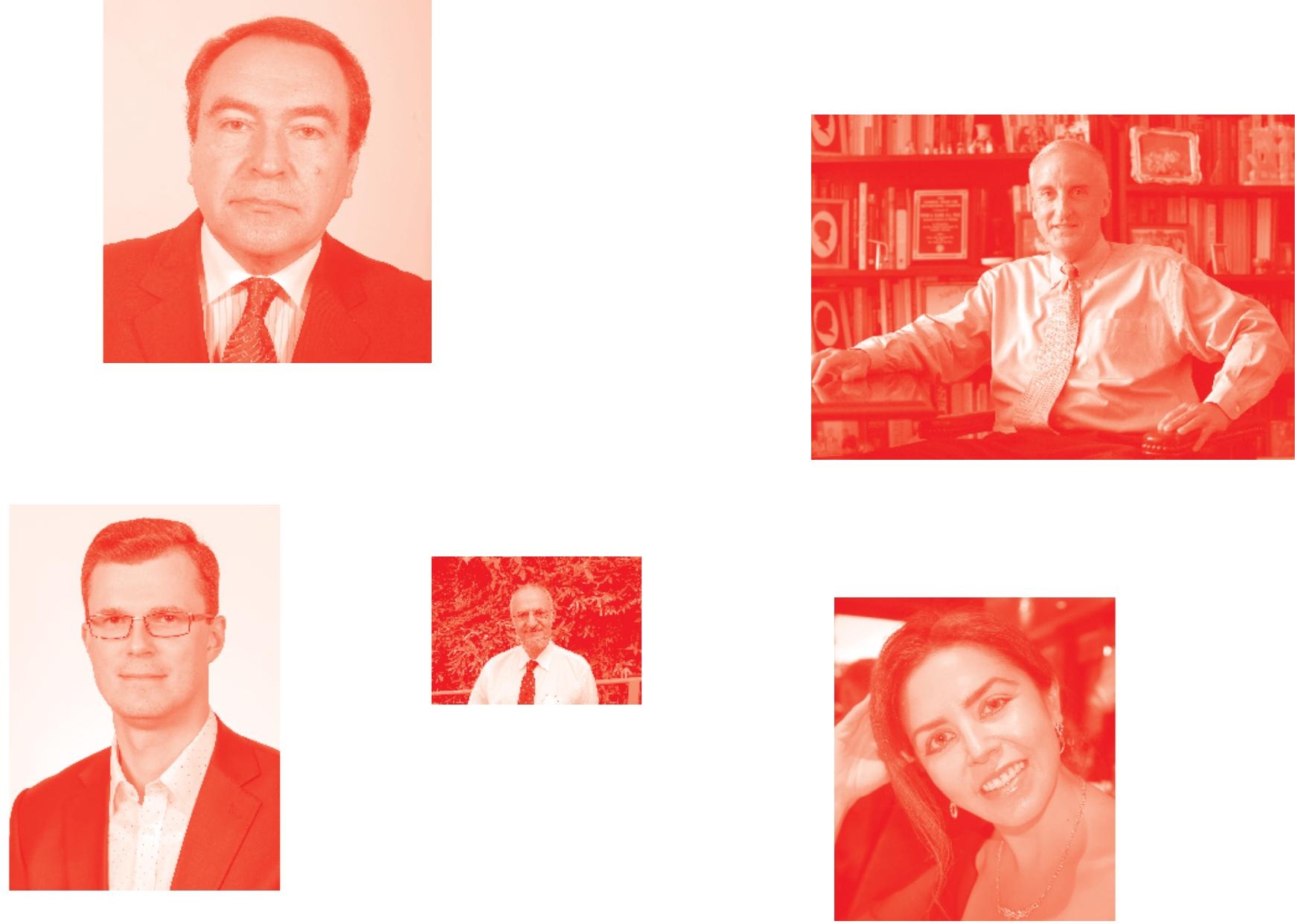

Supporting open minds since 2005
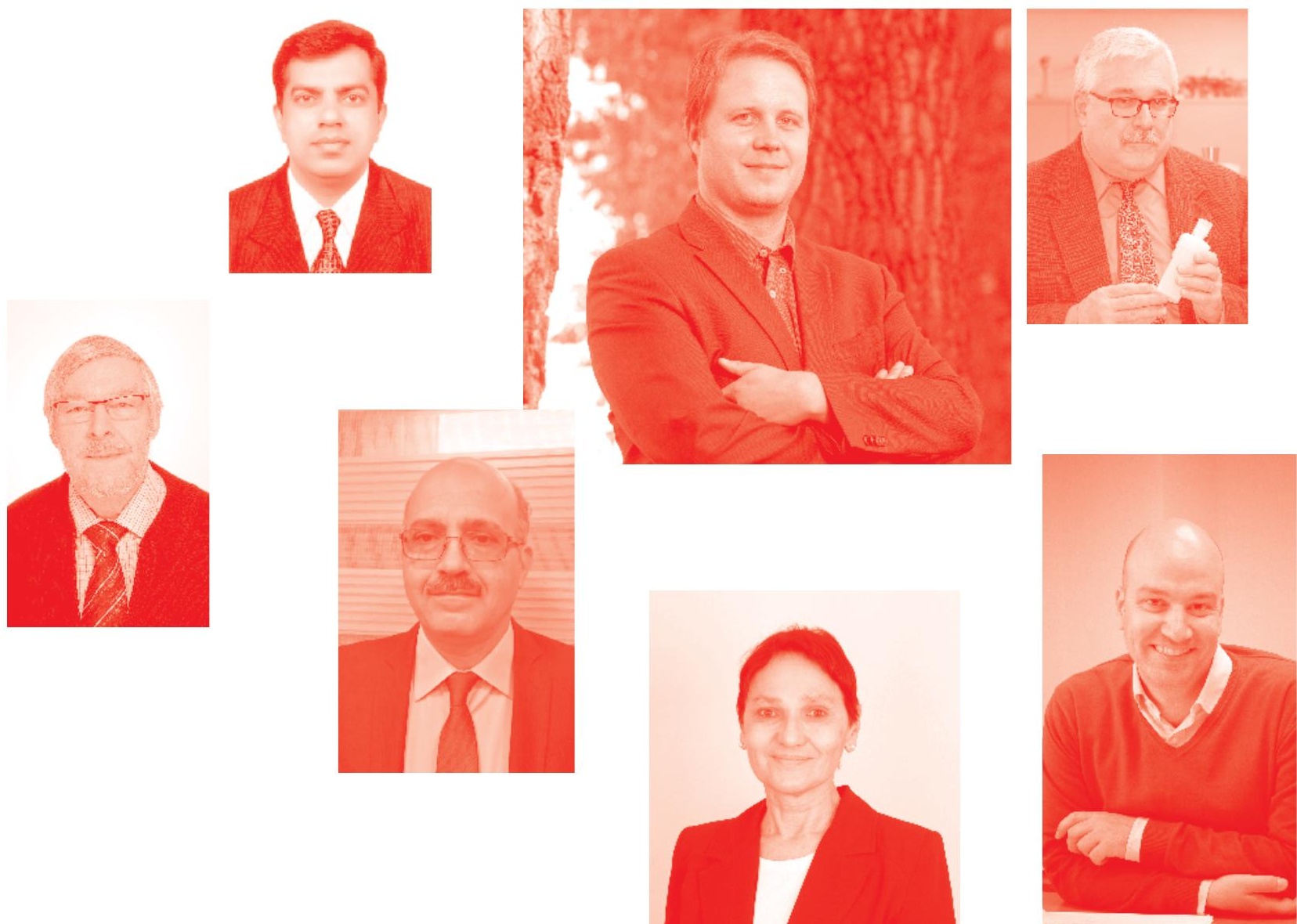
Mitochondria and Brain Disorders

http : //dx . doi . org/10.5772/intechopen. 77668

Edited by Stavros Baloyannis

\section{Contributors}

Lovelesh Kumar Nigam, Aruna V Vanikar, Rashmi D, Kamal V Kanodia, Kamlesh S Suthar, Hideo Tsukada, Xianquan Zhan, Na Li, Cheril Tapia-Rojas, Angie K. Torres, Margrethe A. Olesen, Claudia Jara, Ekaterina Alexandrovna Nikolaeva, Ilgar Mamedov, Irina Zolkina, Stavros J Baloyannis

() The Editor(s) and the Author(s) 2020

The rights of the editor(s) and the author(s) have been asserted in accordance with the Copyright, Designs and Patents Act 1988. All rights to the book as a whole are reserved by INTECHOPEN LIMITED . The book as a whole (compilation) cannot be reproduced, distributed or used for commercial or non-commercial purposes without INTECHOPEN LIMITED's written permission. Enquiries concerning the use of the book should be directed to INTECHOPEN LIMITED rights and permissions department (permissions@intechopen.com).

Violations are liable to prosecution under the governing Copyright Law .

\section{(cc) BY}

Individual chapters of this publication are distributed under the terms of the Creative Commons Attribution 3.0 Unported License which permits commercial use, distribution and reproduction of the individual chapters, provided the original author(s) and source publication are appropriately acknowledged. If so indicated, certain images may not be included under the Creative Commons license. In such cases users will need to obtain permission from the license holder to reproduce the material. More details and guidelines concerning content reuse and adaptation can be found at http : //www . intechopen . com/copyright-policy . html.

\section{Notice}

Statements and opinions expressed in the chapters are these of the individual contributors and not necessarily those of the editors or publisher. No responsibility is accepted for the accuracy of information contained in the published chapters. The publisher assumes no responsibility for any damage or injury to persons or property arising out of the use of any materials, instructions, methods or ideas contained in the book.

First published in London, United Kingdom, 2020 by IntechOpen IntechOpen is the global imprint of INTECHOPEN LIMITED, registered in England and Wales, registration number: 11086078 , 7th floor, 10 Lower Thames Street, London, EC3R 6AF, United Kingdom

Printed in Croatia

British Library Cataloguing-in-Publication Data

A catalogue record for this book is available from the British Library

Additional hard and PDF copies can be obtained from orders@intechopen.com

Mitochondria and Brain Disorders

Edited by Stavros Baloyannis

p. cm.

Print ISBN 978-1-78985-531-9

Online ISBN 978-1-78985-532-6

eBook (PDF) ISBN 978-1-78985-653-8 


\section{We are IntechOpen, \\ the world's leading publisher of Open Access books}

Built by scientists, for scientists

\section{$4,700+$}

Open access books available

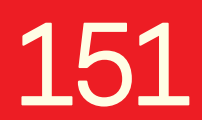

Countries delivered to
$120,000+$

International authors and editors

Our authors are among the

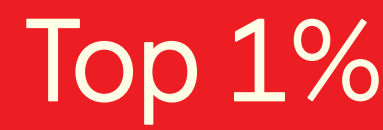

most cited scientists

Contributors from top 500 universities
$135 \mathrm{M}+$

Downloads

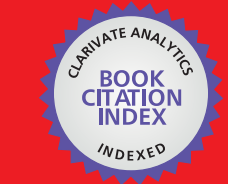

WEB OF SCIENCE ${ }^{\mathrm{MM}}$

Selection of our books indexed in the Book Citation Index in Web of Science ${ }^{\mathrm{TM}}$ Core Collection (BKCI)

\section{Interested in publishing with us? \\ Contact book.department@intechopen.com}

Numbers displayed above are based on latest data collected.

For more information visit www.intechopen.com 



\section{Meet the editor}

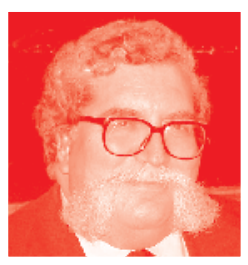

Stavros J. Baloyannis is a Professor Emeritus of neurology at the Aristotelian University, Thessaloniki, Greece and he was born in Thessaloniki. He graduated from the School of Medicine, Aristotelian University. His training was in neurology at the Aristotelian University and Institute of Neurology, London. He undertook training in neuropathology and electron microscopy at the Institute of Neurology, London, Catholic University of Louvain, University of Pennsylvania, as well as in acoustic-neuropathology at Harvard University. He is also trained in neuroimmunology from Yale University. His research interests include $\mathrm{BBB}$, mitochondria in $\mathrm{AD}$, synaptogenesis, neurodegeneration, dendritic and synaptic pathology, and the golgi apparatus in dementias. His special interests are neuroethics, neurolinguistics, neurophilosophy, the history of neurosciences, neurology and art. He is a member of 60 scientific societies and an honorable member of the Academy of Hellenic Air Forces. He is President of the Society for the Amelioration of the Quality of Life in Neurological Diseases and President of the Orthodox Association for Medical Mission. He has been a visiting professor at Tufts University, Democritus University, School of Theology, and School of Philosophy. He is the author of 28 textbooks and 725 papers on neurology, neurosciences and three books of poems. He was the Head of the Department of neurology (19922011) and Director of Research Institute for Alzheimer's Disease. 



\section{Contents}

Preface

Section 1

Introduction

Chapter 1

Introductory Chapter: Mitochondrial Alterations and Neurological

Disorders

by Stavros J. Baloyannis

\section{Section 2}

Mitochondria and Hormones

Chapter 2

Pathology Associated with Hormones of Adrenal Cortex

by Lovelesh K. Nigam, Aruna V. Vanikar, Rashmi D. Patel,

Kamal V. Kanodia and Kamlesh S. Suthar

Section 3

Mitochondrial Imaging

Chapter 3

PET Imaging of Mitochondrial Function in the Living Brain

by Hideo Tsukada

Section 4

Mitochondrial Function and Dysfunction

Chapter 4

Mitochondrial Proteomic and Molecular Network Alterations in

Human Ovarian Cancers

by Xianquan Zhan and $\mathrm{Na} \mathrm{Li}$

Chapter 5

Mitochondrial Dysfunction as a Key Event during Aging: From

Synaptic Failure to Memory Loss

by Claudia Jara, Angie K. Torres, Margrethe A. Olesen and Cheril Tapia-Rojas 
Coenzyme $\mathrm{Q}_{10}$ and L-Carnitine Disturbances in Children with Mitochondrial Diseases

by Ekaterina A. Nikolaeva, Ilgar S. Mamedov and Irina V. Zolkina 


\section{Preface}

The mitochondrion is a unique and ubiquitous organelle that contains its own genome, encoding essential proteins that are major components of the respiratory chain and energy production system. It is reasonable therefore that mitochondria play a dominant role in the life and function of eukaryotic cells including neurons and glia, as their survival and activity depend almost exclusively upon mitochondrial energy production and supply.

Thus, mitochondrial functional impairment is related to a substantial number of neurological disorders, most of them having high incidence in the range of neurodegenerative diseases, such as Parkinson's disease, Alzheimer's disease, Friedreich's ataxia, and Huntington's disease.

New techniques improving mitochondrial DNA analysis and detecting mutation penetrance patterns have also increased the awareness of the rate of mitochondrial involvement in the pathogenetic mechanisms of a substantial number of neurological diseases. In addition, since mitochondria synthesize ATP through oxidative phosphorylation (OXPHOS) as the main energy providers for neurons and glia, their dysfunction induces an energy crisis with tragic consequences for cells of high energy demands.

Besides energy production, mitochondria also play a vital role in neuronal and glial calcium homeostasis due to their high capacity for accumulating Ca2+. On the other hand, mitochondria comprise reactive oxygen species (ROS), which control redox status, intracellular $\mathrm{Ca} 2+$ levels, and may induce apoptosis by activating the mitochondrial permeability transition pore (mtPTP), a crucial point of excitotoxic neuronal injury.

In a parallel manner, ROS may play an important role in inflammatory conditions of the brain such as Multiple Sclerosis (MS) either by decreased activity of mitochondrial enzymes, or by peroxidation of lipids, proteolipid protein or myelin basic protein, therefore destabilizing the anoxic myelin sheath.

In reality, the role of the mitochondria in neuronal survival and function is multidimensional. Thus metabolic intermediates derived from Krebs cycle in the mitochondria may behave as co-factors for epigenetic modifications, playing an essential role in histone acetylation and in the addition and removal of epigenetic marks, controlling the expression of a substantial number of genes in the neuronal genome.

Mitochondria also contribute to the synthesis of steroid hormones such as glucocorticoids, mineralocorticoids, progestogens, estrogens, and androgens; and facilitate the interaction of catecholamines with their receptors, therefore promoting neuronal plasticity by stress mediators. Thyroid hormones also stimulate mitochondrial activity by enhancing oxidative phosphorylation. In turn, steroid hormones regulate mitochondrial respiratory capacity and oxidative stress, since mitochondria are particularly sensitive and dependable on hormonal stimulation. Given that sex hormones regulate mitochondrial biogenesis and function, it is expected that 
mitochondria express sexual dimorphism and show different reactions to stress and disease in males and females.

Mitochondria modulate systemic energy homeostasis in both sexes by the production and release of mitokines, such as humanin, and by operating as the central organelle of adaptation and stress-response modulation.

From the morphological point of view, mitochondrial alterations are accurately visualized in light microscopy in a properly fixed material by means of a number of special staining reactions. Transmission electron microscopy has also contributed substantially in the morphological study of mitochondria in neurological diseases revealing the disruption of the cristae and the disarrangement of their inner architecture, taking in consideration also that mitochondria exhibit high morphological variability according to activity and metabolic demands of the cell. Using transmission electron microscopy, it was also observed that in Alzheimer's disease, mitochondrial cristae are disrupted from the initial stages of the disease even in areas of the brain with minimal Alzheimer's pathology.

A considerable number of syndromes have been described with marked neurological phenomena in the spectrum of mitochondrial disorders. It must be highlighted that the severity of the clinical manifestation of mitochondrial dysfunction varies considerably, given the threshold in the degree of mitochondrial deficiency for the clinical expression of the disease. Thus, the symptoms and clinical phenomena are continuously aggravated, in the majority of the cases of mitochondrial diseases, as the age of the patient advances and the energy deficiency increases in various organs. However, the most frequent clinical manifestations that have been reported in mitochondrial diseases include cognitive impairment, epilepsy, myopathies, renal and liver dysfunction, cardiopathy and disorders of inner secretion resulting in hormonal imbalance.

Molecular genetic testing and muscle biopsy for histochemical investigation in light microscopy and ultrastructural study of the specimens in electron microscopy are essential diagnostic procedures for the documentation and final verification of the diagnosis of mitochondrial disorders. In addition, biochemical testing in blood, urine, and spinal fluid associated with neuroimaging would be useful diagnostic procedures in following up the progression of mitochondrial diseases.

A final escape from the labyrinth of mitochondrial related neurological disorders is extremely difficult and less pragmatic under the present circumstances. Thus the treatment for the majority of mitochondrial diseases remains mostly symptomatic. Therapeutic factors enhancing mitochondrial biogenesis and restoring nitric oxide production might be beneficial at the initial stages of the diseases. The administration of cardiolipin protector and agents aiming at ameliorating mitochondrial function, such as antioxidants, riboflavin, idebenone, CoQ10 (ubiquinone) and thiamin might be reasonably prescribed in attempting to improve the physical and mental condition of the patients who suffer from mitochondrial disorders.

Prospectively, an efficient treatment could be based on a stable modulation of mtDNA heteroplasmy, whereas gene therapy, liver transplantation, gene transfer and tRNA-targeted therapeutic attempts as well as stem cell therapy for nuclear DNA mutations are promising therapeutic endeavors. 
In conclusion, an efficient and easy treatment of mitochondrial dysfunction would open new bright horizons in the therapy of inflammatory and neurodegenerative disorders, being beneficial in the amelioration of the quality of life of a substantial number of patients.

In this book, the authors attempted to describe the complex relationship of mitochondrial disorders with neurodegeneration for further clarification and analysis of the multidimensional background of the pathogenetic mechanisms of neurological diseases.

Stavros J. Baloyannis MD, PhD

Professor Emeritus, Aristotelian University, Thessaloniki, Greece 

Section 1

\section{Introduction}





\title{
Introductory Chapter: Mitochondrial Alterations and Neurological Disorders
}

\author{
Stavros J. Baloyannis
}

\section{Introduction}

Mitochondria (from Greek mito, $\mu$ í $\tau$ s, thread; and chondrion, $\chi$ ó $\delta \rho 10 \nu$, thick granule) are principal cell organelles, which participate in a wide spectrum of essential cellular functions, being the main energy providers for living eukaryotic cells, especially for neurons and glia, which are characterized by high metabolic activity and energy consumption.

Thus, it is expectable that mitochondrial dysfunction, having pleotropic effect on the cell, may play a crucial role in a substantial number of serious neurological disorders including Alzheimer's disease (AD) [1, 2], Parkinson's disease (PD) [3] Huntington's disease [4, 5], amyotrophic lateral sclerosis (ALS) [6], multiple sclerosis (MS) [7, 8], as well as some of the major psychiatric diseases [9], given that both, neurons and glia, are particularly sensitive and vulnerable to energy decline [10].

Mitochondria hypothesis of those devastating diseases advocates reasonably in favor of the important role that mitochondrial dysfunction may play in the early stages of neurodegeneration by inducing energy deficiency and oxidative stress [11].

However, the majority of the mitochondrial diseases, being maternally inherited, which are designated as mitochondrial encephalomyopathies [12], are closely connected either with the impairment of nucleus-to-mitochondria signaling or with mutations in mtDNA or nuclear genome that affect seriously the mitochondrial respiratory function even from the initial steps of the life [13], inducing defective oxidative phosphorylation (OXPHOS).

\section{The genetic background of mitochondrial dysfunction}

It is well known that mitochondria, as very specific organelles, include several copies (2-10 copies) of their own DNA (mtDNA), which consists of a $16.5 \mathrm{~kb}$ circular DNA molecule, being particularly prone to mutation [14]. mtDNA encodes for 37 genes, 13 of them encoding 13 polypeptides, which all are major components of OXPHOS complexes I, III, IV, and V, along with 22 tRNAs and 2 rRNAs, which play an essential role for the expression of the 13 subunits [15].

Mutations in mtDNA may be related to $25 \%$ of childhood-onset diseases [16] and to $75 \%$ of adult-onset ones [17], depending on the existing homoplasmy or heteroplasmy. In addition, the accumulation of mtDNA mutations can also induce or facilitate the aging process [18], since a common phenomenon in mammalian aging is the substantial decrease of electron transfer in mitochondria $[19,20]$. 


\section{Biological consequences of mitochondrial dysfunction}

The mitochondria in addition to energy production compose also reactive oxygen species (ROS), which control redox status and intracellular Ca2+ levels and may induce apoptosis, by activating the mitochondrial permeability transition pore (mtPTP) [21]. In addition, mitochondria play a very important role in neuronal and glial calcium homeostasis due to their high capacity to accumulating Ca2+ [22].

Resting neurons contain usually minimal Ca2+ that can be increased by the activation of NMDA glutamate receptors, which induce a massive entry of $\mathrm{Ca}^{2+}$ into neurons, resulting in its high accumulation in the mitochondria [23]. Continuous activation of NMDA receptors would therefore induce $\mathrm{Ca}^{2+}$ overload of the mitochondria with the tragic consequence of the cell apoptosis, which frequently occurs as an epilogue of the excitotoxicity [24].

The apoptosis consists of a wide spectrum of biological phenomena [25] including the release of caspase activators [26], the alterations of the electron transport system, the change of mitochondrial transmembrane potential, the disruption of the cellular oxidation-reduction equilibrium, and the activation of the pro-apoptotic Bcl-2 family proteins [27, 28].

In the majority of the mitochondria-related neurological disorders, the functional or morphological alteration of the mitochondrial may be induced by increased ROS production, abnormal protein aggregates (Ab, tau) $[29,30]$, mutations in genes encoded by the mitochondrial and nuclear genome, and exposure of the cell to toxic factors [31].

\section{The morphology of mitochondria in health and disease}

Cell mitochondria could be visualized in light microscopy in properly fixed material by means of a number of special staining reactions [32-34]. It is observed that their size generally ranges from 0.5 to 1 micron in diameter, being changeable due to frequent divisions and fusions, which are controlled by mitofusin activity [35]. The shape of the mitochondria is also continuously changed due to their impressive active motility, controlled by calcium signal $[36,37]$, given that they are in constant flux, especially in brain's areas of high energy consumption in order to contribute in energy supply and to participate in the intracellular signaling actively [38].

Electron microscopy has been contributing greatly in the study of mitochondria in health and disease $[39,40]$. Each mitochondrion in healthy condition is surrounded by a limiting double membrane and includes numerous longitudinal or tubular invaginations called mitochondrial cristae that are folds of the inner layer of the double membrane [41], which is four times greater than the outer one.

The cristae are mostly arranged perpendicularly to the long axis of the organelle, exhibiting a high morphological variability according to metabolic demands of the cell [42], being frequently lamellar, tubular, or triangle-shaped. In the majority of the mitochondria, the cristae are arranged parallel to one another inside a structureless matrix, which is clearly seen among the cristae.

Cardiolipin seems to play a crucial role in the morphology of cristae, since the disruption of cardiolipin biosynthesis induces obvious alteration of the cristae morphology [43]. In addition, Opa1, which is a GTPase, demonstrating dynaminlike properties, plays a substantial role in the modulation of the cristae structure and in their remodeling during mitochondrial fusion and fission [44] and apoptotic process [45]. The cristae have a high protein content [46], being also the principal site of the oxidative phosphorylation [47]. 
Electron microscope tomography, revealing the three-dimensional appearance of the cristae, shows that they are connected with the inner mitochondrial membrane by a narrow, tubular opening, characterized as "crista junction" (CJ), which is associated with protein import [48] and mitochondrial inner compartmentalization [49].

In neurodegeneration such as in Alzheimer's disease, mitochondrial cristae are disrupted even from the initial stages of the disease, and concentric patterns of cristae membranes are frequently seen [50].

\section{Mitochondrial trafficking and concentration}

Mitochondria, like many other cell organelles, are oriented and positioned properly in neurons and glia in order to be able to fulfill the energy demands of the cells perpetually. Thus, neurons, axons, dendrites, and synapses, which are characterized by high ceaseless activity, have intensive mitochondrial motility and impressive concentrations [51], via various trafficking patterns [52].

Axonal transport of mitochondria [53] requires microtubules (MTs) $[54,55]$ or actin filaments in axons [56], which facilitate the movement of the mitochondria in areas of high metabolic demands and increased energy consumption [57]. It is noticed that disruption of axonal transport of mitochondria occurs as an early phenomenon in cases of neuroinflammation [58], including multiple sclerosis [59-61].

\section{Clinical expression of mitochondrial dysfunction}

A considerable number of syndromes have been described with marked neurological phenomena in the spectrum of mitochondrial disorders [62]. The severity of the clinical manifestation of mitochondrial dysfunction varies considerably, given that there exists a threshold in the degree of mitochondrial deficiency for the clinical expression of the disease $[63,64]$. Thus, the symptoms and clinical phenomena are continuously aggravated, in the majority of the cases of mitochondrial diseases, as the age of the patients advances [65]. It is reasonable to accept that organs with high energy demand would be more seriously affected by the mitochondrial dysfunction than others with low level of energy necessity. Thus the brain, the skeletal muscles, and the heart have a typical involvement in adolescence and adulthood, though multi-system manifestation is not also an uncommon phenomenon, especially in childhood.

Many clinical syndromes have been described that are associated with mitochondrial dysfunction including encephalomyopathy, stroke-like episodes, myoclonic epilepsy, neuro-gastrointestinal phenomena, cranial or peripheral neuropathy, ataxia, retinitis pigmentosa, chronic progressive external ophthalmoplegia which are associated frequently with lactic acidosis, mental retardation, or progressive mental decline [66].

In addition, oxidative stress, due to mitochondrial dysfunction, plays a principal role, as causative factor, in the neurodegeneration [67] and in Alzheimer's disease particularly $[68,69]$, and it is considered as been among the potential risk factors for the neurometabolic and neoplastic diseases, as well as obesity [70].

Molecular genetic testing on one hand and muscle biopsy on the other hand for the histochemical investigation in light microscopy and the ultrastructural study in electron microscopy of the muscle tissue are essential diagnostic procedures for approaching the diagnosis of mitochondrial disorders [71]. In addition, biochemical testing in blood, urine, and spinal fluid associated with neuroimaging [72] 
would be useful diagnostic procedures in following in time the progression of mitochondrial diseases [71].

\section{The final escape}

A final escape from the labyrinth of mitochondrial-related neurological disorders is extremely difficult and less pragmatic under the present circumstances. Prospectively, an efficient treatment could be based on a stable modulation of mtDNA heteroplasmy [73], whereas gene therapy, gene transfer, and tRNA-targeted therapeutic attempts [74] as well as stem cell therapy for nuclear DNA mutations $[75,76]$ are very promising therapeutic endeavors with substantial medical and scientific value $[77,78]$.

In addition, an efficient and easy to apply treatment of mitochondrial dysfunction would open new bright horizons in the therapy of the inflammatory and neurodegenerative disorders [79], being beneficial in the amelioration of the quality of life of a substantial number of seriously suffering human beings.

\section{Author details}

Stavros J. Baloyannis

Aristotle University of Thessaloniki, Greece

*Address all correspondence to: sibh844@otenet.gr

IntechOpen

(C) 2020 The Author(s). Licensee IntechOpen. This chapter is distributed under the terms of the Creative Commons Attribution License (http://creativecommons.org/licenses/ by/3.0), which permits unrestricted use, distribution, and reproduction in any medium, provided the original work is properly cited. (cc) BY 


\section{References}

[1] Baloyannis SJ. Mitochondrial alterations in Alzheimer's disease. Journal of Alzheimer's Disease. 2006;9(2):119-126

[2] Wang X, Wang W, Li L, Perry G, Lee HG, Zh'u X. Oxidative stress and mitochondrial dysfunction in Alzheimer's disease. Biochimica et Biophysica Acta. 2014;1842(8):1240-1247

[3] Schapira AHV. Mitochondria in the aetiology and pathogenesis of Parkinson's disease. The Lancet Neurology. 2008;7(1):97-109

[4] Browne SE. Mitochondria and Huntington's disease pathogenesis: Insight from genetic and chemical models. Annals of the New York Academy of Sciences. 2008;1147(1):358-382

[5] Damiano M, Galvan L, Déglon N, Brouillet E. Mitochondria in Huntington's disease. Biochimica et Biophysica Acta. 2010;1802(1):52-61

[6] Orrell RW, Schapira AHV. Mitochondria and amyotrophic lateral sclerosis. International Review of Neurobiology. 2002;53:411-426

[7] Dutta R, McDonough J, Yin X, et al. Mitochondrial dysfunction as a cause of axonal degeneration in multiple sclerosis patients. Annals of Neurology. 2006;59(3):478-489

[8] de Barcelos IP, Troxell RM, Graves JS. Mitochondrial dysfunction and multiple sclerosis. Biology. 2019;8(2):37

[9] Rezin GT, Amboni G, Zugno AI, Quevedo J, Streck EL. Mitochondrial dysfunction and psychiatric disorders. Neurochemical Research. 2009;34(6):1021-1029

[10] Chrzanowska-Lightowlers ZMA, Lightowlers RN. How much does a disrupted mitochondrial network influence neuronal dysfunction? EMBO Molecular Medicine. 2019;11(1):e9899

[11] Area-Gomez E, Guardia-Laguarta C, Schon EA, Przedborski S. Mitochondria, OxPhos, and neurodegeneration: Cells are not just running out of gas. The Journal of Clinical Investigation. 2019;129(1):34-45

[12] DiMauro S. Mitochondrial encephalomyopathies--fifty years on: The Robert Wartenberg lecture. Neurology. 2013;81:281-291

[13] DiMauro S. Mitochondrial diseases. Biochimica et Biophysica Acta (BBA) Bioenergetics. 2004;1658(1-2):80-88

[14] Taylor RW, Turnbull DM. Mitochondrial DNA mutations in human disease. Nature Reviews. Genetics. 2005;6(5):389

[15] Frazier AE, Thorburn DR, Compton AG. Mitochondrial energy generation disorders: Genes, mechanisms, and clues to pathology. Journal of Biological Chemistry. 2019;294(14):5386-5395

[16] Skladal D, Halliday J, Thorburn DR. Minimum birth prevalence of mitochondrial respiratory chain disorders in children. Brain. 2003;126:1905-1912

[17] Gorman GS, Schaefer AM, Ng Y, Gomez N, Blakely EL, Alston CL, et al. Prevalence of nuclear and mitochondrial DNA mutations related to adult mitochondrial disease. Annals of Neurology. 2015;77:753-759

[18] Müller-Höcker J. Mitochondria and ageing. Brain Pathology. 1992;2(2):149-158

[19] Fang EF, Scheibye-Knudsen M, Chua KF, Mattson MP, Croteau DL, 
Bohr VA. Nuclear DNA damage signaling to mitochondria in ageing. Nature Reviews. Molecular Cell Biology. 2016;17(5):308-321

[20] Breitenbach M, Rinnerthaler M, Hartl J, et al. Mitochondria in ageing: There is metabolism beyond the ROS. FEMS Yeast Research. 2014;14(1):198-212

[21] Wallace DC, Fan W. Energetics, epigenetics, mitochondrial genetics. Mitochondrion. 2010;10:12-31

[22] Marchi S, Patergnani S, Missiroli S, et al. Mitochondrial and endoplasmic reticulum calcium homeostasis and cell death. Cell Calcium. 2018;69:62-72

[23] Abeti R, Abramov AY. Mitochondrial $\mathrm{Ca} 2+$ in neurodegenerative disorders. Pharmacological Research. 2015; 99:377-381

[24] Sattler R, Xiong Z, Lu WY, MacDonald JF, Tymianski M. Distinct roles of synaptic and extrasynaptic NMDA receptors in excitotoxicity. The Journal of Neuroscience. 2000;20(1):22-33

[25] Green DR, Reed JC. Mitochondria and apoptosis. Science.

1998;281(5381):1309-1312

[26] Fan TJ, Han LH, Cong RS, Liang J. Caspase family proteases and apoptosis. Acta Biochimica et Biophysica Sinica Shanghai. 2005;37(11):719-727

[27] Friedlander RM. Apoptosis and caspases in neurodegenerative diseases. The New England Journal of Medicine. 2003;348(14):1365-1375

[28] Antonsson B, Martinou J-C. The Bcl-2 protein family. Experimental Cell Research. 2000;256(1):50-57

[29] Hashimoto M, Rockenstein E, Crews L, Masliah E. Role of protein aggregation in mitochondrial dysfunction and neurodegeneration in Alzheimer's and Parkinson's diseases. Neuromolecular Medicine. 2003;4(1-2):21-36

[30] Wang X, Su BO, Siedlak SL, Moreira PI, Fujioka H, et al. Amyloid- $\beta$ overproduction causes abnormal mitochondrial dynamics via differential modulation of mitochondrial fission/ fusion proteins. Proceedings of the National Academy of Sciences. 2008;105(49):19318-19323

[31] Lee HK, Cho YM, Kwak SH, Lim S, Park KS, Shim EB. Mitochondrial dysfunction and metabolic syndromelooking for environmental factors. Biochimica et Biophysica Acta. 2010;1800(3):282-289

[32] Cain AJ. An easily controlled method for staining mitochondria. Journal of Cell Science.

1948;3(6):229-231

[33] Roels F. Cytochrome c and cytochrome oxidase in diaminobenzidine staining of mitochondria. The Journal of Histochemistry and Cytochemistry. 1974;22(6):442-444

[34] Neto BA, Carvalho PH, Santos DC, Gatto CC, Ramos LM, et al. Synthesis, properties and highly selective mitochondria staining with novel, stable and superior benzothiadiazole fluorescent probes. RSC Advances. 2012;2(4):1524-1532

[35] Santel A, Fuller MT. Control of mitochondrial morphology by a human mitofusin. Journal of Cell Science. 2001;114(5):867-874

[36] Yi M, Weaver D, Hajnócky G. Control of mitochondrial motility and distribution by the calcium signal: a homeostatic circuit. The Journal of Cell Biology. 2004;167(4):661-672 
[37] Wang X, Schwarz TL. The mechanism of $\mathrm{Ca} 2+-$ dependent regulation of kinesin-mediated mitochondrial motility. Cell. 2009;136(1):163-174

[38] Rizzuto R, Bernardi P, Pozzan T. Mitochondria as all-round players of the calcium game. The Journal of Physiology. 2000;529:37-47

[39] Claude A, Fullam EF. An electron microscope study of isolated mitochondria: Method and preliminary results. The Journal of Experimental Medicine. 1945;81(1):51

[40] Sun MG, Williams J, MunozPinedo C, et al. Correlated threedimensional light and electron microscopy reveals transformation of mitochondria during apoptosis. Nature Cell Biology. 2007;9(9):1057-1065

[41] Lea PJ, Hollenberg MJ. Mitochondrial structure revealed by high-resolution scanning electron microscopy. The American Journal of Anatomy. 1989;184:245-257

[42] Patten DA, Wong J, Khacho M, Soubannier V, Mailloux RJ, et al. Slack OPA1-dependent cristae modulation is essential for cellular adaptation to metabolic demand. The EMBO Journal. 2014;33:2676-2691

[43] Xu Y, Sutachan JJ, Plesken H, Kelley RI, Schlame M. Characterization of lymphoblast mitochondria from patients with Barth syndrome. Laboratory Investigation. 2005;85:823-830

[44] Chan DC. Fusion and fission: Interlinked processes critical for mitochondrial health. Annual Review of Genetics. 2012;46:265-287

[45] Frezza C, Cipolat S, Martins de Brito O, Micaroni M, Beznoussenko GV, et al. OPA1 controls apoptotic cristae remodeling independently from mitochondrial fusion. Cell. 2006;126:177-189

[46] Neupert W, Herrmann JM. Translocation of proteins into mitochondria. Annual Review of Biochemistry. 2007;76:723-749

[47] Gilkerson RW, Selker JM, Capaldi RA. The Cristal membrane of mitochondria is the principal site of oxidative phosphorylation. FEBS Letters. 2003;546:355-358

[48] Perkins GA, Renken CW, van der Klei IJ, Ellisman MH, Neupert W, Frey TG. Electron tomography of mitochondria after the arrest of protein import associated with Tom 19 depletion. European Journal of Cell Biology. 2001;80:139-150

[49] Mannella CA, Marko M, Buttle K. Reconsidering mitochondrial structure: New views of an old organelle. Trends in Biochemical Sciences. 1997;22:37-38

[50] Baloyannis SJ. Mitochondrial alterations in Alzheimer's disease. Journal of Alzheimer's Disease. 2006;9:119-126

[51] Chang DTW, Reynolds IJ. Mitochondrial trafficking and morphology in healthy and injured neurons. Progress in Neurobiology. 2006;80(5):241-268

[52] Sheng ZH. Mitochondrial trafficking and anchoring in neurons: New insight and implications. The Journal of Cell Biology. 2014;204(7):1087-1098

[53] Hollenbeck PJ, Saxton WM. The axonal transport of mitochondria. Journal of Cell Science. 2005;118(23):5411-5419

[54] Grafstein B, Forman DS. Intracellular transport in neurons. Physiological Reviews. 1980;60:1167-1283 
[55] Hollenbeck PJ. The pattern and mechanism of mitochondrial transport in axons. Frontiers in Bioscience. 1996;1:91-102

[56] Langford GM, Kuznetsov SA, Johnson D, Cohen DL, Weiss DG. Movement of axoplasmic organelles on actin filaments assembled on acrosomal processes: Evidence for a barbed-enddirected organelle motor. Journal of Cell Science. 1994;107:2291-2298

[57] Bridgman PC. Myosin-dependent transport in neurons. Journal of Neurobiology. 2004;58:164-174

[58] Errea LO, Moreno B, González FA, García-Roves PM, Villoslada P. The disruption of mitochondrial axonal transport is an early event in neuroinflammation. Journal of Neuroinflammation. 2015;12:152

[59] Ghafourifar P, Mousavizadeh K, Parihar MS, Nazarewicz RR, Parihar A, Zenebe WJ. Mitochondria in multiple sclerosis. Frontiers in Bioscience. 2008;13:3116-3126

[60] Nikic I, Merkler D, Sorbara C, Brinkoetter M, Kreutzfeldt M, Bareyre FM, et al. A reversible form of axon damage in experimental autoimmune encephalomyelitis and multiple sclerosis. Nature Medicine. 2011;17:495-499

[61] Sorbara CD, Wagner NE, Ladwig A, Nikic I, Merkler D, Kleele T, et al. Pervasive axonal transport deficits in multiple sclerosis models. Neuron. 2014;84:1183-1190

[62] McFarland R, Taylor RW, Turnbull DM. A neurological perspective on mitochondrial disease. Lancet Neurology. 2010;9:829-840

[63] Wallace DC. Mitochondrial diseases in man and mouse. Science. 1999;283(5407):1482-1488
[64] Finsterer J. Central nervous system manifestations of mitochondrial disorders. Acta Neurologica Scandinavica. 2006;114(4):217-238

[65] Calabrese V, Scapagnini G, Stella AG, Bates TE, Clark JB. Mitochondrial involvement in brain function and dysfunction: Relevance to aging, neurodegenerative disorders and longevity. Neurochemical Research. 2001;26(6):739-764

[66] Ng YS, Turnbull DM. Mitochondrial disease: Genetics and management. Journal of Neurology. 2016;263(1): 179-191

[67] Islam MT. Oxidative stress and mitochondrial dysfunctionlinked neurodegenerative disorders. Neurological Research. 2017;39(1):73-82

[68] Baloyannis SJ. Mitochondria: Strategic point in the field of Alzheimer's disease. Journal of Alzheimers and Neurodegenerative Diseases. 2016;2:004

[69] Baloyannis SJ. What has electron microscopy contributed to Alzheimer's research? Future Neurology.

2015;10(6):515-527

[70] Greaves LC, Reeve AK, Taylor RW, Turnbull DM. Mitochondrial DNA and disease. The Journal of Pathology. 2012;226:274-286

[71] Parikh S, Goldstein A, Koenig MK, Scaglia F, Enns GM, Saneto R, et al. Diagnosis and management of mitochondrial disease: A consensus statement from the mitochondrial medicine society. Genetics in Medicine. 2015;17(9):689-701

[72] Morava E, van den Heuvel L, Hol F, et al. Mitochondrial disease criteria: Diagnostic applications in children. Neurology. 2006;67:1823-1826 
[73] Minczuk M, Papworth MA, Miller JC, Murphy MP, Klug A.

Development of a single-chain, quasidimeric zinc-finger nuclease for the selective degradation of mutated human mitochondrial DNA. Nucleic Acids Research. 2008;36:3926-3938

[74] Yarham JW, Al-Dosary M, Blakely EL, Alston CL, Taylor RW, Elson JL, et al. A comparative analysis approach to determining the pathogenicity of mitochondrial tRNA mutations. Human Mutation. 2011;32:1319-1325

[75] Hussein E. Non-myeloablative bone marrow transplant and platelet infusion can transiently improve the clinical outcome of mitochondrial neurogastrointestinal encephalopathy: A case report. Transfusion and Apheresis Science. 2013;49:208-211

[76] Spendiff S, Reza M, Murphy JL, Gorman G, Blakely EL, Taylor RW, et al. Mitochondrial DNA deletions in muscle satellite cells: Implications for therapies. Human Molecular Genetics. 2013;22:4739-4747

[77] Kerr DS. Review of clinical trials for mitochondrial disorders: 1997-2012. Neurotherapeutics. 2013;10:307-319

[78] Nightingale H, Pfeffer G, Bargiela D, Horvath R, Chinnery PF. Emerging therapies for mitochondrial disorders. Brain. 2016;139(6):1633-1648

[79] Baloyannis SJ, Baloyannis JS. Mitochondrial alterations in Alzheimer's disease. Neurobiology of Aging. 2004;25:405-406 

Section 2

Mitochondria and Hormones 



\title{
Pathology Associated with Hormones of Adrenal Cortex
}

\author{
Lovelesh K. Nigam, Aruna V. Vanikar, Rashmi D. Patel, \\ Kamal V. Kanodia and Kamlesh S. Suthar
}

\begin{abstract}
Adrenal gland is an endocrine organ comprising of an outer cortex and inner medulla. These secrete various hormones that have a vital role in maintaining the normal homeostasis of the body. Lesions of adrenal cortex are quite common to encounter and most of these are related to the hormones secreted by three layers of adrenal cortex: the zona glomerulosa, the zona fasciculata, and the zona reticularis. Also it is very infrequent to encounter metastatic lesions in the adrenal glands too. So it is very important as a part of a clinician as well as a pathologist to know the pattern in which these hormones are secreted along with their physiological roles. Thus this chapter includes the disease that are related to excess as well as deficiencies of the hormones secreted by adrenal cortex. The chapter also includes various genetic syndromes that are associated with the disorders associated with hormones of adrenal cortex. The last part of the chapter includes a brief description of various benign as well as malignant lesions, the pathological as well as the etiological aspects and the hormonal abnormalities associated. This chapter thus mainly focuses on the pathology associated with the adrenal cortex and hormones secreted by the various layers of adrenal cortex.
\end{abstract}

Keywords: adrenal cortex, hormones, Cushing syndrome

\section{Introduction}

Adrenal gland consists of an outer cortex and inner medulla; the cortex is further subdivided into three distinct zones: the zona glomerulosa, the zona fasciculata, and the zona reticularis. Mineralocorticoids (aldosterone) secreted from the zona glomerulosa are essential for fluid and electrolyte balance and the reninangiotensin-aldosterone system. The fasciculata secretes glucocorticoids (mainly cortisol). The zona reticularis produces steroid sex hormones called androgens. These hormones play an important role in maintaining the normal homeostasis of the body [1-3]. However, it is quite common to encounter disorders related to the hormones of these three layers. These disorders could be possibly due to adrenal cortical masses secondary to cortical hyperplasia. It is very infrequent to encounter metastatic lesions in the adrenal glands.

This chapter mainly focuses on the pathology related to adrenal cortex which includes various forms of adrenocortical hyperplasia and benign and malignant neoplasms of the adrenal gland which lead to various hormonal imbalances encountered in clinical practice. Hormonal deficiency is due to inherited glandular or enzymatic 
disorder, destruction of pituitary gland by autoimmune disorders, infection, infarction, or others $[4,5]$. The major disorders of the adrenal cortex are characterized by excessive or deficient secretion of each type of adrenocortical hormone.

\section{Functional manifestations}

The lesions of the adrenal cortex could be functional as well as nonfunctional, which means that patients with these lesions may exhibit clinical symptoms that are due to hypersecretion of hormones released. Usually cortical hyperplasia and adenomas are nonfunctioning. The functional syndromes associated with pathology of adrenal cortex are hypercortisolism (Cushing's syndrome), adrenal insufficiency (Addison's disease), hyperaldosteronism, and androgen excess (adrenogenital syndrome) [4-9].

\section{Adrenal hyperplasia}

Adrenal hyperplasia is characterized as a smooth, diffuse, bilateral enlargement of the adrenal glands, wherein the glands retain their adreniform shape. Hyperplasia can be either macronodular or micronodular. They are commonly unilateral; however bilateral cases are also observed $[7,8]$. Broadly adrenal cortical hyperplasia can be grouped into three main categories: ACTH-dependent (adrenocorticotropic hormone), ACTH-independent, and congenital adrenal hyperplasia (CAH). Cushing's syndrome is one of the common functional manifestations of adrenal gland hyperplasia and therefore is discussed first $[8,10,11]$.

\subsection{Cushing's syndrome}

\subsubsection{Definition}

It is a syndrome which encompasses various clinical features due to chronic excess of glucocorticoids. The incidence is nearly $1-2$ per 100,000 population per year. Harvey Cushing was the first to observe pituitary adenomas associated with hypercortisolism in 1932 [10-13]. Cushing's syndrome, caused by prolonged exposure of tissues to high levels of cortisol, presents as constellation of symptoms including central obesity, muscle fatigue/atrophy, hirsutism, infertility, osteoporosis, moon facies, dorsocervical and supraclavicular fat pads, and wide purple striae $[8,10,12]$. The syndrome may be ACTH-dependent or ACTH-independent. A fair number of cases attributed to iatrogenic causes are also identified. Most of the cases of Cushing's syndrome are due to ACTH hypersecretion from the anterior pituitary and are associated with pituitary cortical adenoma. Majority of the cases, about 80-90\%, show diffuse hyperplasia of the adrenal cortex $[9,10]$. Nearly $15 \%$ of cases do present with ectopic ACTH secretion associated with small cell lung carcinoma or bronchial carcinoid. Thymic carcinoids, pancreatic islet cell tumor, pheochromocytomas, and medullary carcinoma of thyroid form minor group of tumors associated with ectopic ACTH secretion [12]. In a study by Ejaz et al., lung tumors constituted $44.4 \%$ of all cases of neoplasm-related ectopic ACTH secretion causing Cushing's syndrome [14]. Clinically patients with Cushing's syndrome present with diastolic hypertension, hypokalemia, and edema. Hypogonadism and amenorrhea can also be seen in these patients which are attributed to suppression of gonadotropin secretion secondary to excess glucocorticoid secretion [10-14]. 


\subsubsection{Cushing disease}

Cushing disease, resulting from a pituitary corticotropic adenoma, and rarely carcinoma, makes up to $80-85 \%$ of endogenous Cushing's syndrome cases $[8,10,15]$.

\subsubsection{Investigating a case of Cushing's syndrome}

A two-stage test is usually recommended in a patient to rule out Cushing's syndrome $[8,10,15-17]$ :

1. The first group of tests are to screen for the evidence of hypercortisolism. These comprise urine cortisol excretion and low-dose dexamethasone suppression test.

2. The second group of tests comprise of the diagnostic tests which help to determine the cause of excessive production of cortisol. These are:

a. Plasma ACTH measurement: Low plasma ACTH level suggests an adrenal cause of the disease; however normal/high [ACTH] level suggests ectopic ACTH secretion or hypersecretion of ACTH from pituitary (Cushing's disease).

b.High-dose dexamethasone suppression test: In this test the patient is administered with $2 \mathrm{mg}$ of dexamethasone, 6 hourly for $48 \mathrm{~h}$, following which plasma cortisol levels are measured. In the case of ectopic ACTH secretion or adrenal limited hypercortisolism, there is a failure of suppression of cortisol secretion. Also it is important to remember that cortisol is not suppressed with either low- or high-dose dexamethasone suppression in adrenal hyperplasia associated with ectopic ACTH production [18].

\subsubsection{The 24-h urinary-free cortisol test}

This investigation is used primarily for the diagnosis of hypercortisolism due to Cushing's syndrome, and reference ranges for this test with respect to age are 1.4-20 $\mu \mathrm{g} / 24 \mathrm{~h}$ (3-8 years), 2.6-37 $\mu \mathrm{g} / 24 \mathrm{~h}$ (9-12 years), 4-56 $\mu \mathrm{g} / 24 \mathrm{~h}$ (13-17 years), and $3.5-45 \mu \mathrm{g} / 24 \mathrm{~h}$ in individuals $\geq 18$ years of age. A $24-\mathrm{h}$ urine sample with boric acid $(10 \mathrm{~g})$ as preservative is advisable for performing this analysis [10, 17-19].

\subsubsection{ACTH-independent Cushing's syndrome}

Nearly 15-20\% of Cushing's syndrome are associated with ACTH-independent hypercortisolism and are secondary to a functioning adenoma or carcinoma. Diagnosis of ACTH-independent Cushing's syndrome includes clinical features of hypercortisolism, absence of serum cortisol diurnal rhythm, elevated late-night cortisol levels, and incomplete suppression of cortisol production with low-dose dexamethasone suppression test [10,17-20].

\subsubsection{Pathological findings}

Adrenal glands from patients with Cushing's syndrome/hyperplasia appear variably enlarged in size and weigh approximately 6-12 g. The cortical width is widened as compared to the reticulosa. The zona fasciculata usually shows nodular hyperplasia. Nearly $10-20 \%$ of the patients reveal bilateral nodular hyperplasia, and up to $30 \%$ of patients may have normal adrenal morphology [2, 20, 21]. 


\subsection{Primary pigmented nodular adrenocortical disease (PPNAD)}

Primary pigmented nodular adrenocortical disease is a rare cause of childhood Cushing's disease having female preponderance, whereas Cushing's disease is common in prepubertal males [20-22]. It is the main endocrine manifestation of Carney complex (a multiple neoplasia syndrome caused by mutation in PRKAR1A gene) [23]. This is an autosomal dominant syndrome and is characterized by cutaneous lentigines, myxoma, schwannomas, and endocrinopathy [11, 23]. It was first described by Aidan Carney and co-workers in 1985. Almost 25-30\% of patients with Carney complex have ACTH-independent Cushing's syndrome. Cutaneous pigmentation is the commonest manifestation of the disease [24]. Lentigines are seen in most patients, and this characteristic manifestation can be used to make the definitive diagnosis. The name is derived from the macroscopic appearance of the adrenals that show characteristic small pigmented micronodules in the adrenal cortex. The disease typically involves bilateral adrenal glands. Grossly the adrenal glands may have variable size. The most characteristic finding is the presence of multiple brown-black pigmented cortical nodules that measure $1 \mathrm{~mm}$ to $3 \mathrm{~cm}$ in diameter. The adjacent cortical tissue invariable shows atrophy. These pigmented nodules may extend into corticomedullary junction or peri-adrenal fat $[9,11,24]$.

On microscopy these tumors appear as sharply circumscribed, unencapsulated tumors composed of large eosinophilic lipid-poor cells similar to the zona reticularis arranged predominantly in trabecular growth pattern. However the nucleus appears enlarged, with a variable degree of pleomorphism and prominent nucleoli. There is prominent lipofuscin deposit. Lipid-rich fasciculata-like cells are also seen invariably. The tumor may have focal areas of necrosis, mitotic activity, myelolipomatous change, and lymphocytic infiltrates $[9,11,24]$.

\subsection{ACTH-independent macronodular adrenal hyperplasia (AIMAH)}

(Synonyms: ACTH-independent massive bilateral adrenal disease, massive macronodular hyperplasia, giant macronodular adrenal hyperplasia, macronodular adrenal hyperplasia, macronodular hyperplasia).

AIMAH is a disorder characterized by bilateral adrenocortical nodules, associated with ACTH-independent hypercortisolism, without any clinical features of pigmented nodular adrenocortical disease and histological features consistent with atrophic internodular cortex [25]. It is a rare cause of ACTH-independent Cushing's syndrome with slightly male preponderance. The patients present usually at later age (average: 48 years) [24-26]. In few patients with AIMAH, ectopic expression and/or increased sensitivity to gastric inhibitory peptide, vasopressin receptors, and beta-adrenergic receptors is also seen [25].

Grossly these lesions are characterized by nodules in the adrenal cortex, ranging from 1 to $4.2 \mathrm{~cm}$. The adrenal gland weighs approximately $16.7-218 \mathrm{~g}$. The adrenal gland may have a large mass of cortical tissue and multiple bilateral nodules measuring up to $5 \mathrm{~cm}$. Combined adrenal gland weight of more than $300 \mathrm{~g}$ has also been noted (normal range: 8-12 g). Histology demonstrates large, yellow macronodules comprising of small cells with eosinophilic cytoplasm. Bilateral adrenalectomy and well-controlled glucocorticoid replacement is the most accepted treatment modality $[2,3,9,25,26]$.

\subsection{Congenital adrenal hyperplasia}

$\mathrm{CAH}$ is an autosomal recessive disorder characterized by impaired steroidogenesis finally leading to mineralocorticoid and cortisol deficiency secondary to reduced activity of enzymes required for cortisol biosynthesis in the adrenal cortex. 
These patients usually present during the perinatal period with ambiguous genitalia in females and salt wasting in males. The milder forms of disease may present later with virilization at puberty or even as irregular menses. Most of the cases (nearly 95\%) are attributed to deficiency of the 21-hydroxylase enzyme [27, 28].

Abnormal growth and development, adverse effects on bone and the cardiovascular system, and infertility are few long-term effects seen in these patients. These patients are usually managed by reducing glucocorticoid exposure and improving excess hormone control [29, 30].

Congenital adrenal hyperplasia can be of four forms [8-10, 27-30]:

1. Congenital adrenal hyperplasia: classical 21-hydroxylase deficiency

2. Simple virilizing congenital adrenal hyperplasia

\section{Non-classic or late onset form of congenital adrenal hyperplasia}

\section{Congenital adrenal hyperplasia with steroidogenic acute regulatory (StAR) mutation}

\subsubsection{Congenital adrenal hyperplasia: Classical 21-hydroxylase deficiency}

This form is the most common form of CAH, occurring due to 21-hydroxylase (21-OH) deficiency, accounting for almost $90 \%$ of the cases. It occurs with the frequency of 1:12000 to 1:15000 births, and nearly $75 \%$ of patients with classic $21-\mathrm{OH}$

\begin{tabular}{ll}
$\begin{array}{l}\text { Multiple } \\
\text { endocrine } \\
\text { neoplasia (MEN) } \\
\text { type 1 }\end{array}$ & $\begin{array}{l}\text { Adrenocortical lesions are seen in nearly 36-41\% of individuals with MEN type } \\
\text { I syndrome, the commonest being bilateral nonfunctioning adrenal cortical } \\
\text { hyperplasia or adenoma; adrenocortical carcinoma is exceedingly rare. The } \\
\text { pathogenesis of these lesions is proposed to be due to influence of locally secreted } \\
\text { insulin and insulin-like growth factors and not due to menin gene mutations }\end{array}$ \\
\hline Carney complex & $\begin{array}{l}\text { This syndrome encompasses multiple endocrine hyperplasia, with tumors of two } \\
\text { or more endocrine glands, including primary pigmented adrenocortical disease } \\
\text { (PPNAD), GH- and prolactin-producing pituitary adenomas, testicular neoplasms, }\end{array}$ \\
& $\begin{array}{l}\text { thyroid adenoma or carcinoma, and ovarian cysts. This autosomal dominant } \\
\text { syndrome is mapped to two genetic loci, one present on chromosome 2p16 and } \\
\text { another locus at chromosome 17q22-24 encoding the PRKARIA gene [82] }\end{array}$ \\
\hline $\begin{array}{l}\text { Beckwith- } \\
\text { Wiedemann }\end{array}$ & $\begin{array}{l}\text { This syndrome is characterized by gigantism, ear lobe pits and/or creases, } \\
\text { macroglossia, and defects in the abdominal wall and is associated with chromosomal } \\
\text { syndrome }\end{array}$ \\
$\begin{array}{l}\text { aberration of 11p15.5. These individuals are at higher risk of developing benign } \\
\text { or malignant tumors of multiple organs, commonest being Wilms' tumor, }\end{array}$ \\
rhabdomyosarcoma, hepatoblastoma, and adrenal carcinoma \\
\hline $\begin{array}{l}\text { Li-Fraumeni } \\
\text { syndrome }\end{array}$ & $\begin{array}{l}\text { Rare, autosomal, dominant familial syndrome with high incidence of multiple } \\
\text { malignancies at an early age, including breast cancer, leukemias, soft tissue } \\
\text { sarcomas, gliomas, laryngeal carcinoma, lung cancer, and adrenocortical carcinoma. } \\
\text { The pathogenesis of this syndrome is attributed to germ-line point mutations in } \\
\text { the p53 tumor suppressor gene (chromosome 17p13) in pediatric age group with } \\
\text { adrenocortical carcinoma and deletion of short arm of chromosome 17 (17p) }\end{array}$ \\
$\begin{array}{l}\text { Familial } \\
\text { adenomatous } \\
\text { polyposis }\end{array}$ & $\begin{array}{l}\text { multiple adenomatous polyps of the colon and rectum. The gene [adenomatous } \\
\text { polyposis coli gene] is located at 5q21. These patients are at high risk to develop } \\
\text { adrenocortical adenomas and carcinomas, the incidence being 7.4\% higher than } \\
\text { 0.6-3.4\% reported for normal population }\end{array}$ \\
& \\
&
\end{tabular}

Table 1.

Hereditary adrenocortical tumor syndromes. 
deficiency also have defect in synthesizing aldosterone. These patients die in the neonatal period due to shock from salt wasting. $\mathrm{CAH}$ is associated with multiple tumors like testicular tumors arising from ectopic adrenal cortical rests, testicular and ovarian Leydig cell tumor, and ovarian tumor of the adrenogenital syndrome as ovarian and paraovarian brown masses. Grossly the adrenal gland is marked enlarged having a cerebriform appearance. On cut surface the gland appears tan-brown in color. Under the microscope the adrenal gland reveals diffuse cortical hyperplasia. The cells are compactly arranged like how they are in the zona reticularis [2, 27-30].

Table 1 illustrates various syndromes associated with adrenocortical lesions [31].

\section{Primary hyperaldosteronism (Conn's syndrome)}

This disease was defined first by Conn in 1955, with a prevalence of 5-13\%. This syndrome is characterized by an inappropriate increase in production of aldosterone which is relatively independent from the renin-angiotensin mechanism and is non-suppressible by sodium loading. This is one of the leading causes of secondary hypertension in hypertensive adults [32]. Patients with primary aldosteronism may exhibit adrenal cortical hyperplasia or adenoma in $30 \%$ of sporadic cases, and nearly $1 \%$ of sporadic cases may have adrenocortical carcinoma [33]. Clinically these patients present most commonly as normokalemic hypertension, and severe cases do show hypokalemia (Table 2).

\begin{tabular}{|c|c|c|c|}
\hline S. no. & Tests & Procedure & Interpretation \\
\hline 1. & Postural testing & $\begin{array}{l}\text { - Performed after overnight } \\
\text { recumbency } \\
\text { - IV catheter inserted at } 7 \mathrm{AM} \text { (mea- } \\
\text { sure baseline aldosterone, cortisol, } \\
\text { and PRA values at } 8 \mathrm{AM} \text { ) } \\
\text { - Ambulate the patient for } 2 \mathrm{~h} \\
\text { - Measure baseline aldosterone, } \\
\text { cortisol, and PRA }\end{array}$ & $\begin{array}{l}\text { - } 30-50 \% \text { of APAs respond to } \\
\text { upright posture, and } 20 \% \text { of } \\
\text { bilateral adrenal hyperplasia are } \\
\text { unresponsive } \\
\text { - Diagnostic accuracy of } 85 \%\end{array}$ \\
\hline 2. & $\begin{array}{l}\text { 18-Hydroxycortico- } \\
\text { sterone level }\end{array}$ & & $\begin{array}{l}\text { - Elevated ( }>100 \mathrm{ng} / \mathrm{dL} \text { ) in patients } \\
\text { with APAs and is significantly } \\
\text { lower in patients with IHA } \\
\text { - Diagnostic accuracy of } 82 \% \\
\text { Hybrid steroid levels (18-OHF } \\
\text { and 18-oxoF) are high (3-30 times } \\
\text { normal) in FH-I, normal to mildly } \\
\text { elevated in FH-II (3-4 times normal, } \\
\text { as in sporadic PA), and mildly to } \\
\text { extremely high in FH-III (3-100 times } \\
\text { normal) }\end{array}$ \\
\hline 3. & $\begin{array}{l}\text { Dexamethasone } \\
\text { suppression test: } \\
\text { used for patients } \\
\text { with glucocorticoid- } \\
\text { remediable } \\
\text { aldosteronism } \\
\text { (GRA) as well as for } \\
\text { those patients who } \\
\text { do not have GRA }\end{array}$ & $\begin{array}{l}\text { - 4-day dexamethasone suppression } \\
\text { test (using a dosage of } 0.5 \text { mg every } \\
6 \mathrm{~h} \text { ) } \\
\text { - Measure aldosterone, renin, and } \\
\text { cortisol levels-before suppression } \\
\text { testing, after } 2 \text { days and then after } \\
4 \text { days of testing } \\
\text { - Plasma cortisol suppression (i.e., } \\
<5 \mathrm{mcg} / \mathrm{dL} \text { ) is used as an index of } \\
\text { the dexamethasone effect }\end{array}$ & $\begin{array}{l}\text { - Patients without GRA: aldosterone } \\
\text { levels typically fall by approxi- } \\
\text { mately } 50 \% \text { and return to the refer- } \\
\text { ence range by the end of testing } \\
\text { - Patients with GRA: persistent } \\
\text { suppression of aldosterone levels to } \\
\text { less than } 4 \mathrm{ng} / \mathrm{dL} \\
\text { - Sensitivity of } 92 \% \text { and a specificity } \\
\text { of } 100 \% \text { for the diagnosis of GRA }\end{array}$ \\
\hline
\end{tabular}




\begin{tabular}{|c|c|c|c|}
\hline S. no. & Tests & Procedure & Interpretation \\
\hline 4. & $\begin{array}{l}\text { 18-Oxocortisol and } \\
\text { 18-hydroxycortisol } \\
\text { (>100 nmol/day) }\end{array}$ & & - Markedly elevated level of GRA \\
\hline 5. & $\begin{array}{l}\text { Adrenal venous } \\
\text { sampling }\end{array}$ & $\begin{array}{l}\text { - Test to differentiate unilateral } \\
\text { disease from bilateral disease in } \\
\text { patients with PA } \\
\text { - ACTH may be infused into a } \\
\text { peripheral vein (at a dosage of } \\
50 \mathrm{mcg} / \mathrm{h} \text {, starting } 30 \text { min before } \\
\text { sampling) } \\
\text { - Can be performed with cosyntro- } \\
\text { pin stimulation }\end{array}$ & $\begin{array}{l}\text { - Calculate lateralization index (LI): } \\
\text { Plasma aldosterone (PAC) and } \\
\text { plasma cortisol concentration (PCC) } \\
\text { in both adrenal veins is determined } \\
\text { - The ratio of the higher (dominant) } \\
\text { over the lower (non-dominant) } \\
\text { PAC/PCC ratio is used for the } \\
\text { assessment of lateralization of } \\
\text { aldosterone hypersecretion } \\
\text { - Cutoff values of } 4 \text { during } \\
\text { cosyntropin stimulation and of } 2 \\
\text { for unstimulated AVS-criteria } \\
\text { to document lateralization of } \\
\text { aldosterone excess }\end{array}$ \\
\hline
\end{tabular}

Source: $[9,10,33,34]$.

Table 2.

Investigations.

The aldosterone-to-renin ratio (ARR), a gold standard method to differentiate primary from secondary causes of hyperaldosteronism, is defined as the ratio of plasma aldosterone (expressed in $\mathrm{ng} / \mathrm{dL}$ ) to plasma renin activity (PRA, expressed in $\mathrm{ng} / \mathrm{mL} / \mathrm{h}$ ). The cutoff value of ARR is $30 \mathrm{ng} / \mathrm{dL}$ per/mL per hour (or $750 \mathrm{pmol} / \mathrm{L}$ per $\mathrm{ng} / \mathrm{mL}$ per hour). The principle behind this test is that as aldosterone secretion rises, PRA in ex vivo testing falls due to sodium retention. This negative feedback response should occur when the aldosterone levels are supraphysiologic for that individual patient, and PRA may fall well before plasma aldosterone is clearly increased. Primary aldosteronism is suspected if the ARR is $>30 \mathrm{ng} / \mathrm{dL}$ per $\mathrm{mL}$ per hour. This method is also helpful in differentiating aldosterone-producing adenoma from bilateral adrenal hyperplasia [34].

\subsection{Familial primary aldosteronism}

Familial primary aldosteronism is mainly of three types, all of which are inherited in an autosomal dominant manner $[8,10,32,33]$ :

1. Familial hyperaldosteronism type I (glucocorticoid-remediable aldosteronism): accounts for less than $1 \%$ of cases. This disorder is caused by a recombination between the CYP11B2 and CYP11B1 genes.

2. Familial hyperaldosteronism type II: nearly 3-5\% cases of primary aldosteronism belong to this category and are attributed to 7p22. This disorder still lacks a specific gene.

\subsubsection{Gross features}

Grossly, the adrenal gland in cases of idiopathic hyperaldosteronism is rather unremarkable or may exhibit slight enlargement. The enlargement could be due to the presence of micronodules or macronodules. Usually, adenomas are unilateral and solitary. However few cases of bilateral disease have also been reported. These adenomas 


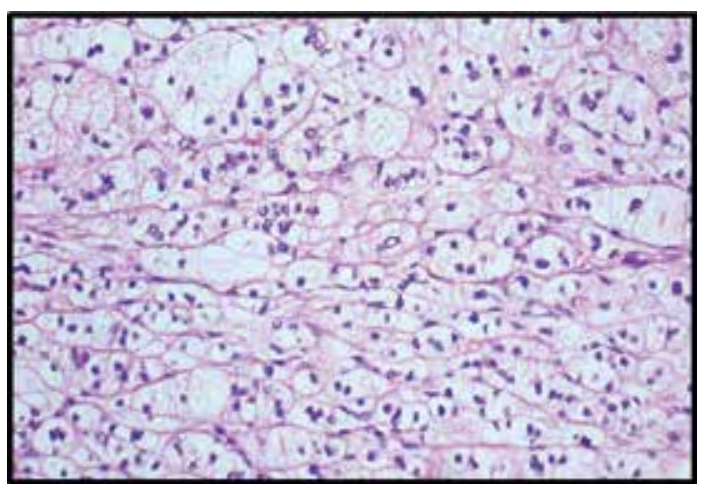

Figure 1.

Section from a 22-year-old patient, presented with a $2 \mathrm{~cm}$ mass in the right adrenal gland. Histology reveals adenoma with clusters of cells with enlarged lipid-rich cytoplasm (hematoxylin and eosin stain, $\times 200$ ).

are mostly intra-adrenal and do not show a capsule. Few cases may reveal the presence of a true capsule or a pseudocapsule $[2,3,35]$. The cut surface of this tumor appears homogenous and golden yellow and is classically described as "canary yellow" [2]. Focal areas of hemorrhage or cystic changes can be present in few cases [35].

\subsubsection{Microscopic features}

Microscopically these adenomas appear encapsulated by compressed fibrous rim or fibrous "pseudocapsule." The tumor cells are most commonly arranged in the form of nests or in alveolar pattern. Occasionally these cells may be arranged in short cords and trabeculae. Few cases may show mixed histological patterns. The tumor is composed of four different varieties of cells which may be present in varying proportions. More commonly seen are clear cells, having optically clear cytoplasm and centrally placed nuclei similar to those of the zona fasciculata cells; then there may be cells resembling to the zona glomerulosa or zona reticularis which appear small with compact eosinophilic cytoplasm. Then we have cells that are designated as "hybrid" cells. These hybrid cells have cytological features resembling both the zona fasciculata and glomerulosa (Figure 1). The uninvolved portion of adrenal cortex reveals atrophy. This atrophy is secondary to the negative feedback suppression effect of the hypothalamic-pituitary axis. Spironolactone bodies which appear as small, intracytoplasmic eosinophilic inclusions, round to oval, measuring 2-12 mm, are often encountered in adrenal cortical adenoma in patients on spironolactone treatment. These inclusions are delineated from the surrounding cytoplasm by a small, clear halo $[2,7,9,35]$.

\section{Adrenal insufficiency}

\subsection{Introduction and definition}

Adrenal insufficiency was first described by Thomas Addison in 1855 and was popularly known as Addison's disease. This disorder can occur either due to failure of the adrenal gland or impairment of the hypothalamic-pituitary axis [36]. Clinically this syndrome is characterized by weakness, fatigue, anorexia, abdominal pain, weight loss, orthostatic hypotension, and salt craving. Characteristic hyperpigmentation is seen in patients with primary adrenal failure [37]. This disease has been reported in three forms [7, 9, 37]: 
1. Primary disease also known as Addison's disease, a result of destruction of $90 \%$ or more of the adrenocortical gland or conditions that involve decreased production of adrenal steroids, resulting in subnormal synthesis of aldosterone, cortisol, and androgens.

2. Secondary and tertiary insufficiency occurs due to deficiency of secretion of corticotropin $(\mathrm{ACTH})$ and corticotropin-releasing hormone $(\mathrm{CRH})$, respectively.

Most of the cases (80-90\%) of primary adrenal insufficiency are caused by autoimmune adrenalitis. Most of the cases fall under the autoimmune polyendocrinopathy syndrome $(60 \%)[1,2,19,32-34]$. Cell-mediated immune mechanisms are implicated in pathogenesis. Various antibodies have been identified, antibodies against steroid 21-hydroxylase ( $85 \%$ cases) and autoantigens like steroid $17 \alpha$-hydroxylase and cholesterol side-chain cleavage enzyme. Other associations include cytotoxic T-lymphocyte antigen 4, protein tyrosine-phosphatase nonreceptor type 22, and the MHC class II transactivator. Secondary adrenal insufficiency results from any process that involves the pituitary gland and interferes with corticotropin secretion. Tertiary adrenal insufficiency results from processes that involve the hypothalamus and interfere with secretion of corticotropin-releasing hormone, arginine vasopressin, or both. Suppression of the hypothalamic-pituitary-adrenal (HPA) axis by long-term administration of high doses of glucocorticoids is the most common cause $[9,36,38]$.

\subsection{Laboratory investigations}

The patients of AI usually present with hyponatremia and hyperkalemia due to decreased aldosterone. Hypoglycemia also occurs due to cortisol. Decreased levels of this hormone also lead to an increase in lymphocytes and eosinophils, as a result of decreased immune-modulatory action of hydrocortisone. Measurement of baseline cortisol levels between 8:00 and 9:00 AM is the test used to diagnose AI. A serum cortisol level of value less than $5 \mu \mathrm{g} / \mathrm{mL}$ favors diagnosis of AI. Stimulation test with cosyntropin which stimulates the cortex helps in differentiating primary and secondary AI. In this test $250 \mu \mathrm{g}$ of cosyntropin is administered intramuscularly or intravenously, and serum cortisol is measured $30 \mathrm{~min}$ after infusion. Serum cortisol value of $\geq 18 \mu \mathrm{g} / \mathrm{dL}$ indicates a normal response. A cortisol peak $<18 \mu \mathrm{g} / \mathrm{dL}$ confirms the diagnosis of AI. Serum cortisol level $\geq 100 \mathrm{pg} / \mathrm{mL}$ confirms the diagnosis of Addison's syndrome. Serum cortisol value of $<10 \mathrm{pg} / \mathrm{mL}$ confirms diagnosis of secondary AI [35-39].

\section{Adrenocortical carcinoma}

\subsection{Definition and introduction}

ACC is a highly aggressive and a very rare malignancy. The incidence of this malignancy is approximately 0.72 per million cases per year according to the study by Surveillance, Epidemiology, and End Results (SEER) database [39]. The median age of diagnosis is usually fifth to sixth decade; however the German ACC Registry reports a median age at diagnosis of 46 years with a predilection for the female gender (female to male ratio: 1.5-2.5:1) [35, 38, 39].

Adrenocortical carcinomas (ACC) are rare tumors with an estimated annual inciᄀdence of $0.7-2$ cases by year and a global prevalence of 4-12 cases per million with a 5 -year survival rate inferior to $35 \%$ in most of the studies published. 


\subsection{Pathogenesis of adrenocortical carcinoma}

Various mutations have been implicated in association with ACC. Most common are germ-line TP53 mutations, associated with childhood ACCs. The adult population shows a prevalence of 3-7\% of similar mutation. Childhood ACC can be found in association with Li-Fraumeni syndrome, Beckwith-Wiedemann syndrome, Lynch syndrome, and multiple endocrine neoplasia type 1. Of late an association with familial adenomatous polyposis (FAP), neurofibromatosis type 1, Werner syndrome, and Carney complex has also been postulated $[39,40]$.

\subsubsection{Molecular mechanisms}

In ACCs, chromosomal gains were frequently observed in regions 4q, 4p16, 5p15, 5q12-13, 5q32-qter, 9q34, 12q13, 12q24, and 19p, and chromosomal losses were observed at 1p, 2q, 11q 17p, 22p, and 22q. Microsatellite studies identified frequent allelic losses in regions 17p13, 11q15, and 2p16 (85\%, 92\%, and 90\% of samples, respectively) [41-43].

Signaling pathways involved in adrenal malignant carcinogenesis [44-47]:

- p53 signaling pathway

- Wnt/beta-catenin signaling pathway

- Insulin growth factor II (IGF-II) locus

\subsubsection{The TP53 alterations}

Protein p53, "guardian of genome," is located at the 17p13 locus, and alterations in this gene have been noticed in various cancers including adrenocortical carcinoma, more so at the somatic level. p53 gene mediates cellular response to stress, and adult sporadic ACCs usually reveal loss of heterozygosity at this locus (nearly 85\%) [48]. Stress leads to inhibition of degradation of p53 by E3 ubiquitin ligase MDM2, leading to inhibition of cell cycle arrest in response to DNA damage as well as apoptosis. These tumors tend to be larger and present at more advanced stage of tumor progression with shorter disease-free survival. Various genetic alterations have been reported in patients with adrenal cortex carcinoma like loss of PTTG1 has been reported in nearly $84 \%$, mutation in retinoblastoma protein $(\mathrm{pRb})$ in nearly $27 \%$ cases and mutation in RB1 gene in $7 \%$ of the cases. Inactivating mutations or homozygous deletions of CDKN2A have also been reported in 11-16\% cases. High-level amplifications of CDK4 and MDM2 were reported in 2-7\% ACCs [49-51]. It is surprising to see that majority of the TP53 mutations occur at the DNA-binding domain. Some tumors also have shown abnormalities in genes that encode for negative regulators of TP53, like PTTG1 which encodes for securin, noted in $84 \%$ of ACC. It is considered as a marker of poor survival [44, 46, 49].

\subsubsection{Wnt/beta-catenin signaling pathway}

Wnt family consists of highly conserved growth factors having similar amino acid sequences and is responsible for various developmental and homeostatic processes $[4,44,46-48,51]$. A prevalence of 39 and $84 \%$ has been reported by various authors on immunohistochemistry for $\beta$-catenin. The Wnt receptor is composed of members of the frizzled family and low-density lipoprotein receptor-related 
protein. $\beta$-Catenin accumulates in the cytoplasm and gets translocated into the nucleus and then binds with Wnt receptor leading to inhibition of the axin-adenomatous polyposis coli-glycogen synthase kinase $3 \beta$ (GSK-3) complex. This blocks the phosphorylation of $\beta$-catenin, leading to increased accumulation of $\beta$-catenin in the cytoplasm which further translocates into the nucleus. Interaction between $\beta$-catenin with the $T$ cell-specific transcription factor/lymphoid enhancer-binding factor-1 family of transcription factors occurs in the nucleus, thus regulating transcription of Wnt target genes. If Wnt stimulation of GSK-3 phosphorylating $\beta$-catenin does not occur, degradation by proteosomes occurs following ubiquitylation of this receptor. Wnt pathway has been implicated in patients with familial adenomatous polyposis and in the development of colorectal carcinomas as well as ACCs. Wnt/beta-catenin pathway can be activated in both benign and malignant tumors by CTNNB1 mutations and by ZNRF3 inactivation in adrenal cancer. ZNRF3 is a recent gene that encodes a cell-surface transmembrane $\mathrm{E} 3$ ubiquitin ligase which acts as a negative feedback regulator of Wnt signaling. Recently, ZNRF3 was found to be the most frequently altered gene in study cohorts of ACC investigated by integrated genomics, with a prevalence of 21 and 19\% in studies by Assié et al. and Zheng et al., respectively $[50,51]$.

\subsubsection{Insulin growth factor II (IGF-II)}

Nearly $85-90 \%$ of the adult adrenocortical carcinomas are attributed to IGF-II overexpression. This molecular abnormality is associated with DNA demethylation at IGF-II locus in most of cases. Various transcriptome studies have confirmed that $I G F-I I$ is the most upregulated gene in ACC $[52,53]$.

\subsubsection{Biochemistry}

ACC are the tumors characterized by adrenocortical hormone production in nearly $45-70 \%$ of patients. Hypercortisolism is the most common presentation of patients presenting with hormone excess leading to a plethora of symptoms like diabetes mellitus, hypertension, hypokalemia, muscle weakness/atrophy, and osteoporosis [40-43]. Excess of androgens which comprise nearly 40-60\% of hormone-secreting ACCs can cause rapid-onset male pattern baldness, hirsutism, virilization, and menstrual irregularities in women. Estrogen production occurs in $1-3 \%$ of male ACC patients, causing gynecomastia and testicular atrophy (through suppression of the gonadal axis). In the evaluation of adrenal tumors, regardless of size, androgen or estrogen production should always raise the suspicion of a malignant tumor [44].

\subsubsection{Gross findings}

ACCs are generally large tumors, measuring on average $10-13 \mathrm{~cm}$. Only a minority of tumors are less than $6 \mathrm{~cm}(9-14 \%)$, with only $3 \%$ presenting as lesions less than $4 \mathrm{~cm}[2,3,6,9,35]$.

\subsubsection{Microscopy findings}

Microscopically these tumors have variable architectural patterns. The tumor cells are arranged in a trabecular, alveolar, or diffuse pattern. Occasionally mixed patterns are also noted. Some areas may also exhibit free-floating tumor cells forming balls [2, 3, 6, 9, 35] (Figure 2A, B). 

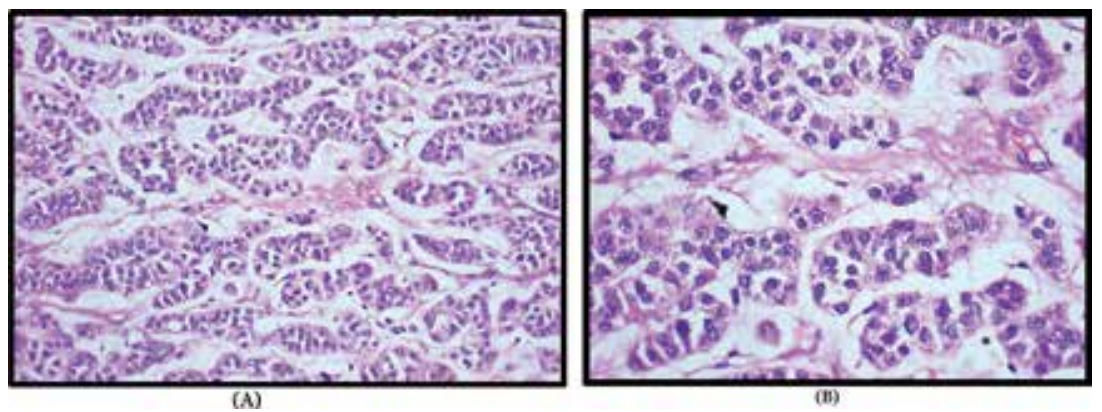

Figure 2.

(A) Section from a 45-year-old patient, presented with a $13 \mathrm{~cm}$ mass in the left adrenal gland. Histology reveals clusters of cells having anisocytosis and enlarged nuclei with prominent nucleoli. The fair number of darkly stained atypical mitosis is also evident (hematoxylin and eosin stain, $\times 200$ ). (B) Histology reveals clusters of cells having anisocytosis and enlarged nuclei with prominent nucleoli. The cells are separated by myxoid stroma. The fair number of darkly stained atypical mitosis is also evident (hematoxylin and eosin stain, $\times 400$ ).

Histologic criteria for malignancy in adrenal cortical tumors are assessed as follows $[2,3,6,9,35,43-45]$ :

1. High nuclear grade (grades III and IV according to the criteria of Fuhrman)

2. Mitotic rate $>5$ per $50 \mathrm{HPF}$ ( $10 \mathrm{HPF}$ in each of the five areas that are most suspicious to be malignant)

3. Atypical mitotic figures (abnormal distribution of chromosomes or an excessive number of mitotic spindles)

4. Eosinophilic tumor cell cytoplasm ( $>75 \%$ of tumor cells or $<25 \%$ clear vacuolated cells resembling the normal fasciculata)

5. Diffuse architecture ( $>33 \%$ of the tumor forming patternless sheets of cells)

6. Necrosis (occurring in confluent nests of cells)

7. Venous invasion (endothelial-lined vessel with smooth muscle as a component of the wall)

8. Sinusoidal invasion (endothelial-lined vessel in the adrenal with little supportive tissue)

9. Capsular invasion (nests or cords of tumor extended into or through the capsule with the corresponding stromal reaction)

Weiss et al. proposed a scoring system which was further modified and is widely accepted to report adrenal cortex carcinomas. These criteria include [35, 43-45, 54] (Table 3).

\subsubsection{Interpretation}

Adrenal cortical adenoma: total score $<3$.

Adrenal cortical carcinoma: total score $\geq 3$.

Thus if the modified Weiss score is $\geq 3$, then a diagnosis of adrenocortical carcinoma is given. 
Pathology Associated with Hormones of Adrenal Cortex

DOI: http://dx.doi.org/10.5772/intechopen. 84815

\begin{tabular}{|c|c|c|c|}
\hline \multirow[t]{2}{*}{ Criteria } & & \multicolumn{2}{|c|}{ Score } \\
\hline & & Absent & Present \\
\hline \multicolumn{2}{|c|}{ Mitotic rate ( $\geq 6$ mitotic figures $/ 50 \mathrm{HPF}$ ) } & 0 & 1 \\
\hline \multicolumn{2}{|c|}{$\begin{array}{l}\text { Cytoplasm characteristics } \\
\text { [clear vs. compact (compact }>75 \% \text { of cells)] }\end{array}$} & 0 & 1 \\
\hline \multicolumn{2}{|l|}{ Abnormal mitoses } & 0 & 1 \\
\hline \multicolumn{2}{|l|}{ Tumor necrosis } & 0 & 1 \\
\hline \multicolumn{2}{|c|}{ Invasion of the capsule } & 0 & 1 \\
\hline \multicolumn{4}{|c|}{ Overall score $=2 \times$ mitotic rate $+2 \times$ cytoplasm + abnormal mitoses + necrosis + capsular invasion. } \\
\hline \multicolumn{4}{|c|}{$\begin{array}{l}\text { Table } 3 . \\
\text { Weiss scoring for adrenocortical carcinoma. }\end{array}$} \\
\hline Characteristics & Adrenocortical adenoma & \multicolumn{2}{|c|}{ Adrenocortical carcinoma } \\
\hline \multicolumn{4}{|l|}{ Macroscopy } \\
\hline Weight & Usually less than $100 \mathrm{~g}$ & \multicolumn{2}{|l|}{ More than $100 \mathrm{~g}$} \\
\hline Hemorrhage & $+/-$ & \multicolumn{2}{|l|}{+++} \\
\hline Necrosis & $+1-$ & \multicolumn{2}{|l|}{+++} \\
\hline Cystic degeneration & $+/-$ & \multicolumn{2}{|l|}{+++} \\
\hline \multicolumn{4}{|l|}{ IHC } \\
\hline MIB-1 & Negative & \multicolumn{2}{|l|}{ Positive } \\
\hline Vimentin & Negative & \multicolumn{2}{|l|}{ Positive } \\
\hline Inhibin & Positive & \multicolumn{2}{|l|}{ Positive } \\
\hline Melanin & Positive & \multicolumn{2}{|l|}{ Positive } \\
\hline Calretinin & Positive & \multicolumn{2}{|l|}{ Positive } \\
\hline BCL-2 & Positive & \multicolumn{2}{|l|}{ Positive } \\
\hline C-kit & Negative & \multicolumn{2}{|l|}{ Positive } \\
\hline EMA & Negative & \multicolumn{2}{|l|}{ Negative } \\
\hline Cytokeratin & Negative & \multicolumn{2}{|l|}{ Negative } \\
\hline NSE & - & \multicolumn{2}{|l|}{ Positive } \\
\hline Synaptophysin & - & \multicolumn{2}{|l|}{ Positive } \\
\hline Chromogranin & - & \multicolumn{2}{|l|}{ Negative } \\
\hline
\end{tabular}

Table 4.

Differentiating features between adrenocortical adenoma and adrenocortical carcinoma.

However there are other features that may help in differentiating between adenomas and carcinoma. These are listed in Table 4 [35, 43-45].

\section{Conclusion}

Adrenal glands have an essential role in maintaining the normal hemostasis. However the three layers of adrenal cortex, the zona glomerulosa, zona fasciculata, and zona reticularis, secrete essential hormones that are involved in fluid and electrolyte balance, regulating renin-angiotensin-aldosterone system, production of glucocorticoids, and synthesis of sex hormones. These hormones play an important 
role in maintaining the normal homeostasis of the body. Various lesions in adrenal, benign as well as malignant, are known to cause disturbances in the internal milieu of our body. It is therefore essential to know the physiology as well as various types of disorders that can be encountered so as to define proper management of the patient. Also lesions of adrenal gland are attributed to various genetic abnormalities, knowledge of which can be implicated to study the pathogenesis and in applying this knowledge in prognosis as well as developing targeted therapy for these lesions.

\section{Author details}

Lovelesh K. Nigam $^{1 *}$, Aruna V. Vanikar ${ }^{1,2}$, Rashmi D. Patel ${ }^{1}$, Kamal V. Kanodia ${ }^{1}$ and Kamlesh S. Suthar ${ }^{1}$

1 Department of Pathology, Laboratory Medicine, Transfusion Services and Immunohematology, G.R. Doshi and K.M. Mehta Institute of Kidney Diseases and Research Centre and Dr. H.L. Trivedi Institute of Transplantation Sciences, Civil Hospital Campus, Asarwa, Ahmedabad, India

2 Department of Cell Therapy and Regenerative Medicine, Asarwa, Ahmedabad, India

*Address all correspondence to: drloveleshnigam@gmail.com

\section{IntechOpen}

(C) 2019 The Author(s). Licensee IntechOpen. This chapter is distributed under the terms of the Creative Commons Attribution License (http://creativecommons.org/licenses/ by/3.0), which permits unrestricted use, distribution, and reproduction in any medium, provided the original work is properly cited. (cc) BY 


\section{References}

[1] Tischler AS. Paraganglia. In: Mills SE, editor. Histology for Pathologists. 3rd ed. Philadelphia: Lippincott Williams \& Wilkins; 2012. pp. 1277-1294

[2] Zhang R, Lloyd RV. Chapter 2: The pathology of adrenal masses. In: Kebebew E, editor. Management of Adrenal Masses in Children and Adults. Cham: Springer; 2017. DOI: 10.1007/978-3-319-44136-8_2

[3] Mangray S, De Lellis R. Adrenal glands. In: Mills SE, editor. Sternberg's Diagnostic Surgical Pathology. Philadelphia: Wolters Kluwer; 2015. pp. 585-646

[4] Else T, Hammer GD, McPhee SJ. Chapter 21: Disorders of the adrenal cortex. In: Pathophysiology of Disease: An Introduction to Clinical Medicine. 7th ed. USA: McGraw Hill Education; 2014. pp. 593-624

[5] Silverman ML, Lee AK. Anatomy and pathology of the adrenal glands. The Urologic Clinics of North America. 1989;16(3):417-432. PMID: 2665268

[6] Hughes S, Lynn J. Chapter 37: Surgical anatomy and surgery of the adrenal glands. In: Surgical Endocrinology. Philadelphia: Elsevier Ltd; 1993. pp. 458-467. DOI: $10.1016 /$ B978-0-7506-1390-.50042-8

[7] Zynger DL. Chapter 10: Adrenal Primary Tumors and non-tumors. In: Epstein JI, editor. Biopsy Interpretation of the Kidney and Adrenal Gland. 1st ed. Philadelphia: Wolters Kluwer; 2016. pp. 173-186

[8] Innes JA, Maxwell S. Chapter 10: Endocrine disease. In: Davidson's Essentials of Medicine. 23rd edition, Philadelphia: Elsevier; 2016. pp. 327-380

[9] Rosai J. Chapter 16: Adrenal gland and other paraganglia. In: Rosai and
Ackerman's Surgical Pathology. 10th ed. Vol. 2. Philadelphia: Elsevier; 2012. pp. $1057-1100$

[10] Arlt W. Disorders of the adrenal cortex. In: Kasper DL, Hauser SL, Jameson JL, Fauci AS, Longo DL, Loscalzo, editors. Harrison's Principles of Internal Medicine. 19th ed. Vol. 2. USA: McGraw Hill Education; 2015. pp. 2309-2330

[11] Agrons MM, Jensen CT, Habra MA, Menias CO, Shaaban AM, Wagner-Bartak NA, et al. Adrenal cortical hyperplasia: Diagnostic workup, subtypes, imaging features and mimics. The British Journal of Radiology. 2017;90:20170330

[12] MvNicol AM. Lesions of adrenal cortex. Archives of Pathology \& Laboratory Medicine. 2008;132:1263-1269

[13] Nieman L, Ilias I. Evaluation and treatment of Cushing's syndrome. The American Journal of Medicine. 2005;118:1340-1346.

[14] Ejaz S, Vassilopoulou-Sellin R, Busaidy NL, Hu MI, Waguespack SG, Jimenez C, et al. Cushing syndrome secondary to ectopic adrenocorticotropic hormone secretion. Cancer. 2011;117:4381-4389. DOI: 10.1002/ cncr.26029

[15] Chaudhary V, Bano S. Imaging of the pituitary: Recent advances. Indian Journal of Endocrinology and Metabolism. 2011;15(Suppl. 3):216S223. DOI: $10.4103 / 2230-8210.84871$

[16] Lila AR, Sarathi V, Jagtap VS, Bandgar T, Menon P, Shah NS. Cushing's syndrome: Stepwise approach to diagnosis. Indian Journal of Endocrinology and Metabolism. 2011;15:317-321 
[17] Elamin MB, Murad MH, Mullan R, Erickson D, Harris K, Nadeem S. Accuracy of diagnostic tests for Cushing's syndrome a systematic review and meta-analyses. The Journal of Clinical Endocrinology and Metabolism. 2008;93:1553-1562

[18] Al-Saadi N, Diederich S, Oelkers W. A very high dose dexamethasone suppression test for differential diagnosis of Cushing's syndrome. Clinical Endocrinology. 1998;48(1):45-51

[19] Raff H, Sharma ST, Nieman LK. Physiological basis for the etiology, diagnosis, and treatment of adrenal disorders: Cushing's syndrome, adrenal insufficiency, and congenital adrenal hyperplasia. Comprehensive Physiology. 2014;4(2):739-769. DOI: 10.1002/cphy. c130035

[20] Manipadam MT, Abraham R, Sen S, Simon A. Primary pigmented nodular adrenocortical disease. Journal of Indian Association of Pediatric Surgeons. 2011;16:160-162. DOI: 10.4103/0971-9261.86881

[21] Pernick N. Cushing Syndrome. Available from: http://www. pathologyoutlines.com/topic/ adrenalcushings.html [Accessed: 22 December 2018]

[22] Katanić D, Kafka D, Živojinov M, Vlaški J, Budakov Z, Pogančev MK, et al. Primary pigmented nodular adrenocortical disease: Literature review and case report of a 6-year-old boy. Journal of Pediatric Endocrinology \& Metabolism. 2017;30(5):603-609. DOI: 10.1515/jpem-2016-0249

[23] Ngow HA, Khairin WM. Primary pigmented nodular adrenocortical disease. Endokrynologia Polska (Polish Journal of Endocrinology). 2011;62(3):268-270
[24] Bain J. Carney's complex. Mayo Clinic Proceedings. 1986;61:508. DOI: 10.1016/S0025-6196(12)61989-2

[25] Swain JM, Grant CS, Schlinkert RT, Thompson GB, vanHeerdenJA, Lloyd RV, et al. Corticotropin-independent macronodular adrenal hyperplasia. Archives of Surgery. 1998;133:541-546

[26] New MI, Wilson RC. Steroid disorders in children: Congenital adrenal hyperplasia and apparent mineralocorticoid excess. Proceedings of the National Academy of Sciences of the United States of America. 1999;96:12790-12797. DOI: 10.1073/ pnas.96.22.12790

[27] Chung EM, Biko DM, Schroeder JW, Cube R, Conran RM. From the radiologic pathology archives: Precocious puberty: Radiologic-pathologic correlation. RadioGraphics. 2012;32:2071-2099. DOI: $10.1148 /$ rg.327125146

[28] Witchel SF. Congenital adrenal hyperplasia. Journal of Pediatric and Adolescent Gynecology. 2017;30(5):520-534

[29] El Maouche D, Arlt W, Merke DP. Congenital adrenal hyperplasia. The Lancet. 2017;390(10108):2121-2241

[30] Speiser PW, White PC. Congenital adrenal hyperplasia. The New England Journal of Medicine. 2003;349(8): 776-788. PMID: 12930931

[31] Åkerström G, Hellman P. Genetic syndromes associated with adrenal tumors. In: Linos D, van Heerden JA, editors. Adrenal Glands. Berlin, Heidelberg: Springer; 2005. DOI: 10.1007/3-540-26861-8_25

[32] Mattson C, Young WF. Primary aldosteronism: Diagnostic and treatment strategies. Nature Clinical Practice. Nephrology. 2006;2(4):198-208 
[33] Ganguly A. Primary aldosteronism. The New England Journal of Medicine. 1998;339(25):1828-1834

[34] Umakoshi H, Tsuiki M, Yokomoto Umakoshi M, Takeda Y, Kurihara I, et al. Correlation between lateralization index of adrenal venous sampling and standardized outcome in primary aldosteronism. Journal of the Endocrine Society. 2018;2(8):893-902. DOI: $10.1210 /$ js.2018-00055

[35] Lack EE, Wieneke J. Chapter 19: Tumors of the adrenal gland. In: Fletcher C, editor. Diagnostic Histopathology of Tumors. 4th ed. Vol. 2. Philadelphia: Elsevier Saunders; 2013. pp. 1294-1352

[36] Fares AB, dos Santos RA. Conduct protocol in emergency: Acute adrenal insufficiency. Revista da Associação Médica Brasileira. 2016;62(8):728-734. DOI: $10.1590 / 1806-9282.62 .08 .728$

[37] Addison T. On the Constitutional and Local Effects of Disease of the Supra-Renal Capsules. London: Samuel Highley; 1855

[38] Betterle C, Morlin L. Autoimmune Addison's disease. Endocrine Development. 2011;20:161-172

[39] Reiff E, Duh QY, Clark OH, McMillan A. Extent of disease at presentation and outcome for adrenocortical carcinoma: Have we made progress? World Journal of Surgery. 2006;30:872-878

[40] Lack EE. Tumors of the adrenal gland and extra-adrenal paraganglia. In: Atlas of Tumor Pathology-3rd Series. Washington, DC: Armed Forces Institute of Pathology; 1997. pp. 102-104

[41] Aubert S, Wacrenier A, Leroy X, Devos P, Carnaille B, Proye C, et al. Weiss system revisited: A clinicopathologic and immunohistochemical study of 49 adrenocortical tumors. The American Journal of Surgical Pathology. 2002;26(12):1612-1619

[42] Stojadinovic A, Brennan MF, Hoos A, Omeroglu A, Leung DNY, Dudas ME, et al. Adrenocortical adenoma and carcinoma: Histopathological and molecular comparative analysis. Modern Pathology. 2003;16(8):742-751. DOI: 10.1097/01.MP.0000081730.72305.81

[43] Giordano TJ. Adrenocortical tumors: An integrated clinical, pathologic, and molecular approach at the University of Michigan. Archives of Pathology \& Laboratory Medicine. 2010;134:1440-1443

[44] Bonnet-Serrano F, Bertherat J. Genetics of tumors of the adrenal cortex. Endocrine-Related Cancer. 2018;25:131-152

[45] Soon PSH, Mcdonald KL, Robinson BG, Sidhu SB. Molecular markers and the pathogenesis of adrenocortical cancer. The Oncologist. 2008;13:548-561

[46] Lerario AM. Genetics and epigenetics of adrenocortical tumors. Molecular and Cellular Endocrinology. 2014;386:67-84. DOI: 10.1016/j. mce.2013.10.028

[47] Else T, Kim AC, Sabolch A, Raymond VM, Kandathil A, Caoili EM, et al. Adrenocortical carcinoma. Endocrine Reviews. 2014;35(2):282-326

[48] Gicquel C, Bertagna X, Gaston V, Coste J, Louvel A, Baudin E, et al. Molecular markers and long-term recurrences in a large cohort of patients with sporadic adrenocortical tumors. Cancer Research. 2001;61:6762-6767

[49] Ragazzon B, Libé R, Assié G, Tissier F, Barreau O, Houdayer C, et al. Mass-array screening of frequent 
mutations in cancers reveals RB1

alterations in aggressive adrenocortical carcinomas. European Journal of Endocrinology. 2014;170:385-391. DOI: 10.1530/EJE-13-0778

[50] Assié G, Letouzé E, Fassnacht M, Jouinot A, Luscap W, Barreau O, et al. Integrated genomic characterization of adrenocortical carcinoma. Nature Genetics. 2014;46:607-612. DOI: 10.1038/ng.2953

[51] Zheng S, Cherniack AD, Dewal N, Moffitt RA, Danilova L, Murray BA, et al. Comprehensive pan-genomic characterization of adrenocortical carcinoma. Cancer Cell. 2016;29: 723-736. DOI: 10.1016/j. ccell.2016.04.002

[52] De Reyniès A, Assié G, Rickman DS, Tissier F, Groussin L, René-Corail F, et al. Gene expression profiling reveals a new classification of adrenocortical tumors and identifies molecular predictors of malignancy and survival. Journal of Clinical Oncology. 2009;27:1108-1115. DOI: $10.1200 /$ JCO.2008.18.5678

[53] Else T. Association of adrenocortical carcinoma with familial cancer susceptibility syndromes. Molecular and Cellular Endocrinology. 2012;351(1): 66-70. DOI: 10.1016/j.mce.2011.12.008

[54] Scarpellia M, Algabab F, Kirkalic Z, Poppeld HV. Handling and pathology reporting of adrenal gland specimens. European Urology. 2004;45:722-729 
Section 3

Mitochondrial Imaging 



\title{
PET Imaging of Mitochondrial Function in the Living Brain
}

\author{
Hideo Tsukada
}

\begin{abstract}
In the last two and half decades, we have conducted research on brain functional imaging in nonhuman primates using animal positron emission tomography (PET) scanners with high spatial resolution. We recently designed and synthesized the novel PET probe $\left[{ }^{18} \mathrm{~F}\right] \mathrm{BCPP}-\mathrm{EF}$ to quantitatively image mitochondria complex-I (MC-I) activity in the living brain. Brain MC-I activity, measured using $\left[{ }^{18} \mathrm{~F}\right]$ BCPP-EF, was significantly lower in aged monkeys than that in young animals, while no significant reduction was observed in SV2A activity, a synaptic-specific parameter that was measured using $\left[{ }^{11} \mathrm{C}\right] \mathrm{UCB}-J$. Some aged monkeys exhibited increased amyloid- $\beta$ deposition in the brain, measured using $\left[{ }^{11} \mathrm{C}\right] \mathrm{PiB}$, which induced neuroinflammation. A positive correlation was noted with neuroinflammation, measured using $\left[{ }^{11} \mathrm{C}\right] \mathrm{DPA}-713$ and a negative correlation with MC-I activity. Furthermore, a monkey model of Parkinson's disease prepared by the chronic administration of MPTP revealed suppressed MC-I activity not only in the nigrostriatal dopamine pathway, measured using $\left[{ }^{11} \mathrm{C}\right] \mathrm{PE} 2 \mathrm{I}$ and $\left[{ }^{11} \mathrm{C}\right] 6 \mathrm{Me} m \mathrm{Tyr}$, but also in cortical serotonergic neurons, measured using $\left[{ }^{11} \mathrm{C}\right] \mathrm{DASB}$. This review introduces the translational application of a novel PET probe for noninvasive MC-I imaging from preclinical to clinical PET measurements.
\end{abstract}

Keywords: brain, mitochondria, aging, neurodegeneration, PET

\section{Introduction}

The brain has the most complex system among all human organs and plays a central role in physiological, neurological, and metabolic regulation throughout the body. The brain is very metabolically active in proportion to its volume, consuming $20 \%$ of total oxygen and $25 \%$ of total glucose, and each cell relies on mitochondria to produce energy as adenosine triphosphate (ATP). The brain consists of neuronal and glial cells, each of which uses the different metabolic pathways to produce ATP; astrocytes are highly glycolytic, while neurons depend on oxidative phosphorylation (OXPHOS) in the mitochondria [1]. The electron transport chain (ETC) for OXPHOS in mitochondria consists of five types of complexes from I to $\mathrm{V}$, with complex-I (MC-I; NADH-ubiquinone oxidoreductase, EC 1.6.5.3) forming the first and rate-limiting steps of overall respiratory and OXPHOS.

Neuronal death is regarded the dominant cause of brain aging. The "Mitochondrial Free Radical Theory of Aging" considers mitochondria to be the main drivers of aging due to the generation of reactive oxygen (ROS) and nitrogen (RNS) species through the ETC, and the cumulated impairment of mitochondria by oxidative stress in mitochondrial lipids, proteins, and DNA leads to neuronal 
death in the brain [2]. Neuronal damage related to impaired mitochondrial function is a hallmark for several neurodegenerative diseases, including Alzheimer's (AD), Parkinson's (PD), Huntington's diseases (HD), as well as amyotrophic lateral sclerosis (ALS) and multiple sclerosis (MS).

The etiology of $\mathrm{AD}$, the most prominent age-related neurodegenerative disease, is multifactorial and associated with various environmental and genetic factors that play a role in its pathogenesis. The deposition of amyloid- $\beta(A \beta)$ in the brain has been suggested to enhance neurodegenerative damage. Structural disruption and loss of neuronal cells induced by $\mathrm{A} \beta$, leading to neuronal network dysfunction and synaptic loss in the hippocampus and cerebral cortex, is associated with cognitive impairment in $\mathrm{AD}$ patient [3]. Although the molecular mechanisms underlying synaptic dysfunction induced by $A \beta$ have not been fully elucidated, mitochondrial dysfunction caused by $A \beta$ is associated with synaptic functional alterations in the living brain [3].

$\mathrm{PD}$ is the second most prominent neurodegenerative disease and is characterized by the progressive degradation of the nigrostriatal pathway with the selective loss of dopamine (DA) neurons, resulting in movement abnormalities such as resting tremor, rigidity, akinesia, and impaired postural reflexes. A hallmark of idiopathic PD is the deposition of Lewy bodies containing insoluble and aggregated $\alpha$-synuclein in the cytoplasmic fraction of nigrostriatal neurons in the DA pathway [4]. The loss of MC-I catalytic activity in the ETC has been reported in tissues obtained from sporadic PD patients [5] with increased oxidative stress [6].

Regarding the noninvasive assessment of mitochondrial function in the living brain, we recently developed a novel probe, $\left[{ }^{18} \mathrm{~F}\right] 2$-tert-nutyl-4-chloro-5- $\{6-[2-(2-$ fluoroethyl)-ethoxyl-pyridin-3-3-ylmetoxy $]-2 \mathrm{H}$-pyrisazin-3-one ([$\left.\left.{ }^{18} \mathrm{~F}\right] \mathrm{BCPP}-\mathrm{EF}\right)$, for positron emission tomography (PET) [7]. The effects of physiological aging, aging-related A $\beta$ deposition, and chronic MPTP treatments on cortical MC-I function were assessed in conscious monkeys using $\left[{ }^{18} \mathrm{~F}\right] \mathrm{BCPP}-\mathrm{EF}$, with the aim of translating clinical PET research to $\mathrm{AD}$ and $\mathrm{PD}$ patients.

\section{Effects of aging on MC-I and SV2A function in the living brain}

Mitochondria from aged brains consume less oxygen and, thus, produce lower amounts of ATP [8]. Different types of neurons show differences in topologies with various numbers of synaptic connections. Since synaptic and non-synaptic mitochondria have different protein compositions and respiratory and ROS production rates, synaptic mitochondria are more vulnerable to oxidative damage during the aging process than non-synaptic mitochondria [9]. In quantitative assessments of the effects of physiological aging on mitochondria and synaptic function in the living brain, the activities of MC-I and synaptic vesicle glycoprotein 2A (SV2A), an ideal biomarker for synaptic density, were comparatively evaluated in the living brains of young and aged rhesus monkeys.

\subsection{Methods}

Six young male (3-5 years old) and eight aged male (20-24 years old) rhesus monkeys (Macaca mulatta) were examined in the PET study using $\left[{ }^{18} \mathrm{~F}\right] \mathrm{BCPP}-\mathrm{EF}$ for MC-I and $(R)-1-\left(\left(3-\left[{ }^{11} \mathrm{C}\right]\right.\right.$ methyl- $\left.\left[{ }^{11} \mathrm{C}\right]\right)$ pyridine-4-yl) methyl)-4-(3,4,5-trifluorophenyl)pyrrolidin-2-one ( $\left.\left[{ }^{11} \mathrm{C}\right] \mathrm{UCB}-\mathrm{J}\right)$ for SV2A [10]. MRI was performed on each monkey using a 3.0 T MR imager (Singna Excite HDxt 3.0 T, GE Healthcare) using a 3D spoiled gradient echo (SPGR) sequence under pentobarbital anesthesia. To avoid anesthetic effects on brain function as well as PET probe kinetics, PET scans were 
conducted under conscious condition using high-resolution animal PET scanners (SHR-7700 and 38,000, Hamamatsu Photonics) as reported previously [11-14].

$\left[{ }^{18} \mathrm{~F}\right] \mathrm{BCPP}-\mathrm{EF}$ was prepared by the nucleophilic $\left[{ }^{18} \mathrm{~F}\right]$ fluorination of the corresponding precursor, as reported previously [9]. Radiochemical purity was more than $99 \%$, and specific radioactivity was $47.8 \pm 12.7 \mathrm{GBq} / \mu \mathrm{mol}$. $\left[{ }^{11} \mathrm{C}\right] \mathrm{UCB}-\mathrm{J}$ was labeled via the Suzuki cross-coupling of $\left[{ }^{11} \mathrm{C}\right]$ methyl iodide with a boronate precursor, as reported previously [10]. Radiochemical purity was more than $98 \%$, and specific radioactivity was $62.3 \pm 25.1 \mathrm{GBq} / \mu \mathrm{mol}$.

After overnight fast, a venous cannula for the PET ligand injection and an arterial cannula for blood sampling were inserted into both inferior limbs. The animal's head was rigidly fixed to a monkey chair using an acrylic head-restraining device surgically attached on the skull. The monkey sitting in the chair was placed at a position in the PET gantry with stereotactic coordinates aligned parallel to the orbito-metal $(\mathrm{OM})$ plane. After a transmission scan for 30 min using a $\left[{ }^{68} \mathrm{Ge}\right]-$ $\left[{ }^{68} \mathrm{Ga}\right]$ rotation rod source, a dynamic emission scan with $\left[{ }^{18} \mathrm{~F}\right] \mathrm{BCPP}-\mathrm{EF}$ or $\left[{ }^{11} \mathrm{C}\right]$ UCB-J was conducted for $90 \mathrm{~min}$ after the PET probe injection as a bolus.

To assess the specificity of $\left[{ }^{18} \mathrm{~F}\right] \mathrm{BCPP}-\mathrm{EF}$ binding to MC-I, which was previously examined in rats [15], rotenone, an MC-I inhibitor, at a dose of $0.1 \mathrm{mg} / \mathrm{kg}$ was infused into young monkeys through a vein cannula for $1 \mathrm{~h}$, followed by $\left[{ }^{18} \mathrm{~F}\right]$ BCPP-EF injection.

PET data were reconstructed by the dynamic row action maximum likelihood algorithm (DRAMA) method using a 2.0-mm Gaussian post filter [16], with attenuation correction using transmission scan data. Individual PET and MRI images were co-registered. Volumes of interest (VOIs) in brain regions were drawn manually on MRI, and the time activity curve (TAC) of each PET probe was taken for kinetic analyses. These imaging annalistic processes were performed using PMOD software (PMOD Technologies Ltd.).

In a quantitative analyses of $\left[{ }^{18} \mathrm{~F}\right] \mathrm{BCPP}-\mathrm{EF}$ and $\left[{ }^{11} \mathrm{C}\right] \mathrm{UCB}-J$, arterial blood samples were frequently obtain after the PET probe injection, centrifuged to separate plasma, and ethanol was added to some plasma samples, followed by centrifugation. The supernatants obtained were developed with thin layer chromatography with a mobile phase of ethyl acetate for $\left[{ }^{18} \mathrm{~F}\right] \mathrm{BCPP}-\mathrm{EF}$ and chloroform/methanol $=9: 1$ for $\left[{ }^{11} \mathrm{C}\right] \mathrm{UCB}-J$, respectively. The ratio of the unmetabolized fraction was assessed using a phosphoimaging plate analyzed by a bioimaging analyzer (FLA7000, GE Healthcare).The arterial input function of unmetabolized $\left[{ }^{18} \mathrm{~F}\right] \mathrm{BCPP}-\mathrm{EF}$ or $\left[{ }^{11} \mathrm{C}\right]$ UCB-J was calculated using data obtained by a correction of the radioactivity ratio in the unmetabolized fraction to total fraction. A kinetic analysis of $\left[{ }^{18} \mathrm{~F}\right]$ BCPP-EF or $\left[{ }^{11} \mathrm{C}\right] \mathrm{UCB}-J$ was performed to calculate distribution volume $\left(\mathrm{V}_{\mathrm{T}}\right)$ using a Logan graphical analysis [17] with PMOD software (PMOD Technologies Ltd.).

\subsection{Results}

Brain TACs of $\left[{ }^{18} \mathrm{~F}\right] \mathrm{BCPP}-\mathrm{EF}$ in young animals peaked at approximately $15 \mathrm{~min}$ after the injection, except in the occipital cortex, which peaked at $40 \mathrm{~min}$, and TACs then were gradually eliminated with time under conscious condition. The pre-administration of rotenone resulted in a faster elimination rate of $\left[{ }^{18} \mathrm{~F}\right] \mathrm{BCPP}-\mathrm{EF}$ from the brain than that in normal. In aged animals, the peak time of TACs shifted to slightly later after the injection and showed significant lower $\left[{ }^{18} \mathrm{~F}\right] \mathrm{BCPP}-\mathrm{EF}$ uptake levels than those in young animals.

The washout of $\left[{ }^{18} \mathrm{~F}\right] \mathrm{BCPP}-\mathrm{EF}$-related radioactivity and its metabolites rate in plasma were very rapid, with only $10 \%$ of the non-metabolized parent probe remaining $60 \mathrm{~min}$ after the injection. These kinetic patterns of $\left[{ }^{18} \mathrm{~F}\right] \mathrm{BCPP}-\mathrm{EF}$ were almost identical among control young, rotenone-treated young, and aged animals. 
A metabolic analysis confirmed that its metabolites were very polar, indicating no uptake of metabolites into the brain through the blood-brain barrier. These results confirmed that this PET probe has ideal properties for the quantitative analysis of MC-I activity using a metabolite-corrected arterial input function.

As shown in the upper panel of Figure 1, $\mathrm{V}_{\mathrm{T}}$-PET images of young brains indicated that the binding of $\left[{ }^{18} \mathrm{~F}\right] \mathrm{BCPP}-\mathrm{EF}$ was highest in the occipital cortex, higher in the striatum, intermediate in the frontal and temporal cortices and cerebellum, and lowest in the hippocampus. The pre-administration of rotenone at a dose of $0.1 \mathrm{mg} /$ $\mathrm{kg} / \mathrm{h}$ significantly reduced the uptake of $\left[{ }^{18} \mathrm{~F}\right] \mathrm{BCPP}-\mathrm{EF}$ into the young monkey brain, specifically in the frontal and temporal cortices and striatum. When aging effects on $\mathrm{V}_{\mathrm{T}}$-PET images were assessed, the binding of $\left[{ }^{18} \mathrm{~F}\right] \mathrm{BCPP}-\mathrm{EF}$ throughout the brain was significantly lowered in aged animals than in young animals, as shown in the lower panel of Figure 1.

The TAC of $\left[{ }^{11} \mathrm{C}\right] \mathrm{UCB}-J$ in young animals exhibited slower kinetics than $\left[{ }^{18} \mathrm{~F}\right]$ $\mathrm{BCPP}-\mathrm{EF}$ throughout the brain regions, peaking approximately $30 \mathrm{~min}$ after the injection, and TACs gradually decreased with time under conscious conditions. TACs in aged animals peaked $30 \mathrm{~min}$ after the injection and showed slightly lower $\left[{ }^{11} \mathrm{C}\right]$ UCB-J uptake levels than those in young animals. The washout of $\left[{ }^{11} \mathrm{C}\right] \mathrm{UCB}-J-$ related radioactivity and metabolic rates in plasma were slower than those of $\left[{ }^{18} \mathrm{~F}\right] \mathrm{BCPP}-\mathrm{EF}$, with $25 \%$ of the non-metabolized parent probe remaining $60 \mathrm{~min}$ after the injection. These kinetic patterns of $\left[{ }^{18} \mathrm{~F}\right] \mathrm{BCPP}-\mathrm{EF}$ were not significantly different between young and aged animals. A metabolic analysis confirmed that its metabolites were very polar, suggesting no uptake of the metabolites into the brain through the bloodbrain barrier. These results confirmed that this PET probe is useful for the quantitative analysis of SV2A activity using a metabolite-corrected arterial input function.

As shown in the upper panel of Figure 2, $\mathrm{V}_{\mathrm{T}}$-PET images of the young brain revealed the highest binding of $\left[{ }^{11} \mathrm{C}\right] \mathrm{UCB}-\mathrm{J}$ in the frontal, temporal, and occipital

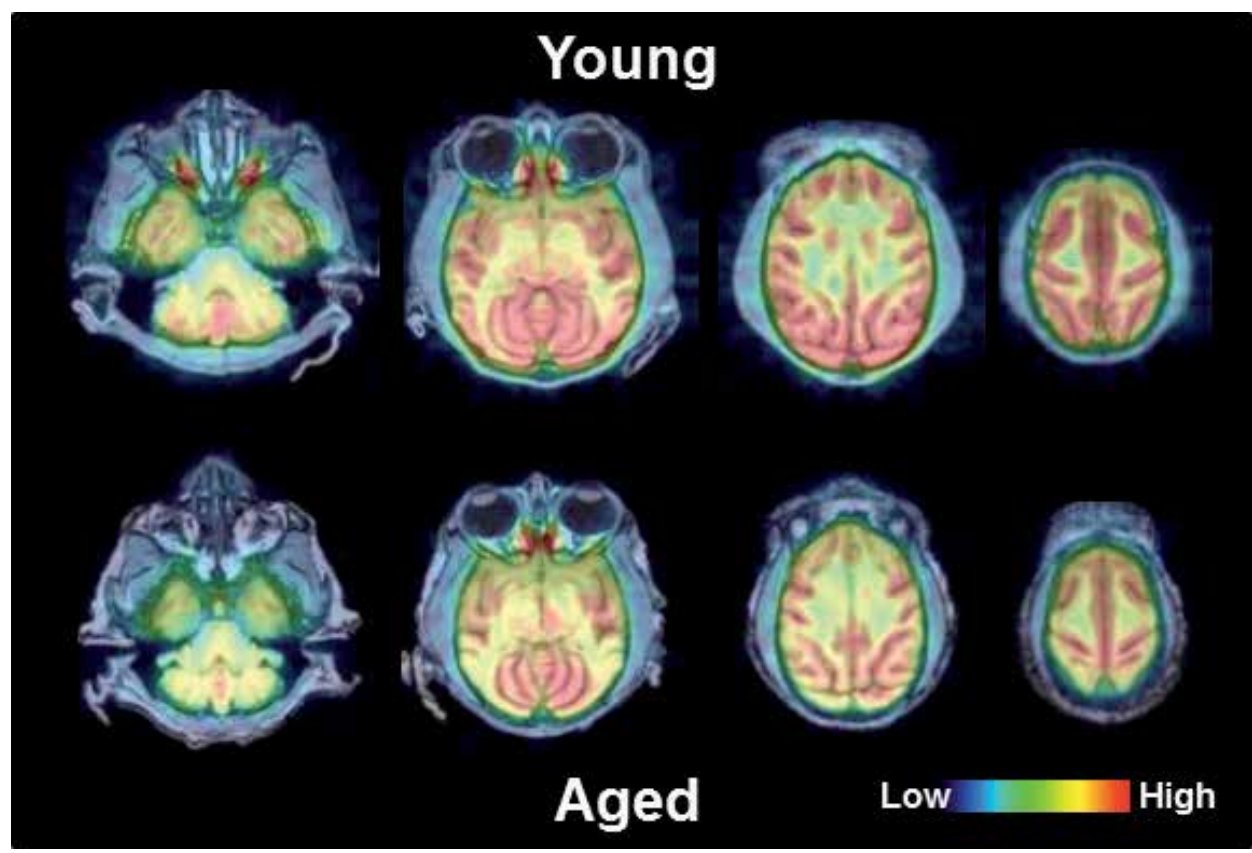

Figure 1.

Effects of aging on PET images of MC-I in living brains of conscious monkeys. PET scans were conducted for 91 min using $\left[{ }^{18} F\right] B C P P-E F$ for MC-I, and $V_{T}$ images of $\left[{ }^{18} F\right] B C P P-E F$ were created using a Logan graphical plot analysis with metabolite-corrected plasma input. 


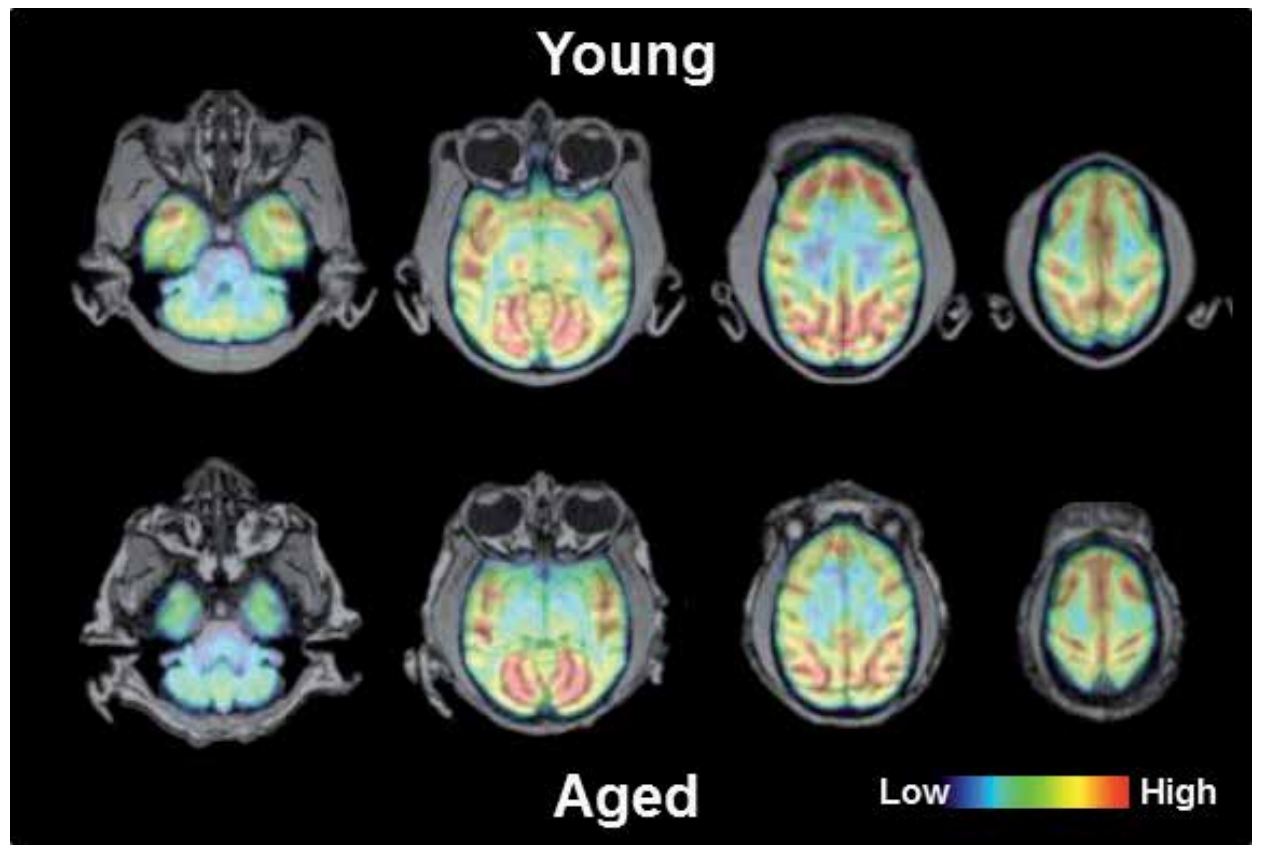

Figure 2.

Effects of aging on PET images of $S V 2 A$ in living brains of conscious monkeys. PET scans were conducted for 91 min using $\left[{ }^{11} C\right] U C B-J$ for $S V_{2} A$, and $V_{T}$ images of $\left[{ }^{11} C\right] U C B-J$ were created using a Logan graphical plot analysis with metabolite-corrected plasma input.

cortices, higher in the striatum, intermediate in the hippocampus, and the lowest in the cerebellum. Thus, the distribution pattern of $\left[{ }^{11} \mathrm{C}\right] \mathrm{UCB}-\mathrm{J}$ resembled to that of $\left[{ }^{18} \mathrm{~F}\right] \mathrm{BCPP}-\mathrm{EF}$ throughout the brain of young animal.

However, in contrast to $\left[{ }^{18} \mathrm{~F}\right] \mathrm{BCPP}-\mathrm{EF}$, when the $\mathrm{V}_{\mathrm{T}}$ of $\left[{ }^{11} \mathrm{C}\right] \mathrm{UCB}-\mathrm{J}$ was compared between young and aged monkeys, no significant age-related changes in cerebral SV2A activity were detected except the olfactory bulb, as shown in the lower panel of Figure 2.

\subsection{Discussion}

The present results showed age-related reduction in mitochondria function assessed by MC-I activity using $\left[{ }^{18} \mathrm{~F}\right] \mathrm{BCPP}-\mathrm{EF}$, as reported previously [11], while no significant alterations in synaptic density were observed based on SV2A activity using $\left[{ }^{11} \mathrm{C}\right]$ UCB-J.

We evaluated $\left[{ }^{18} \mathrm{~F}\right] \mathrm{BCPP}-\mathrm{EF}$ by in vitro (living brain slices), ex vivo (dissected tissues), and in vivo (living rat brains) assessments in comparison with the conventional MC-I PET probe, $\left[{ }^{18} \mathrm{~F}\right] \mathrm{BMS}-747158-02$ ( $\left.\left[{ }^{18} \mathrm{~F}\right] \mathrm{BMS}\right)$, which was developed as a myocardial perfusion PET imaging probe [18], and the results obtained suggested that $\left[{ }^{18} \mathrm{~F}\right] \mathrm{BCPP}-\mathrm{EF}$ is a more suitable PET probe than $\left[{ }^{18} \mathrm{~F}\right] \mathrm{BMS}$ for $\mathrm{MCI}$ assessments in the living brain $[7,15]$. $\left.{ }^{18} \mathrm{~F}\right] \mathrm{BCPP}-\mathrm{EF}$ was characterized by (1) high specific binding with moderate affinity, (2) a proper $\log \mathrm{D}_{7.4}$ value, (3) long metabolic stability with fast clearance in plasma, (4) sufficient brain uptake with a proper elimination rate from the brain, and (5) low dependency to cerebral blood flow changes [19]. As a PET probe, these properties of $\left[{ }^{18} \mathrm{~F}\right] \mathrm{BCPP}-\mathrm{EF}$ may contribute for a noninvasive and quantitative analysis of MC-I in the living brain [11], thereby allowing for the high detectability of age-related reductions in MC-I activity in the living monkey brain. Although several postmortem in vitro studies previously reported that (1) 
age-related brain MC-I impairments were associated with a decline in mitochondria respiration [20,21] and (2) the activities of MC-I and -IV, but not MC-II, III, or V, decreased with aging in the brains of rodents [22] and humans [20,21], this study was the first to successfully confirm age-related reductions in MC-I activity in the living brain of nonhuman primates [11].

As described above, $\left[{ }^{18} \mathrm{~F}\right] \mathrm{BCPP}-\mathrm{EF}$ detected age-related reduction in MC-I activity; however, this PET probe was unable to discriminate the subdomain (synapse, dendrites, or soma) of MC-I that was exclusively damaged due to the limitation of the spatial resolution of PET. In attempts to answer this question, $\left[{ }^{11} \mathrm{C}\right] \mathrm{UCB}-\mathrm{J}$, a novel PET probe for SV2A [10], was applied to the same subject groups on the assumption that if this MC-I reduction mainly reflected the presynaptic domain, the binding of $\left[{ }^{11} \mathrm{C}\right] \mathrm{UCB}-\mathrm{J}$ to SV2A will also show a similar age-related reduction pattern in the brain. However, contrary to this assumption, no significant changes in $\left[{ }^{11} \mathrm{C}\right] \mathrm{UCB}-J$ binding to SV2A were observed, except the olfactory bulb, from those in the same young and aged animals applied in the assessment using $\left[{ }^{18} \mathrm{~F}\right] \mathrm{BCPP}-\mathrm{EF}$.

Several postmortem in vitro studies have suggested age-related reductions in spine density; however, these findings remain controversial. One study using rat brains revealed that the synaptic vesicle density in axospinous synapse, a major population of synapses, rapidly increased until 3 weeks old and then decreased to the adult level, followed by no changes in senescence [23]. However, another study on mouse brain showed that age-related deficits in sensory perception were not associated with synaptic loss in the somatosensory cortex but were related to alterations in the size and stability of spine buttons [24], which might not be detected as the changes in SV2A activity.

The discrepancy in age-related effects between $\left[{ }^{11} \mathrm{C}\right] \mathrm{UCB}-J$ and $\left[{ }^{18} \mathrm{~F}\right] \mathrm{BCPP}-\mathrm{EF}$ suggest that MC-I dysfunction detected by $\left[{ }^{18} \mathrm{~F}\right] \mathrm{BCPP}-\mathrm{EF}$ mainly reflect neuronal damage in dendrite and soma domains and are not specific to presynaptic domain. Although difficulties are associated with assessing mitochondrial distribution in neuronal cells, it was demonstrated in the cultured neuron that more than $90 \%$ of mitochondria were confirmed to be in the dendrite shaft overlapping in soma and large-diameter proximal dendrites [25]. This localized distribution pattern of the mitochondria suggests that even if mitochondria in the presynaptic domain are specifically impaired, difficulties may be associated with detecting changes in the minor subdomain using $\left[{ }^{18} \mathrm{~F}\right] \mathrm{BCPP}-\mathrm{EF}$. The present results also suggested that in the early stage of the aging process, at least, in nonhuman primates, neuronal damage in the synaptic domain, if any, may be too subtle to be detected as decreased $\left[{ }^{11} \mathrm{C}\right] \mathrm{UCB}-\mathrm{J}$ binding to SV2A.

\section{Effects of amyloid- $\beta$ deposition on MC-I function in the living brain}

Patients of $\mathrm{AD}$, the most prominent age-related neurodegenerative disease, are characterized by the deposition of fibrillary $A \beta$ into senile plaques and hyperphosphorylated tau (P-tau) into neurofibrillary tangle (NFT) in the brain. Monomer A $\beta$ has been implicated in normal developmental synaptic plasticity, for example, in the olfactory bulb under physiological conditions [26]. However, the aggregation of $A \beta$ switches its physiological role into a pathologically toxic function; thus dense plaques damage the surrounding brain tissues [27], causing synaptic elimination and impaired synaptic function [28]. Although the molecular mechanisms underlying neuronal damage induced by $A \beta$ have not been fully elucidated, mitochondrial dysfunction may be associated with $A \beta$-induced synaptic dysfunction [3] and also with neuroinflammation [29], resulting in cognitive impairment in AD patients. In order to clarify the relationship between $A \beta$ deposition, neuroinflammation, and mitochondrial function, $\left[{ }^{11} \mathrm{C}\right] \mathrm{PiB}$ for $\mathrm{A} \beta[30]$, $\left[{ }^{11} \mathrm{C}\right] \mathrm{DPA}-713$ for translocator protein 
(TSPO) [31] and $\left[{ }^{18} \mathrm{~F}\right] \mathrm{BCPP}-\mathrm{EF}$ for MC-I were comparatively evaluated in the living brains of aged rhesus monkeys. Furthermore, as a gold standard parameter of cerebral metabolism, $\left[{ }^{18} \mathrm{~F}\right]$ fluoro-2-deoxy-D-glucose $\left(\left[{ }^{18} \mathrm{~F}\right] \mathrm{FDG}\right)$ was also applied to compare the diagnostic and prognostic usefulness with $\left[{ }^{18} \mathrm{~F}\right] \mathrm{BCPP}-\mathrm{EF}$.

\subsection{Methods}

Twenty aged male (20-24 years old) rhesus monkeys (Macaca mulatta) were investigated in the PET study using $\left[{ }^{11} \mathrm{C}\right] \mathrm{PiB}$ for $\mathrm{A} \beta,\left[{ }^{11} \mathrm{C}\right] \mathrm{DPA}-713$ for TSPO, and $\left[{ }^{18} \mathrm{~F}\right] \mathrm{BCPP}-\mathrm{EF}$ for MC-I under conscious conditions using a high-resolution PET scanner as described in 2.1.

$\left[{ }^{11} \mathrm{C}\right] \mathrm{PiB}$ was synthesized by the $N$-methylation of nor-compound $N$-desmethyl$\mathrm{PiB}$ with $\left[{ }^{11} \mathrm{C}\right]$ methyl triflate [30]. Radiochemical purity was more than $99 \%$, and specific radioactivity was $36.7 \pm 10.1 \mathrm{GBq} / \mu \mathrm{mol}$. $\left[{ }^{11} \mathrm{C}\right] \mathrm{DPA}-713$ was synthesized by the $N$-methylation of nor-compound $N$-desmethyl-DPA with $\left[{ }^{11} \mathrm{C}\right]$ methyl triflate [31]. Radiochemical purity was more than 99\%, and specific radioactivity was $99.3 \pm 32.2 \mathrm{GBq} / \mu \mathrm{mol}$. $\left[{ }^{18} \mathrm{~F}\right] \mathrm{BCPP}-\mathrm{EF}$ was radiolabeled as shown in 2.1. Radiochemical purity was more than $99 \%$, and specific radioactivity was $139.6 \pm 37.0 \mathrm{GBq} / \mu \mathrm{mol}$. $\left[{ }^{18} \mathrm{~F}\right] \mathrm{FDG}$ was produced by the nucleophilic $\left[{ }^{18} \mathrm{~F}\right]$ fluorination of mannose triflate following the basic hydrolysis of $2-\left[{ }^{18} \mathrm{~F}\right]$ fluoro-1.3.4.6-tetra-O-acetyl-D-glucose.

In the analysis of $\left[{ }^{11} \mathrm{C}\right] \mathrm{PiB}$, standard uptake value (SUV) images from 60 to 90 min were created, VOIs were set on each SUV images, and the SUV ratios (SUVR) of each region (SUVreg) against SUV in the cerebellum (SUVcereb) were calculated [32]. In the analysis of [ $\left.{ }^{11} \mathrm{C}\right] \mathrm{DPA}-713$, SUV images from 40 to $60 \mathrm{~min}$ were created, and VOIs were set on each SUV image. Since any cerebral regions were not applicable as the reference region with negligible TSPO levels [33], the SUV, not SUVR, was assessed. A quantitative analysis of $\left[{ }^{18} \mathrm{~F}\right] \mathrm{BCPP}-\mathrm{EF}$ was performed as described in 2.1. During PET scanning with $\left[{ }^{18} \mathrm{~F}\right] \mathrm{FDG}$, continuous arterial sampling was conducted, and PET images from 40 to $60 \mathrm{~min}$ after the injection were obtained to calculate the regional cerebral metabolic rate of glucose (rCMRglc) using an autoradiographic method. The rCMRglc ratios of each region (rCMRglcregion) against rCMRglc in the cerebellum (rCMRglc-cere) were calculated [34].

\subsection{Results}

Since the cortical $\mathrm{V}_{\mathrm{T}}$ values of $\left[{ }^{18} \mathrm{~F}\right] \mathrm{BCPP}-\mathrm{EF}$ in aged monkeys were previously shown to have a higher CV value of ca. $25 \%$ than those in young ones of ca. $7 \%$ [11], the reasons for the lager variation of MC-I activity were elucidated using PET imaging with $\left[{ }^{11} \mathrm{C}\right] \mathrm{PiB}$ for $\mathrm{A} \beta$ deposition and $\left[{ }^{11} \mathrm{C}\right] \mathrm{DPA}-713$ for TSPO in 20 aged monkeys. Figure 3 shows the PET/MRI images of aged monkeys with the lowest (A) and highest $(\mathrm{E})\left[{ }^{11} \mathrm{C}\right] \mathrm{PiB}$ binding, with high SUV not only being detected in cortical but also subcortical regions. PET results obtained with $\left[{ }^{11} \mathrm{C}\right] \mathrm{PiB}$ were supported by an immunohistochemical assessment conducted after PET assessments [12]. The images of $\left[{ }^{11} \mathrm{C}\right] \mathrm{DPA}-713$ ( $\mathrm{B}$ and $\mathrm{F}$ ) corresponding to each monkey ( $\mathrm{A}$ and $\mathrm{E}$ ) revealed that monkeys with the lowest $(A)$ and highest $(E)\left[{ }^{11} \mathrm{C}\right] \mathrm{PiB}$ binding showed the lower $(\mathrm{B})$ and higher $(\mathrm{F})\left[{ }^{11} \mathrm{C}\right] \mathrm{DPA}-713$ binding. In contrast, the images of $\left[{ }^{18} \mathrm{~F}\right]$ BCPP-EF corresponding to each monkey with the lowest $(\mathrm{A})\left[{ }^{11} \mathrm{C}\right] \mathrm{PiB}$ binding exhibited higher $\left[{ }^{18} \mathrm{~F}\right] \mathrm{BCPP}-\mathrm{EF}$ uptake $(\mathrm{C})$, while those with the highest $\left[{ }^{11} \mathrm{C}\right] \mathrm{PiB}$ binding (E) showed the lower $\left[{ }^{18} \mathrm{~F}\right] \mathrm{BCPP}-\mathrm{EF}$ uptake $(\mathrm{G})$.

As shown in Figure 4A, when the SUV values of $\left[{ }^{11} \mathrm{C}\right] \mathrm{DPA}-713$ were plotted against the SUVR of $\left[{ }^{11} \mathrm{C}\right] \mathrm{PiB}$ in the cortical VOIs of all animals, the results 
obtained revealed a significant positive correlation between each parameter, indicating that $A \beta$ deposition-induced neuroinflammation in the living brains of aged monkeys. In contrast, the plotting of $\mathrm{V}_{\mathrm{T}}$ of $\left[{ }^{18} \mathrm{~F}\right] \mathrm{BCPP}-\mathrm{EF}$ against SUVR of $\left[{ }^{11} \mathrm{C}\right] \mathrm{PiB}$ showed a reverse correlation in the cortical VOIs of all animals, suggesting that $A \beta$ deposition-induced MC-I impairments in the brains of aged monkeys (Figure 4B).

Based on Figures $3 \mathrm{H}$ and $\mathbf{4 C}$, it is important to note that a correlation was not observed between glucose metabolism assessed as the SUVR of $\left[{ }^{18} \mathrm{~F}\right] \mathrm{FDG}$ and A $\beta$ deposition measured as the SUVR of $\left[{ }^{11} \mathrm{C}\right] \mathrm{PiB}$, and this may have been due to $\left[{ }^{18} \mathrm{~F}\right]$ FDG uptake into the neuroinflammation-related activated microglial cells.

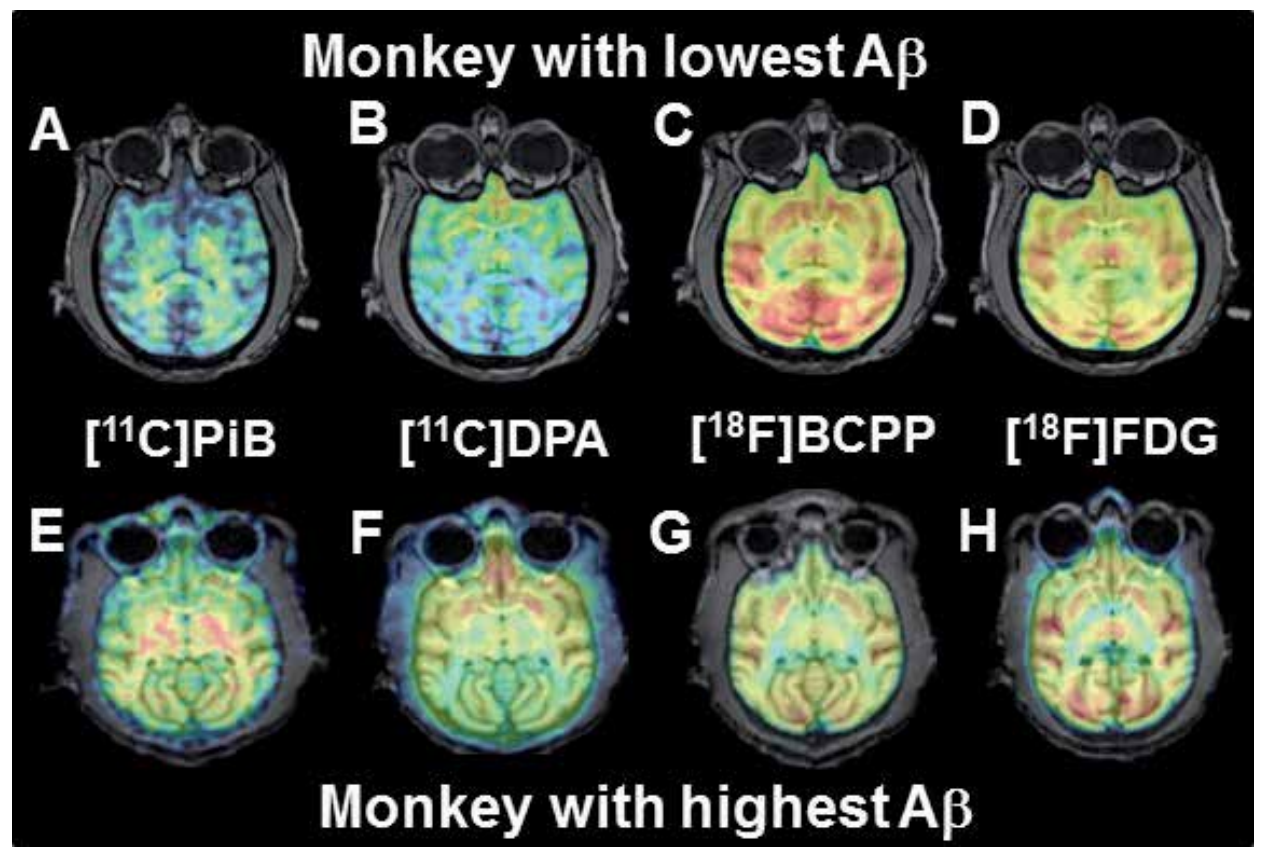

Figure 3.

Effects of $A \beta$ deposition on PET images of $\left[{ }^{11} C\right] P i B$ ( $A$ and $E$ ), $\left[{ }^{11} C\right] D P A-713$ ( $B$ and $F$ ), $\left[{ }^{18} F\right] B C P P-E F(C$ and $G)$, and $\left[{ }^{18} F\right] F D G(D$ and $H)$ in living brains of conscious monkeys. PET scans were conducted in monkey with the lowest $(A-D)$ and highest $(E-H) A \beta$ deposition among 20 aged monkeys.
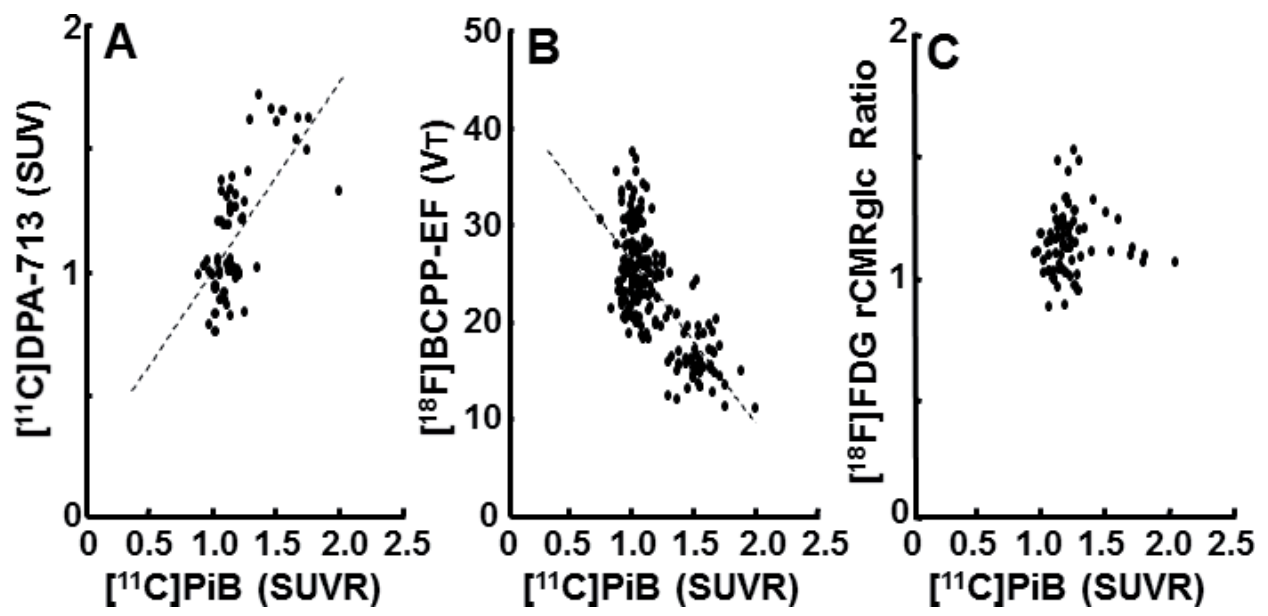

Figure 4 .

Correlations between the SUV of $\left[{ }^{11} C\right] D P A-713(A), V_{T}$ of $\left[{ }^{18} \mathrm{~F}\right] B C P P-E F(B)$, and rCMRglc ratio of $\left[{ }^{18} F\right]$ FDG $(C)$ against the SUVR of $\left[{ }^{11} \mathrm{C}\right]$ PiB in cortical and hippocampal regions of living brains of aged monkeys. 


\subsection{Discussion}

The present results demonstrated the potential of MC-I impairment assessed using $\left[{ }^{18} \mathrm{~F}\right] \mathrm{BCPP}-\mathrm{EF}$ as a useful biomarker for $\mathrm{A} \beta$ deposition-related neurodegeneration, measured using $\left[{ }^{11} \mathrm{C}\right] \mathrm{PiB}$, and neuroinflammation, measured using $\left[{ }^{11} \mathrm{C}\right]$ DPA-713. In contrast, the assessment of rCMRglc using conventional $\left[{ }^{18} \mathrm{~F}\right] \mathrm{FDG}$ was not as sensitive for detecting the neurodegenerative damage associated with inflammation in the early stage of disease onset because of $\left[{ }^{18} \mathrm{~F}\right] \mathrm{FDG}$ uptake into not only normal neuronal cells but also into inflammatory cells, such as activated microglia in the brain $[15,19,29]$. Since activated microglia dominantly facilitate glycolysis, not ORPHOS system through mitochondria, to produce ATP, more glucose is required in microglia than in normal neuron, resulting in higher $\left[{ }^{18} \mathrm{~F}\right] \mathrm{FDG}$ uptake than in normal cells. Thus, MC-I assessed using $\left[{ }^{18} \mathrm{~F}\right] \mathrm{BCPP}-\mathrm{EF}$ has a potential as a biomarker to assess neurodegeneration more accurately without being affected by inflammation in the living brain.

The present PET images obtained using $\left[{ }^{11} \mathrm{C}\right] \mathrm{PiB}$ did not reveal as prominent $\mathrm{A} \beta$ deposition in aged monkey brains as that in the brains of PD patients. Previous studies suggested that no species other than humans exhibited marked neuron loss or cognitive impairment observed as clinical grade AD in humans, and aged monkeys did not exhibit as high $\mathrm{A} \beta$ deposition as seen in $\mathrm{AD}$ patients [35] or $\left[{ }^{11} \mathrm{C}\right]$ $\mathrm{PiB}$ binding [36] as that in AD patients. Therefore, we assumed that the aged monkey model exhibited a similar mild cognitive impairment (MCI)-like, not $\mathrm{AD}$-like, state to that in humans. In the AD state after a lag period of $\mathrm{MCI}, \mathrm{A} \beta$ deposition level reached a plateau; therefore no correlation was observed between $\left[{ }^{11} \mathrm{C}\right] \mathrm{PiB}$ uptake and cognitive levels or metabolic dysfunction assessed using $\left[{ }^{18} \mathrm{~F}\right] \mathrm{FDG}[37]$. In contrast, $\left[{ }^{11} \mathrm{C}\right] \mathrm{PiB}$ may function as a quantitative and sensitive biomarker for $A \beta$-related neuronal damage in aged monkey brains resembling the MCI-like state in humans [38]. Furthermore, a recent study reported the primary role of non-deposited, non-fibrillar assembles of $A \beta$ peptides, and, thus, they may become precursors for fibrillogenesis, which lead to oxidative neurotoxicity by ROS in the brains of very early stage of AD patients [39]. ROS-related mitochondrial OXPHOS failure in the brain has been implicated in neurodegenerative disorders [40]. Mitochondria are the main intercellular source of ROS and also the main target of oxidative damage, leading to the significant disruption of brain function. A recent study demonstrated the direct effects of $A \beta$ on mitochondria; thus, in addition to extracellular deposition, $A \beta$ was detected in cytoplasmic mitochondria compartments [41], leading to dysfunction with the suppressed availability of nucleus-encoded proteins, a decreased rate of NABH reduction, and enhanced ROS generation [42]. Since we previously confirmed a positive correlation between the $\mathrm{V}_{\mathrm{T}}$ of $\left[{ }^{18} \mathrm{~F}\right] \mathrm{BCPP}-\mathrm{EF}$ and $\mathrm{rCMRO}_{2}$, a gold standard for brain activation [19], the A $\beta$ deposition-related MC-I functional impairment observed in the present study may reflect diminished activity and/or the loss of neurons with neuroinflammation. The present study revealed a correlation between $\left[{ }^{11} \mathrm{C}\right] \mathrm{PiB}$ binding and $\left[{ }^{18} \mathrm{~F}\right] \mathrm{BCPP}-\mathrm{EF}$ uptake, demonstrating the usefulness of an assessment of MC-I for the diagnostic staging of MCI and early stage AD.

In the present study, TSPO activity evaluated using $\left[{ }^{11} \mathrm{C}\right] \mathrm{DPA}-713$, an index of neuroinflammation, was stronger in the aged monkey brain with higher $\left[{ }^{11} \mathrm{C}\right] \mathrm{PiB}$ binding to A $\beta$. Furthermore, $\left[{ }^{11} \mathrm{C}\right] \mathrm{DPA}-713$ binding to TSPO and rCMRglc measured using $\left[{ }^{18} \mathrm{~F}\right] \mathrm{FDG}$ revealed a correlation (data not shown) [12]. These results suggest $\mathrm{A} \beta$ deposition-induced neuroinflammation with the activation of microglial cells.

Therefore, the detectability of MC-I impairment using $\left[{ }^{18} \mathrm{~F}\right] \mathrm{BCPP}-\mathrm{EF}$ for neuronal damage in $\mathrm{AD}$ appears to be superior to the assessment of glucose metabolism measured using conventional $\left[{ }^{18} \mathrm{~F}\right] \mathrm{FDG}$. 


\section{Effects of MPTP-induced parkinsonism on MC-I in the living brain}

Patients with PD show the progressive degradation of the nigrostriatal pathway with the selective loss of DA neurons in the substantia nigra pars compacta (SNc), resulting in movement disorders, which are induced after the loss of ca. $50 \%$ of neurons in the SNc and a reduction in DA to ca. $20 \%$ of normal levels in the striatum [43]. A pathological hallmark of PD is Lewy bodies and Lewy neurites, containing intracytoplasmic insoluble and aggregated protein of $\alpha$-synuclein [4]. The spread of these pathologies closely correlates with disease progression. Furthermore, an intracerebral injection of insoluble $\alpha$-synuclein converted normal $\alpha$-synuclein into an abnormal form, which then propagated throughout the brains of monkeys [44] and common marmosets [45]. The soluble, $\beta$ sheet-rich oligomers of $\alpha$-synuclein induced mitochondrial dysfunction by inhibiting MC-I, enhancing ROS production, and activating the mitochondrial permeability transition pore (PTP), leading to mitochondrial swelling and neuronal death [46].

Since exposure to 1-methyl-4-phenyl-1,2,3,6-tetrahydropyridine (MPTP) induces a syndrome mimicking PD symptoms accompanied by selective DA damage in the nigrostriatal pathway [47], we developed a PD model of monkeys by systemic and repeated MPTP administration [48, 49] and evaluated serotonin (5-HT) transporter (SERT) availability using [ $\left.{ }^{11} \mathrm{C}\right]$-3-amino-4-(2-dimethylaminomethylphenylsulfanyl)-benzonitrile ([ $\left.\left.{ }^{11} \mathrm{C}\right] \mathrm{DASB}\right)$ [50] 5-HT $1 \mathrm{~A}$ receptor $\left(5-\mathrm{HT}_{1 \mathrm{~A}} \mathrm{R}\right)$ binding using 4-(2'-methoxyphenyl)-1- $\left[2^{\prime}-\left(N-2^{\prime \prime}\right.\right.$-pyridinyl $)-p-\left[{ }^{18} \mathrm{~F}\right]$ fluoro-benzamido] ethylpiperazine $\left(\left[{ }^{18} \mathrm{~F}\right] \mathrm{MPPF}\right)[51]$ in parallel with DA parameters for presynaptic DA synthesis (DAS) using $6-\left[{ }^{11} \mathrm{C}\right]$ methyl-m-tyrosine $\left(\left[{ }^{11} \mathrm{C}\right] 6 \mathrm{Me} m \mathrm{Tyr}\right)[52$, 53], DA transporter (DAT) using $\left[{ }^{11} \mathrm{C}\right] N$-(3-iodoprop-2E-enyl)-2 $\beta$-carbomethoxy$3 \beta$-(4-methyl-phenyl) nortropane $\left(\left[{ }^{11} \mathrm{C}\right] \mathrm{PE} 2 \mathrm{I}\right)[54]$, postsynaptic $\mathrm{DA} \mathrm{D}_{2} \mathrm{R}$ using $\left[{ }^{11} \mathrm{C}\right]$ Raclopride, and MC-I activity using $\left[{ }^{18} \mathrm{~F}\right] \mathrm{BCPP}-\mathrm{EF}$ in the living brains of MPTP-treated monkeys [13].

\subsection{Methods}

Young adult male rhesus monkeys (Macaca mulatta) were used to prepare the PD model, as reported previously $[48,49]$. MPTP at doses ranging between 0.2 and $0.4 \mathrm{mg} / \mathrm{kg}$ in phosphate-buffered saline was injected intravenously over a 4-month period until stable Parkinsonian syndrome developed. MPTP-treated monkeys were subjected to PET scans using specific PET probes for DA, 5-HT neuronal systems, and MC-I under conscious condition using a high-resolution PET scanner, as described in 2.1. In order to avoid the potential for spontaneous recovery as well as direct inhibition of $\left[{ }^{18} \mathrm{~F}\right] \mathrm{BCPP}-\mathrm{EF}$ binding to MC-I by MPTP, all PET measurements were started at least after 2 months after the last treatment with MPTP.

$\left[{ }^{11} \mathrm{C}\right] \mathrm{PE} 2 \mathrm{I}$ was radiolabeled by the $O-\left[{ }^{11} \mathrm{C}\right]$ methylation of its nor-compound with $\left[{ }^{11} \mathrm{C}\right]$ methyl triflate. Radiochemical purity was more than $98 \%$ and specific radioactivity of $117.1 \pm 42.9 \mathrm{GBq} / \mu \mathrm{mol}$. $\left[{ }^{11} \mathrm{C}\right] 6 \mathrm{Me} m \mathrm{Tyr}$ was developed in our laboratory using rapid $\mathrm{Pd}(0)$-mediated cross-coupling between $\left[{ }^{11} \mathrm{C}\right]$ methyl iodide and its boronate precursor $[52,53]$, showing radiochemical purity of more than $99 \%$ and specific radioactivity of $71.6 \pm 37.4 \mathrm{GBq} / \mu \mathrm{mol}$. $\left[{ }^{11} \mathrm{C}\right]$ Raclopride was radiolabeled by $N$ - $\left[{ }^{11} \mathrm{C}\right]$ methylation of its nor-compound with $\left[{ }^{11} \mathrm{C}\right]$ methyl triflate. Radiochemical purity was more than $98 \%$ and specific radioactivity of $65.4 \pm 15.8 \mathrm{GBq} / \mu \mathrm{mol}$. $\left[{ }^{18} \mathrm{~F}\right] \mathrm{BCPP}-\mathrm{EF}$ was radiolabeled as shown in 2.1. Radiochemical purity was more than $99 \%$, and specific radioactivity was $58.9 \pm 7.9 \mathrm{GBq} / \mu \mathrm{mol} .\left[{ }^{11} \mathrm{C}\right] \mathrm{DASB}$ was prepared by the $N-\left[{ }^{11} \mathrm{C}\right]$ methylation of its nor-compound with $\left[{ }^{11} \mathrm{C}\right]$ methyl triflate [50] with radiochemical purity of more than $99 \%$ and specific radioactivity of 
$47.6 \pm 11.1 \mathrm{GBq} / \mu \mathrm{mol}$. $\left[{ }^{18} \mathrm{~F}\right] \mathrm{MPPF}$ was synthesized by the nucleophilic $\left[{ }^{18} \mathrm{~F}\right]$ fluorination of its nitro precursor [51] with radiochemical purity of more than $99 \%$ and specific radioactivity of $90.4 \pm 25.6 \mathrm{GBq} / \mu \mathrm{mol}$.

Quantitative analyses of $\left[{ }^{11} \mathrm{C}\right] \mathrm{PE} 2 \mathrm{I},\left[{ }^{11} \mathrm{C}\right]$ Raclopride, $\left[{ }^{11} \mathrm{C}\right] \mathrm{DASB}$, and $\left[{ }^{18} \mathrm{~F}\right]$ MPPF were performed with a simplified reference tissue model to calculate non-displaceable binding potential $\left(\mathrm{BP}_{\mathrm{ND}}\right)$ [55] using PMOD software (PMOD Technologies Ltd., Zurich, Switzerland). As an indirect input function, TAC in the cerebellum was applied. A quantitative analysis of $\left[{ }^{18} \mathrm{~F}\right] \mathrm{BCPP}-\mathrm{EF}$ was performed as described in 2.1. A quantitative analysis of $\left[{ }^{11} \mathrm{C}\right] 6 \mathrm{Me} m \mathrm{Tyr}$ to calculate the Ki value was performed using a multiple-time graphical analysis [56] using PMOD software (PMOD Technologies Ltd., Zurich, Switzerland) applying the TAC in the occipital cortex as an input function.

\subsection{Results}

The effects of chronic MPTP treatments on the DA neuronal system in the brain were revealed in Figure 5. PET measurements using $\left[{ }^{11} \mathrm{C}\right]$ PE2I for DAT (A), $\left[{ }^{11} \mathrm{C}\right] 6 \mathrm{Mem}$ Tyr for DAS $(\mathrm{B})$, and $\left[{ }^{11} \mathrm{C}\right]$ Raclopride for $\mathrm{D}_{2} \mathrm{R}(\mathrm{C})$ clearly imaged the striatum of the normal monkey brain. After the repeated treatment with MPTP, presynaptic DAT availability assessed using $\left[{ }^{11} \mathrm{C}\right] \mathrm{PE} 2 \mathrm{I}$ was significantly lower in the caudate $(4.0 \%$ of normal), putamen ( $4.9 \%$ of normal), and SNc (18.6\% of normal) (E) of the MPTP-treated monkey brain than in the normal monkey (A). Another presynaptic parameter of DAS assessed using $\left[{ }^{11} \mathrm{C}\right] 6 \mathrm{Me} m \mathrm{Tyr}$ was also markedly lower in the caudate (13.6\% of normal), putamen (12.3\% of normal), and SNc $(41.1 \%$ of normal) (F) of MPTP monkey brain than in normal animal monkey brain (B). In contrast, no significant changes in $\left[{ }^{11} \mathrm{C}\right]$ Raclopride binding to postsynaptic $\mathrm{D}_{2} \mathrm{R}$ were observed in the striatum or SNc between normal (C) and MPTP-treated animals (G).

The effects of the MPTP treatments on PET images of MC-I in the brain are shown in Figure 5D and $\mathbf{H}$. The cerebral uptake of $\left[{ }^{18} \mathrm{~F}\right] \mathrm{BCPP}-\mathrm{EF}$ in normal monkeys showed homogeneous and symmetric patterns in the both hemispheres with clear separation of the cortical and basal ganglion regions (D). After the repeated treatment with MPTP, the $\mathrm{V}_{\mathrm{T}}$ of $\left[{ }^{18} \mathrm{~F}\right] \mathrm{BCPP}-\mathrm{EF}$ exhibited significant reductions ranging between 60 and $70 \%$ of normal levels not only in the nigrostriatal pathway with abundant DA neurons but also in extra-striatal non-DA regions such as the cortex $(\mathrm{H})$. No significant decreases in the $\mathrm{V}_{\mathrm{T}}$ of $\left[{ }^{18} \mathrm{~F}\right] \mathrm{BCPP}-\mathrm{EF}$ were observed in the cerebellum.

Since the chronic treatment with MPTP, known as a DA specific toxin, unexpectedly induced decreases in MC-I activity in extra-striatal non-DA regions, another monoaminergic neuronal system of 5-HT was further evaluated. In the normal monkey brain, $\left[{ }^{11} \mathrm{C}\right] \mathrm{DASB}$ binding to SERT was high in the striatal and midbrain regions (Figure 6A), while $\left[{ }^{18} \mathrm{~F}\right] \mathrm{MPPF}$ binding to $5-\mathrm{HT}_{1 \mathrm{~A}} \mathrm{R}$ was high in the cortical regions $(\mathrm{B})$. The quantitative analysis of $\left[{ }^{11} \mathrm{C}\right] \mathrm{DASB}$ revealed significantly lower SERT availability throughout the brain in MPTP-treated monkey, except the raphe nucleus (Figure 6C), than in normal monkeys (A). The reduction in $\left[{ }^{11} \mathrm{C}\right]$ DASB availability to SERT was the greatest in the occipital cortex (19.7\% of normal); intermediate in the frontal, parietal, and temporal cortices (50.0, 40.7, and $51.6 \%$ of normal); smaller in the caudate $(60.3 \%$ of normal); and the smallest in the putamen and SNc (66.0 and $67.7 \%$ of normal). In contrast, no significant changes were observed in $\left[{ }^{18} \mathrm{~F}\right] \mathrm{MPPF}$ binding to $5-\mathrm{HT}_{1 \mathrm{~A}} \mathrm{R}$ throughout the brain between normal (Figure 3B) and MPTP-treated monkeys (D).

In order to assess the relationship between MC-I and DA and 5-HT neuronal systems in MPTP-treated monkey brains, the degrees of reductions in DAT measured using $\left[{ }^{11} \mathrm{C}\right]$ PE2I, DAS measured using $\left[{ }^{11} \mathrm{C}\right] 6 \mathrm{Mem}$ Tyr in the nigrostriatal pathway (caudate, putamen, and SNc), and SERT measured using $\left[{ }^{11} \mathrm{C}\right] \mathrm{DASB}$ in 


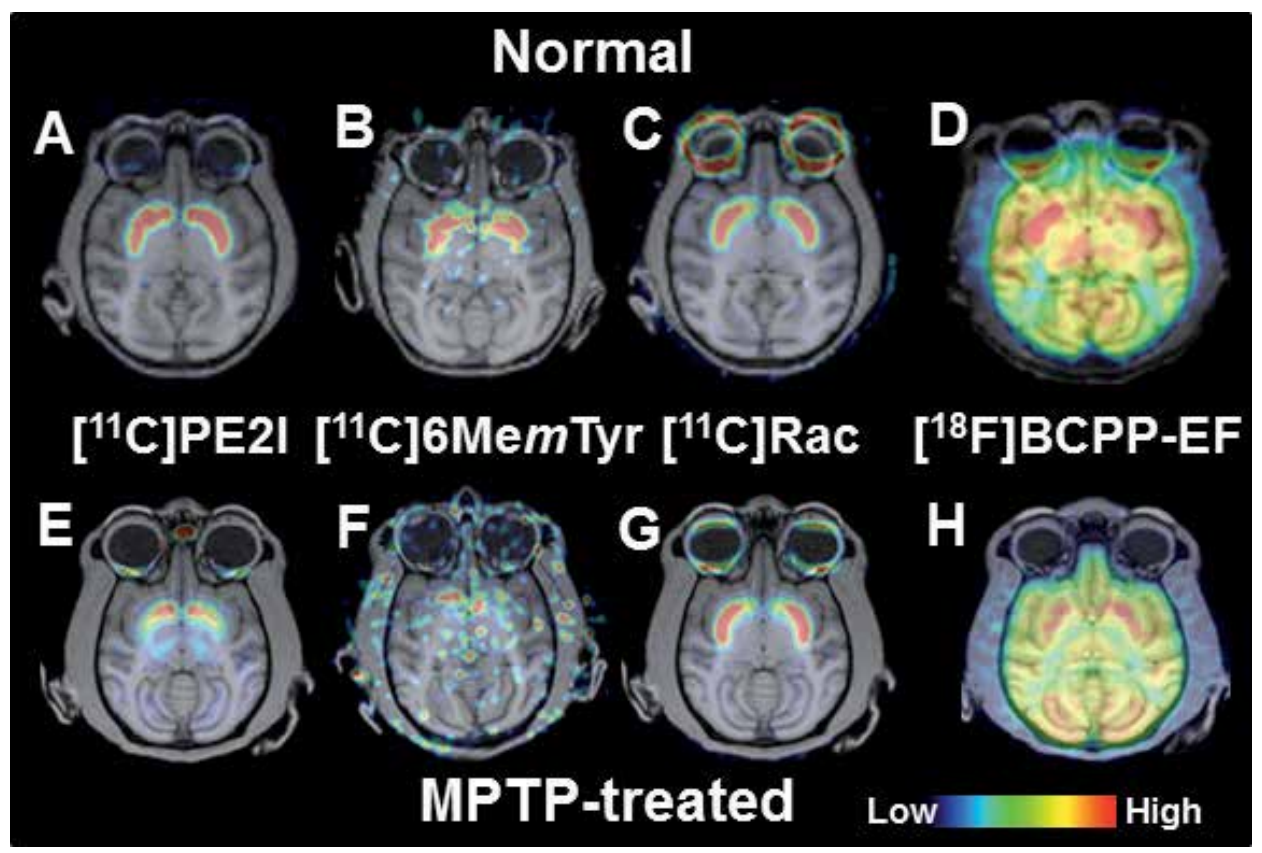

Figure 5.

Effects of the MPTP treatment on PET images of DA and MC-I in living brains of conscious monkeys. PET scans were conducted for 91 min using $\left[{ }^{11} C\right] P E_{2} I$ for DAT ( $A$ and $\left.E\right)$ and $\left[{ }^{18} F\right] B C P P-E F$ for $M C-I(D$ and $H)$ and for 60 min using $\left[{ }^{11} C\right] 6 M e m T y r$ for $D A S(B$ and $F)$ and $\left[{ }^{11} C\right]$ Raclopride for $D_{2} R(C$ and $D) . V_{T}$ images of $\left[{ }^{18} \mathrm{~F}\right] B C P P-E F(D$ and $H)$ were created using a Logan graphical plot analysis with metabolite-corrected plasma input. $B P_{N D}$ images of $\left[{ }^{11} C\right] P E_{2} I(A$ and $E)$ and ${ }^{11} C$-Raclopride $(C$ and $G)$ and multiple-time graphical analysis Ki images of $\left[{ }^{11} C\right] 6 \mathrm{MemTyr}(B$ and $F$ ) were created using the corresponding TACs in the cerebellum as input functions.

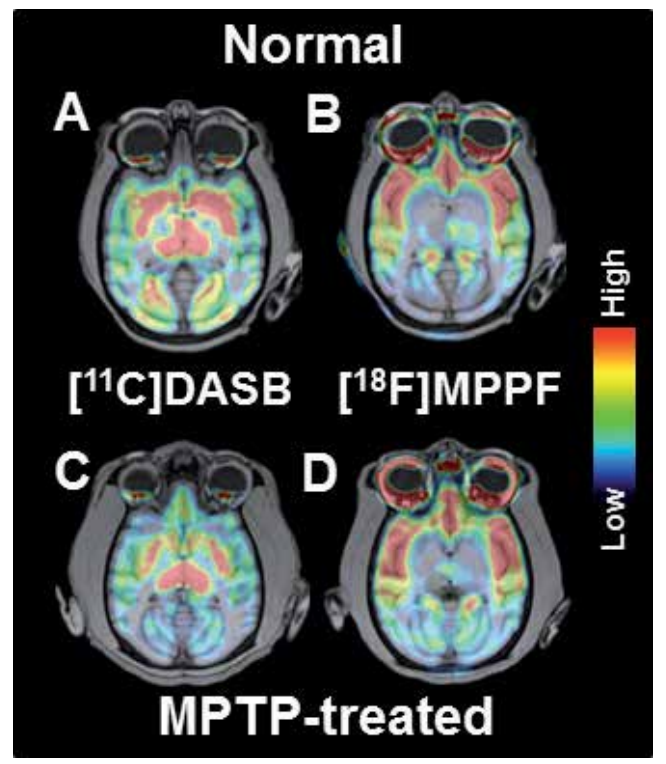

Figure 6.

Effects of the MPTP treatment on PET images of 5-HT in living brains of conscious monkeys. PET scans were conducted for 91 min with $\left[{ }^{11} C\right] D A S B$ for SERT ( $A$ and $C$ ) and $\left[{ }^{18} F M P P F\right.$ for $5-H T_{1 A} R$ (B and D). BP $P_{N D}$ images of $\left[{ }^{11} C\right] D A S B(A$ and $C)$ and $\left[{ }^{18} F\right] M P P F(B$ and $D)$ were created using the corresponding TACs in the cerebellum as input functions. 
the nigrostriatal and cortical (frontal, occipital, temporal, and parietal cortices) regions were plotted against those in MC-I measured using $\left[{ }^{18} \mathrm{~F}\right] \mathrm{BCPP}-\mathrm{EF}$. Positive correlations were observed between the $\Delta \mathrm{BP}_{\mathrm{ND}}$ of $\left[{ }^{11} \mathrm{C}\right] \mathrm{PE} 2 \mathrm{I}$ and $\Delta \mathrm{V}_{\mathrm{T}}$ of $\left[{ }^{18} \mathrm{~F}\right]$ BCPP-EF and between $\Delta \mathrm{Ki}$ of $\left[{ }^{11} \mathrm{C}\right] 6 \mathrm{Me} m \mathrm{Tyr}$ and $\Delta \mathrm{V}_{\mathrm{T}}$ of $\left[{ }^{18} \mathrm{~F}\right] \mathrm{BCPP}-\mathrm{EF}$ in the nigrostriatal regions. In addition to the $\mathrm{DA}$ system, a positive correlation was noted between the $\triangle \mathrm{BP}_{\mathrm{ND}}$ of $\left[{ }^{11} \mathrm{C}\right] \mathrm{DASB}$ and $\Delta \mathrm{V}_{\mathrm{T}}$ of $\left[{ }^{18} \mathrm{~F}\right] \mathrm{BCPP}-\mathrm{EF}$ in the cortical regions, while no correlation was found between $\Delta \mathrm{BP}_{\mathrm{ND}}$ of $\left[{ }^{11} \mathrm{C}\right] \mathrm{DASB}$ and $\Delta \mathrm{V}_{\mathrm{T}}$ of $\left[{ }^{18} \mathrm{~F}\right]$ $\mathrm{BCPP}-\mathrm{EF}$ in the nigrostriatal regions.

\subsection{Discussion}

The administration of MPTP causes the slow progressive loss of DA neurons over a period of several months, and the decrease in nigrostriatal DA levels is responsible for the motor symptoms of MPTP-treated animals, resembling clinical symptoms in PD patient. Thus, impaired ETC for OXPHOS due to a MC-I deficiency may account for neuronal cell death in PD. Alternatively, the MC-I deficiency in nigrostriatal DA system of PD patients may be secondary to mitochondrial damage due to oxidative stress. MC-I is a site of ROS production and is particularly vulnerable to oxidative damage [57]. The results of the present study showing a deficiency in presynaptic DA activity in the nigrostriatal pathway were consistent with the conventional theory shown above.

In contrast, the present study applying $\left[{ }^{18} \mathrm{~F}\right] \mathrm{BCPP}-\mathrm{EF}$, a novel PET probe for MC-I, demonstrated that systemic and chronic MPTP treatments induced neuronal damage not only in the nigrostriatal DA pathway but also in the 5-HT neuronal system in the cortex of the monkey brain. Recent clinical studies suggested that in addition to motor symptoms, which are exclusively related to the nigrostriatal DA system, PD is a disease associated with non-motor symptoms, such as depression and cognitive deficits, which may be related to changes in other monoamines (noradrenaline and serotonin) in extra-striatal regions [58]. Lewy body and neurite deposition, a pathological hallmark of PD, occurs within the raphe nucleus containing 5-HT neurons of the caudal brainstem [59]. Decreases in 5-HT concentrations have been reported in the cortical regions of the postmortem brains of PD patients [60]. Furthermore, PET imaging on non-depressed PD patients revealed diffuse reductions in SERT availability throughout the brain [61] and decreased 5- $\mathrm{HT}_{1 \mathrm{~A}} \mathrm{R}$ binding in the brains of non-depressed and depressed PD patients [62]. The present results obtained in MPTP-treated monkeys were consistent with the recent clinical observations on 5-HT abnormalities in PD patients, which cannot be diagnosed by PET measurements of dopaminergic parameters only.

\section{Conclusion}

This chapter introduced the potential of $\left[{ }^{18} \mathrm{~F}\right] \mathrm{BCPP}-\mathrm{EF}$ as a PET probe for the noninvasive and quantitative imaging of $\mathrm{MC}-\mathrm{I}$ activity in the living brain. The detectability of MC-I impairments using $\left[{ }^{18} \mathrm{~F}\right] \mathrm{BCPP}-\mathrm{EF}$ for neuronal damage in AD appears to be superior to the assessment of glucose metabolism measured using conventional $\left[{ }^{18} \mathrm{~F}\right]$ FDG. Furthermore, impaired serotonergic neuronal function in cortical regions suggests a relationship with depressive syndrome in $\mathrm{PD}$ patients. PET imaging of mitochondria function using $\left[{ }^{18} \mathrm{~F}\right] \mathrm{BCPP}-\mathrm{EF}$ will provide novel insights into the pathology, diagnosis, and treatment efficacy assessments of a wide range of neurodegenerative diseases, including AD, PD, HD, ALS, and MS. 


\section{Acknowledgements}

We gratefully acknowledge the technical assistant of the members of the PET research group of Central Research Laboratory, Hamamatsu Photonics for PET studies.

\section{Conflict of interest}

All authors are employees of Hamamatsu Photonics K.K., and this research was supported by the company's budget. The authors declare that they have no competing interests.

\section{Author details}

Hideo Tsukada

Central Research Laboratory, Hamamatsu Photonics K.K., Hamamatsu, Shizuoka, Japan

*Address all correspondence to: tsukada@crl.hpk.co.jp

\section{IntechOpen}

(C) 2019 The Author(s). Licensee IntechOpen. This chapter is distributed under the terms of the Creative Commons Attribution License (http://creativecommons.org/licenses/ by/3.0), which permits unrestricted use, distribution, and reproduction in any medium, provided the original work is properly cited. (cc) BY 


\section{References}

[1] Bolanos JP, Almeida A, Moncada S. Glycolysis: A bioenergetic or a survival pathway? Trends in Biochemical Sciences. 2010;35:145-149. DOI: 10.1016/j.tibs.2009.10.006

[2] Lopez-Otin C, Blasco MA, Partridge L, Serrano M, Kroemer G. The hallmarks of aging. Cell. 2013;153:1194-1217. DOI: 10.1016/j.cell.2013.05.039

[3] Spires-Jones TL, Hyman BT. The intersection of amyloid beta and tau at synapses in Alzheimer's disease. Neuron. 2014;82:756-771. DOI: 10.1016/j.neuron.2014.05.004

[4] Spillantini MG, Schmidt ML, Lee VM, Trojanowski JQ, Jakes R, Goedert M. Alpha-synuclein in Lewy bodies. Nature. 1997;388:839-840. DOI: $10.1038 / 42166$

[5] Schapira AHV, Cooper JM, Dexter D, Clark JB, Jenner P, Marsden CD. Mitochondrial complex I deficiency in Parkinson's disease. Journal of Neurochemistry. 1990;54:823-827. DOI: 10.1111/j.1471-4159.1990.tb02325.x

[6] Keeney PM, Xie J, Capaldi RA, Bennett JP Jr. Parkinson's disease brain mitochondrial complex I has oxidatively damaged subunits and is functionally impaired and misassembled. The Journal of Neuroscience. 2006;26:5256-5264. DOI: 10.1523/ JNEUROSCI.0984-06.2006

[7] Tsukada H. The use of ${ }^{18} \mathrm{~F}-\mathrm{BCPP}-\mathrm{EF}$ as a $\mathrm{PET}$ probe for complex I activity in the Brain. In: Murphy AN, Chan DC, editors. Methods in Enzymology. Vol. 547. Burlington: Academic Press; 2014. pp. 417-431. DOI: $10.1016 /$ B978-0-12-801415-8.00020-5

[8] Navarro A, Boveris A. Rat brain and liver mitochondria develop oxidative stress and lose enzymatic activities on aging. American Journal of Physiology. Regulatory, Integrative and Comparative Physiology. 2004;287:R1244-R1249. DOI: 10.1152/ ajpregu.00226.2004

[9] Stauch KL, Purnell PR, Fox HS. Quantitative proteomics of synaptic and nonsynaptic mitochondria: Insights for synaptic mitochondrial vulnerability. Journal of Proteome Research. 2014;13:2620-2636. DOI: 10.1021/ pr500295n

[10] Nabulsi NB, Mercier J, Holden D, Carré S, Najafzadeh S, Vandergeten $\mathrm{M}-\mathrm{C}$, et al. Synthesis and preclinical evaluation of ${ }^{11} \mathrm{C}$-UCB-J as a PET tracer for imaging the synaptic vesicle glycoprotein 2A in the brain. Journal of Nuclear Medicine. 2016;57:777-784. DOI: 10.2967/jnumed.115.168179

[11] Tsukada H, Ohba H, Kanazawa M, Kakiuchi T, Harada N. Evaluation of ${ }^{18} \mathrm{~F}$-BCPP-EF for mitochondrial complex I imaging in conscious monkey brain using PET. European Journal of Nuclear Medicine and Molecular Imaging. 2014;41:755-763. DOI: 10.1007/ s00259-013-2628-z

[12] Tsukada $H$, Nishiyama S, Ohba $H$, Kanazawa M, Kakiuchi T, Harada N. Comparing amyloid- $\beta$ deposition, neuroinflammation, glucose metabolism, and mitochondrial complex I activity in brain: A PET Study in aged monkeys. European Journal of Nuclear Medicine and Molecular Imaging. 2014;41:2127-2136. DOI: 10.1007/s00259-014-2821-8

[13] Kanazawa M, Ohba H, Nishiyama S, Kakiuchi T, Tsukada H. Effects of MPTP on serotonergic neuronal systems and mitochondrial complex I activity in the living brain: A PET study on conscious rhesus monkeys. Journal of Nuclear Medicine. 2017;58:1111-1116. DOI: 10.2967/jnumed.116.189159 
[14] Hashimoto F, Ohba H, Kanazawa M, Nishiyama S, Kakiuchi T, Tsukada H. Mitochondrial complex I deficit in the olfactory systems of age-related neurodegenerative monkey models: A PET study using ${ }^{18}$ F-BCPP-EF. Journal of Alzheimers Disease and Parkinsonism. 2018;8:433. DOI: 10.4172/2161-0460.1000433

[15] Tsukada H, Nishiyama S, Fukumoto D, Kanazawa M, Harada N. Novel PET probes ${ }^{18} \mathrm{~F}$-BCPP-EF and ${ }^{18} \mathrm{~F}$-BCPP-BF for mitochondrial complex I: A PET study by comparison with ${ }^{18} \mathrm{~F}$-BMS747158-02 in rat brain. Journal of Nuclear Medicine. 2014;55:473-480. DOI: 10.2967/jnumed.113.125328

[16] Tanaka E, Kudo H. Optimal relaxation parameters of DRAMA (dynamic RAMLA) aiming at one-pass image reconstruction for 3D-PET. Physics in Medicine and Biology. 2010;55:2917-2939. DOI: 10.1088/0031-9155/55/10/009

[17] Logan J, Fowler JS, Volkow ND, Wang GJ, Ding YS, Alexoff DL. Distribution volume ratios without blood sampling from graphical analysis of P'ET data. Journal of Cerebral Blood Flow and Metabolism. 1996;16:834-840. DOI: 10.1097/00004647-199609000-00008

[18] Yalamanchili P, Wexler E, Hayes M, Yu M, Bozek J, Kagan M, et al. Mechanism of uptake and retention of F-18 BMS-747158-02 in cardiomyocytes: A novel PET myocardial imaging agent. Journal of Nuclear Cardiology. 2007;14:782-788. DOI: 10.1016/j. nuclcard.2007.07.009

[19] Tsukada H, Ohba H, Nishiyama S, Kanazawa M, Kakiuchi T, Harada N. PET imaging of ischemia-induced impairment of mitochondrial complex I function in monkey brain. Journal of Cerebral Blood Flow and Metabolism. 2014;34:708-714. DOI: $10.1038 /$ jcbfm.2014.5
[20] Ojaimi J, Masters CL, Opeskin K, McKelvie P, Byrne E. Mitochondrial respiratory chain activity in the human brain as a function of age. Mechanisms of Ageing and Development. 1999;111:39-47. DOI: $10.1016 /$ S0047-6374(99)00071-8

[21] Navarro A, Boveris A. The mitochondrial energy transduction system and the aging process. American Journal of Physiology. Cell Physiology. 2007;292:C670-C686

[22] Manczak M, Jung Y, Park BS, Partovi D, Reddy PH. Time-course of mitochondrial gene expressions in mice brains: Implications for mitochondrial dysfunction, oxidative damage, and cytochrome $\mathrm{c}$ in aging. Journal of Neurochemistry. 2005;92:494-504. DOI: 10.1111/j.1471-4159.2004.02884.x

[23] Nakamura H, Kobayashi S, Ohashi Y, Anso S. Age-changes of brain synapses and synaptic plasticity in response to an enriched environment. Journal of Neuroscience Research. 1999;56:

307-315. DOI: $10.1002 /$ (SICI)1097-4547 (19990501)56:3<307::AID-

JNR10>3.0.CO;2-3

[24] Mostany R, Anstey JE, Crump KL, Maco B, Knott G, Portera-Cailliau C. Altered synaptic dynamics during normal brain aging. The Journal of Neuroscience. 2013;33:4094-4104. DOI: 10.1523/JNEUROSCI.4825-12.2013

[25] Li Z, Okamoto K, Hayashi Y, Sheng $M$. The Importance of dendritic mitochondria in the morphogenesis and plasticity of spines and synapses. Cell. 2004;119:873-887. DOI: 10.1016/j. cell.2004.11.003

[26] Cao L, Schrank BR, Rodriguez S, Benz EG, Moulia TW, Rickenbacher GT, et al. A $\beta$ alters the connectivity of olfactory neurons in the absence of amyloid plaques in vivo. Nature Communications. 2012;3:1009. DOI: 10.1038/ncomms2013 
[27] Allsop D, Mayes J, Moore S, Masad A, Tabner BJ. Metal-dependent generation of reactive oxygen species from amyloid proteins implicated in neurodegenerative disease. Biochemical Society Transactions. 2008;36:1293-1298. DOI: 10.1042/BST0361293

[28] Ingelsson M, Fukumoto H, Newell KL, Growdon JH, Hedley-Whyte ET, Frosch MP, et al. Early A $\beta$ accumulation and progressive synaptic loss, gliosis, and tangle formation in AD brain. Neurology. 2004;62:925-931. DOI: 10.1212/01.WNL.0000115115.98960.37

[29] Monson NL, Ireland SJ, Ligocki AJ, Chen D, Rounds WH, Li M, et al. Elevated CNS inflammation in patients with preclinical Alzheimer's disease. Journal of Cerebral Blood Flow and Metabolism. 2014;34:30-33. DOI: $10.1038 / \mathrm{jcbfm} .2013 .183$

[30] Klunk WE, Engler H, Nordberg A, Wang Y, Blomqvist G, Holt DP, et al. Imaging brain amyloid in Alzheimer's disease with Pittsburgh Compound-B. Annals of Neurology. 2004;55:306-319. DOI: $10.1002 /$ ana.2009

[31] Boutin H, Chauveau F, Thominiaux C, Gregoire MC, James ML, Trebossen $\mathrm{R}$, et al. Receptor PET ligand for in vivo imaging of neuroinflammation. Journal of Nuclear Medicine. 2007;48:573-581. DOI: 10.2967/jnumed.106.036764

[32] Price JC, Klunk WE, Lopresti BJ, Lu X, Hoge JA, Ziolko SK, et al. Kinetic modeling of amyloid binding in humans using PET imaging and Pittsburgh compound-B. Journal of Cerebral Blood Flow and Metabolism. 2005;25:1528-1547. DOI: $10.1038 /$ sj.jcbfm.9600146

[33] Kumar A, Muzik O, Shandal V, Chugani D, Chakraborty P, Chugani HT. Evaluation of age-related changes in translocator protein (TSPO) in human brain using ${ }^{11} \mathrm{C}$-[R]-PK11195 PET. Journal of
Neuroinflammation. 2012;9:232. DOI: 10.1186/1742-2094-9-232

[34] Dukart J, Mueller K, Horstmann A, Vogt B, Frisch S, Barthel H, et al. Differential effects of global and cerebellar normalization on detection and differentiation of dementia in FDG-PET studies. NeuroImage. 2010;49:1490-1495. DOI: 10.1016/j. neuroimage.2009.09.017

[35] Finch CE, Austad SN. Primate aging in the mammalian scheme: The puzzle of extreme variation in brain aging. Age. 2012;34:1075-1091. DOI: 10.1007/ s11357-011-9355-9

[36] Noda A, Murakami Y, Nishiyama S, Fukumoto D, Miyoshi S, Tsukada H, et al. Amyloid imaging in aged and young macaques with $\left[{ }^{11} \mathrm{C}\right] \mathrm{PIB}$ and $\left[{ }^{18} \mathrm{~F}\right]$ FDDNP. Synapse. 2008;62:472-475.

DOI: $10.1002 /$ syn.20508

[37] Edison P, Archer HA, Hinz R, Hammers A, Pavese N, Tai YF, et al. Amyloid, hypometabolism, and cognition in Alzheimer disease: An $\left[{ }^{11} \mathrm{C}\right]$ PIB and $\left[{ }^{18} \mathrm{~F}\right]$ FDG PET study. Neurology. 2007;68:501-508. DOI: 10.1212/01.wnl.0000244749.20056.d4

[38] Kemppainen NM, Aalto S, Wilson LA, Nagren K, Helin S, Bruck $\mathrm{A}$, et al. PET amyloid ligand $\left[{ }^{11} \mathrm{C}\right]$ PIB uptake is increased in mild cognitive impairment. Neurology. 2007;68:1603-1606. DOI: 10.1212/01. wnl.0000260969.94695.56

[39] Swomley AM, Förster S, Keeney JT, Triplett J, Zhang Z, Sultana R, et al. $A \beta$, oxidative stress in Alzheimer disease: Evidence based on proteomics studies. Biochimica et Biophysica Acta. 2014;1842:1248-1257

[40] Schon EA, Przedborski

S. Mitochondria: The next (neurode) generation. Neuron. 2011;70:1033-1053. DOI: 10.1016/j.neuron.2011.06.003 
[41] Lin MT, Beal MF. Mitochondrial dysfunction and oxidative stress in neurodegenerative diseases. Nature. 2006;443:787-795. DOI: 10.1038/ nature 05292

[42] Pagani L, Eckert A. Amyloidbeta interaction with mitochondria. International Journal of Alzheimer's Disease. 2011;2011:1-12. DOI: 10.4061/2011/925050

[43] Kish SJ, Shannak K, Hornykiewicz O. Uneven pattern of dopamine loss in the striatum of patients with idiopathic Parkinson's disease. Pathophysiologic and clinical implications. The New England Journal of Medicine. 1988;318:876-880. DOI: $10.1056 /$ NEJM198804073181402

[44] Recasens A, Dehay B, Bove J, Carballo-Carbajal I, Dovero S, Perez-Villalba A, et al. Lewy body extracts from Parkinson disease brains trigger alpha-synuclein pathology and neurodegeneration in mice and monkeys. Annals of Neurology. 2014;75:351-362. DOI: 10.1002/ ana. 24066

[45] Shimozawa A, Ono M, Takahara D, Tarutani A, Imura S, MasudaSuzukake M, et al. Propagation of pathological $\alpha$-synuclein in marmoset brain. Acta Neuropathologica Communications. 2017;5:12. DOI: 10.1186/s40478-017-0413-0

[46] Ludtmann MHR, Angelova PR, Horrocks MH, Choi ML, Rodrigues $\mathrm{M}$, Baev AY, et al. $\alpha$-Synuclein oligomers interact with ATP synthase and open the permeability transition pore in Parkinson's disease. Nature Communications. 2018;9:2293. DOI: 10.1038/s41467-018-04422-2

[47] Burns RS, Chiueh CC, Markey SP, Ebert MH, Jacobowitz DM, Kopin IJ. A primate model of parkinsonism: Selective destruction of dopaminergic neurons in the pars compacts of the substantia nigra by MPTP. Proceedings of the National Academy of Sciences of the United States of America. 1983;80:4546-4550. DOI: 10.1073/ pnas.80.14.4546

[48] Muramatsu S, Okuno T, Suzuki Y, Nakayama T, Kakiuchi T, Takino N, et al. Multitracer assessment of dopamine function after transplantation of embryonic stem cell-derived neural stem cells in a primate model of Parkinson's disease. Synapse. 2009;63:541-548. DOI: 10.1002/ syn. 20634

[49] Tsukada H, Kanazawa M, Ohba H, Nishiyama S, Harada N, Kakiuchi T. PET imaging of mitochondrial complex I with ${ }^{18} \mathrm{~F}$-BCPP-EF in brain of Parkinson's disease model monkey. Journal of Nuclear Medicine. 2016;57:950-953. DOI: $10.2967 /$ jnumed.115.169615

[50] Wilson AA, Ginovart N, Schmidt M, Meyer JH, Threlkeld PG, Houle S. Novel radiotracers for imaging the serotonin transporter by positron emission tomography: Synthesis, radiosynthesis, and in vitro and ex vivo evaluation of ${ }^{11} \mathrm{C}$-labeled 2-(phenylthio) araalkylamines. Journal of Medicinal Chemistry. 2000;43:3103-3110. DOI: 10.1021/jm000079i

[51] Le Bars D, Lemaire C, Ginovart $\mathrm{N}$, et al. High-yield radiosynthesis and preliminary in vivo evaluation of $\mathrm{p}-\left[{ }^{18} \mathrm{~F}\right] \mathrm{MPPF}$, a fluoro analog of WAY-100635. Nuclear Medicine and Biology. 1998;25:343-350. DOI: 10.1016/ S0969-8051(97) 00229-1

[52] Kanazawa M, Ohba H, Iwazaki A, Kakiuchi T, Tsukada H. Synthesis of 6 - ${ }^{11} \mathrm{C}$-methyl-m-tyrosine $\left({ }^{11} \mathrm{C}-6 \mathrm{Me}\right.$ T Tyr) for dopamine synthesis imaging in living brain using PET. Bioorganic and Medicinal Chemistry. 2015;23:729-734. DOI: 10.1016/j.bmc.2014.12.061 
[53] Kanazawa M, Ohba H, Harada N, Kakiuchi T, Muramatsu S, Tsukada $\mathrm{H}$. Evaluation of $6-{ }^{11} \mathrm{C}$-methyl-mtyrosine as a PET probe for presynaptic dopaminergic activity: A comparison PET study with $\beta-{ }^{11} \mathrm{C}-\mathrm{L}-\mathrm{DOPA}$ and ${ }^{18} \mathrm{~F}$-FDOPA in Parkinson's disease monkeys. Journal of Nuclear Medicine. 2016;57:303-308. DOI: $10.2967 /$ jnumed.115.161802

[54] Halldin C, Erixon-Lindroth N, Pauli S, Chou YH, Okubo Y, Karlsson P, et al. $\left[{ }^{11} \mathrm{C}\right]$ PE2I: A highly selective radioligand for PET examination of the dopamine transporter in monkey and human brain. The European Journal of Nuclear Medicine and Molecular Imaging. 2003;30:1220-1230. DOI: 10.1007/ s00259-003-1212-3

[55] Innis RB, Cunningham VJ, Delforge J, Fujita M, Gjedde A, Gunn RN, et al. Consensus nomenclature for in vivo imaging of reversibly binding radioligands. Journal of Cerebral Blood Flow and Metabolism. 2007;27:1533-1539. DOI: $10.1038 /$ sj.jcbfm.9600493

[56] Patlak CS, Blasberg RG. Graphical evaluation of blood-to-brain transfer constants from multiple-time uptake data: Generalizations. Journal of Cerebral Blood Flow and Metabolism. 1985;5:584-590. DOI: 10.1038/ jcbfm.1985.87

[57] Robinson BH. Human complex I deficiency: Clinical spectrum and involvement of oxygen free radicals in the pathogenicity of the defect. Biochimica et Biophysica Acta. 1998;1364:271-286. DOI: 10.1016/ S0005-2728(98)00033-4

[58] Chaudhuri KR, Healy DG, Schapira AH. Non-motor symptoms of Parkinson's disease: Diagnosis and management. Lancet Neurology. 2006;5:235-245. DOI: 10.1016/ S1474-4422(06)70373-8

[59] Orth M, Schapira AHV. Mitochondrial involvement in
Parkinson's disease. Neurochemistry International. 2002;40:533-541. DOI: 10.1016/S0197-0186(01)00124-3

[60] Scatton B, Javoy-Agid F, Rouquier L, Dubois B, Agid Y. Reduction of cortical dopamine, noradrenaline, serotonin and their metabolites in Parkinson's disease. Brain Research. 1998;275:321-328. DOI: 10.1016/0006-8993(83)90993-9

[61] Albin RL, Koeppe RA, Bohnen NI, Wernette K, Kilbourn MA, Frey KA. Spared caudal brainstem SERT binding in early Parkinson's disease. Journal of Cerebral Blood Flow and Metabolism. 2008;28:441-444. DOI: 10.1038/sj.jcbfm.9600599

[62] Ballanger B, Klinger $\mathrm{H}$, Eche J, Lerond J, Vallet AE, Le Bars D, et al. Role of serotonergic $1 \mathrm{~A}$ receptor dysfunction in depression associated with Parkinson's disease. Movement Disorders. 2012;27:84-89. DOI: 10.1002/ mds.23895 

Section 4

\section{Mitochondrial Function and Dysfunction}





\title{
Mitochondrial Proteomic and Molecular Network Alterations in Human Ovarian Cancers
}

\author{
Xianquan Zhan and $\mathrm{Na} \mathrm{Li}$
}

\begin{abstract}
Mitochondrion is a multi-functional organelle, which plays important role in human ovarian cancers. Mitochondrial quantitative proteomics was used to detect, identify, and quantify proteins from mitochondrial samples prepared from ovarian cancer and normal control ovary tissues. A total of 5115 mitochondrial proteins and 1198 mitochondrial differentially expressed proteins (mtDEPs) were identified in human ovarian cancer compared to control tissues. Pathway network analysis revealed multiple pathway network changes to involve those mitochondrial proteins and mtDEPs. These findings provide the scientific data about the role of mitochondria plays in ovarian cancer, and offer the source for discovery of mitochondrial biomarker for ovarian cancers.
\end{abstract}

Keywords: mitochondrial proteome, proteomics, molecular networks, biomarker, ovarian cancer

\section{Introduction}

Mitochondrion is a multi-functional organelle, which is the center of cell energy metabolism, cell signaling, and oxidative stress [1, 2]. Mitochondrial dysfunction is a hallmark in human ovarian cancers, and plays important roles in ovarian carcinogenesis, which has been looked as the cause, biomarker, and therapeutic target for ovarian cancers [3-5]. First, a study finds mitochondrial morphology is significantly changed in ovarian cancers compared to controls. Electron microscopy morphology study shows that mitochondria are abundant and large volume in ovarian cancer cells and tissues $[6,7]$. Second, mitochondrial ribosomal proteinencoding genes might be the anti-oncogenes to serve as new biomarkers and therapeutic targets. For example, bcl-2-interacting mitochondrial ribosomal protein L41 (MRPL41) is differentially expressed in carcinomas to associate with various epigenetic states [8]. Mitochondrial ribosomal protein S23 (MRPS23) is involved in cancer cell proliferation, which might serve as the therapeutic target [9]. MRPS15 is significantly upregulated in epithelial breast cells and tissues [10]. Mitochondrial COX1 is expressed abnormally in multiple cancers [11-13]. Many cancer-relevant communication signaling pathways are linked to mitochondrial proteins. Third, mitochondria are the center of oxidative stress, which might be the 'fuel' center for a cancer metabolism [10]. The abnormal energy metabolism, namely the Warburg and reverse-Warburg effects, is the important characteristics in cancers [14]. 
Therefore, mitochondria play important roles in tumorigenesis, proliferation, angiogenesis, invasiveness, and metastasis of cancer cells $[14,15]$. Proteins are the important performer in maintaining mitochondrial morphology and functions. It emphasizes the important scientific merits of mitochondrial proteomics in ovarian cancer research and clinical practice [16-22]. Mitochondrial proteins function in mutually interacted molecular pathway network system, which fits the real situation of ovarian cancer that is a multi-cause, multi-process, and multi-result disease [23-25]. It is very difficult to use single-parameter biomarker to predict, diagnose, and prognostic assess ovarian cancer, thus multi-parameter biomarkers or molecule pattern biomarker is necessary for ovarian cancer prediction, prevention, and treatment [26, 27]. Mitochondrial proteomics is an effective approach to systematically investigate the role of mitochondria in ovarian cancer for discovery of reliable mitochondrial protein biomarkers to insight into the molecular mechanism and determination of therapeutic target to mitochondria for ovarian cancers. Quantitative proteomic methods commonly include two-dimensional gel electrophoresis (2DGE) $[28,29]$ or two-dimensional difference in-gel electrophoresis (2D DIGE) [30] comparative proteomics, and gelfree-based quantitative proteomics $[14,15]$, for example, isobaric tags for relative and absolute quantification (iTRAQ) [31, 32], tandem mass tag (TMT) [33], or label-free-based quantitative proteomics [34, 35], with different advantages and disadvantages, respectively. Those quantitative proteomic methods can achieve a high-throughput and high-sensitive identification of mitochondrial proteins and post-translational modifications. Currently, stable isotopic labeled large-scale 2DGE coupled with high-sensitivity liquid chromatography-tandem mass spectrometry (LC-MS/MS) is able to detect, identify, and quantify up to least 500,000 protein proteoforms in human tissue proteoforms [36, 37]. iTRAQ, TMT, or label-free is commonly coupled with two-dimensional LC-MS/MS (2DLC-MS/MS), which enables detect, identify, and quantify up to several thousands of proteins and PTMs, even though these gel-free methods are unable to discriminate proteoforms and homolog proteins [38].

Ovarian cancer is a malignant cancer with high morbidity and mortality $[39,40]$ and without clear molecular mechanisms and effectively reliable biomarkers for its early-stage diagnosis to improve its prognosis. This book chapter used iTRAQ-labeled strong cation exchange chromatography (SCX)-LC-MS/MS method to detect, identify, and quantify mitochondrial proteins and mitochondrial differentially expressed proteins (mtDEPs) between human ovarian cancer and control ovary tissues. The identified mitochondrial proteins and differentially expressed proteins were subject to gene ontology (GO) and Kyoto Encyclopedia of Genes and Genomes (KEGG) pathway network analysis for revealing pathway network alteration in ovarian cancers compared to controls. Those findings provide the scientific data to establish mitochondrial proteomic reference map of ovarian cancer, mtDEP profile and the corresponding pathway network alterations to link with ovarian cancer pathogenesis, which is the resource for discovery of potential biomarkers and mitochondria-targeting drug targets for ovarian cancers.

\section{Methods}

\subsection{Ovarian cancer tissues and preparation of mitochondria protein samples}

Seven ovarian cancer tissues and eleven control ovaries with benign gynecologic disease were used in this study. Mitochondria were isolated and purified from ovarian cancer and control tissues with differential-speed centrifugation and 
Nycodenz density gradient centrifugation. The purified mitochondria were verified with electron microscopy, and Western blot with different antibodies specific to different subcellular organelles, including COX4I1 (mitochondrion), flotillin-1 (cytomembrane), GM130 (Golgi apparatus), catalase (peroxisomes), cathepsin B (lysosome), and lamin B (cell nucleus). The proteins were extracted from purified mitochondrial samples for iTRAQ-labeled quantitative proteomic analysis. The detailed procedure was described in our previous publications $[14,15]$.

\section{2 iTRAQ-based quantitative proteomics analysis}

The prepared mitochondrial proteins $(200 \mu \mathrm{g} / \mathrm{each}$ sample) were treated with $N$-hydroxysuccinimide (SDT), followed by reduction, alkylation, digestion with trypsin, and desalination. The tryptic peptide $(100 \mu \mathrm{g} / \mathrm{each}$ sample) was labeled with iTRAQ reagent, and each sample was labeled three times. The six labeled tryptic peptide samples were mixed, followed by peptide fractionation with strong cation exchange (SCX) chromatography. Each SCX-fractionated sample was subject to LC-MS/MS analysis on a Q Exactive mass spectrometer (Thermo Scientific) within a 60-min LC separation gradient to obtain MS/MS data. The MS/MS data were used for identity of proteins with MASCOT search engine. The iTRAQ reporter-ion intensities were used to quantify each protein and determine each mtDEPs. The detailed procedure was described in our previous publications $[14,15]$.

\subsection{Bioinformatics and pathway network analysis}

The identified proteins and DEPs in mitochondrial samples were subject to GO and KEGG pathway enrichment analysis with Cytoscape, and DAVID online software (https://david.ncifcrf.gov/home.jsp). Multiple Experiment Viewer (https://sourceforge.net/projects/mev-tm4/files/mev-tm4/) was used to make heat map. GO analysis included cellular component (CC), molecular function (MF), and biological process (BP). PANTHER (http://www.pantherdb.org/) was used to further enrich GO CC.

\subsection{Validation of mtDEPs and molecular networks in cell models and mitochondrial tissues}

Ovarian cancer cells TOV-21G and control cells IOSE80 were used to extract RNAs and proteins. Quantitative real-time PCR (qRT-PCR) was used to measure the mRNA expression levels of GLDC, PCK2, IDH2, CPT2 and HMGCS2 in TOV-21G cells compared to IOSE80 cells. Western blot was used to measure the protein expression levels of GLDC, PCK2, IDH2, CPT2 and HMGCS2 in TOV-21G cells compared to IOSE80 cells, and in ovarian cancer mitochondrial samples compared to control mitochondrial samples; and $\beta$-actin was used as internal standard for Western blot analysis.

\subsection{Statistical analysis}

For GO and KEGG enrichment analyses, $p$ values were corrected with Benjamini-Hochberg (FDR) for multiple testing. For qRT-PCR and Western blot, the student's t-test was used to measure between-group difference with SPSS software 13.0, and data was presented as the mean \pm SD with $\mathrm{p}<0.05$. Each experiment was repeated at least three times. 


\section{Results and discussion}

\subsection{Mitochondrial proteomic profile in human ovarian cancer tissue}

iTRAQ-labeling coupled with SCX-LC-MS/MS identified 5115 proteins in mitochondrial samples prepared from human ovarian cancer and control ovary tissues, with at least one peptide sequence matches (PSMs). All of identified proteins was collected in the supplemental Table 1 in our previous publication [15]. Those 5115 proteins mainly distributed within pI 3.81-12.25 and molecular weight (MW) $2.6-1158.2 \mathrm{kDa}$, and in multiple cell components including cell junction (0.8\%), cell part (42.7\%), extracellular matrix (0.6\%), macromolecular complex (17.8\%), organelle (28.2\%), and synapse (0.3\%) (Figure 1). Of them, 2565 (50.14\%) were increased, and 2550 (49.86\%) were decreased in the abundance in ovarian cancers compared to control ovaries. Furthermore, statistical significance analysis revealed $1198 \mathrm{mtDEPs}$ in human ovarian cancers compared to control ovaries, including 523 (43.66\%) upregulated proteins and 675 (56.34\%) downregulated proteins, with fold-change $\geq 1.5$ or $\leq-1.5$, and $p<0.05$. Those $1198 \mathrm{mtDEPs}$ were collected in the supplemental Table 1 in our previous publication [14]. Those mtDEPs might be directly linked to ovarian cancer pathogenesis, and the potential resource for biomarkers. From a systemic molecular network angle, one must realize that those non-significant difference proteins might be also important in ovarian cancer pathogenesis because they might be the hub-molecule in a network, because some studies have found that some hub-molecules changed smaller than those boundary molecules in a molecular network in a given condition.

\subsection{Pathway networks involved in mitochondrial proteins in ovarian cancer}

KEGG pathway network analysis revealed 52 statistically significant pathways to involve mitochondrial proteins including mtDEPs in ovarian cancers compared to

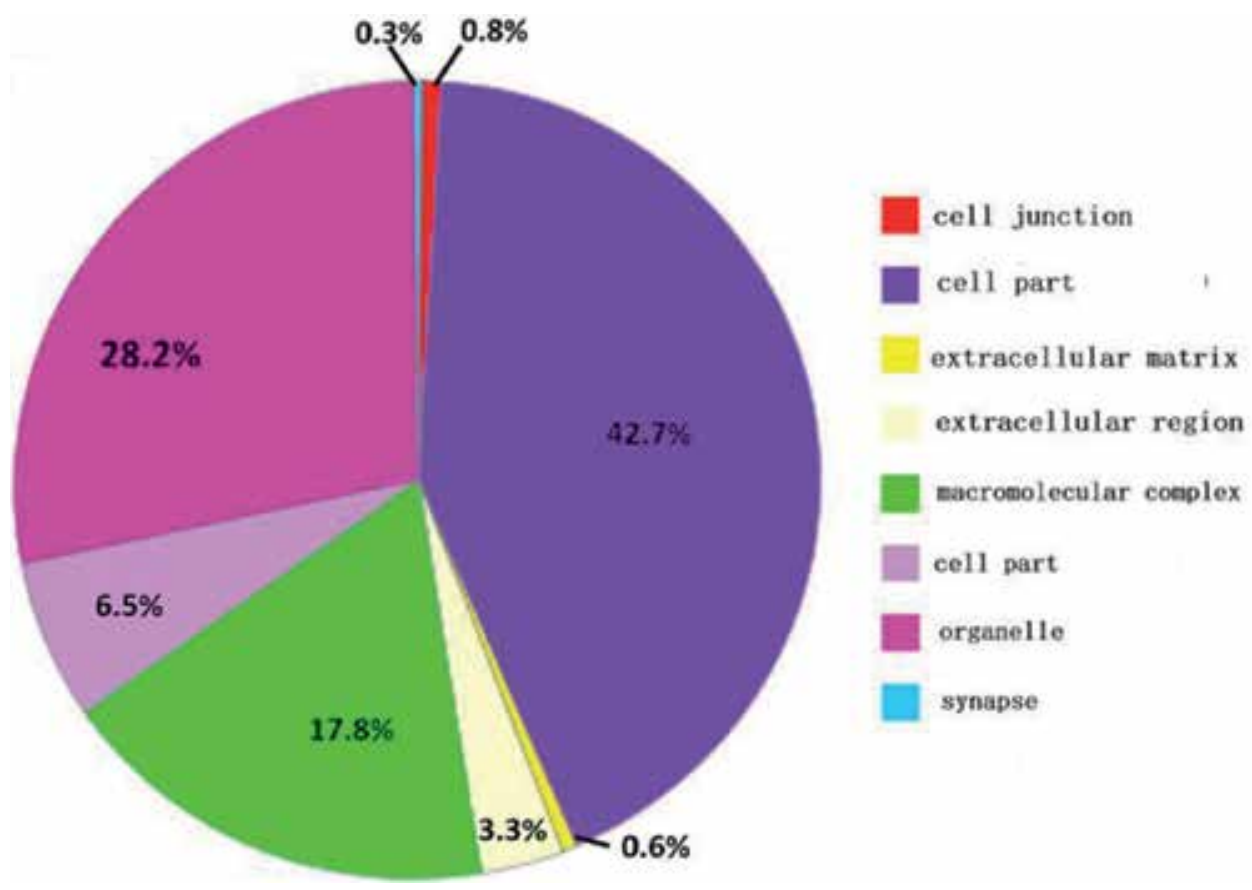

Figure 1.

Subcellular location of 5115 proteins analyzed with PANTHER. Modified from Li et al. [15], with permission from Bioscientifica Ltd., copyright 2018. 
Mitochondrial Proteomic and Molecular Network Alterations in Human Ovarian Cancers DOI: http://dx.doi.org/10.5772/intechopen.86493

\begin{tabular}{|c|c|c|c|c|c|c|}
\hline Category & Term & RT & Count & $\%$ & P-value & Benjamini \\
\hline KEGG_PATHWAY & Lysosome & RT & 52 & 1.3 & $3.70 \mathrm{E}-02$ & $2.00 \mathrm{E}-01$ \\
\hline KEGG_PATHWAY & Peroxisome & RT & 53 & 1.5 & $8.00 \mathrm{E}-08$ & $4.60 \mathrm{E}-06$ \\
\hline KEGG_PATHWAY & $\begin{array}{l}\text { Valine, leucine } \\
\text { and isoleucine } \\
\text { degradation }\end{array}$ & RT & 41 & 1.0 & $1.10 \mathrm{E}-07$ & $5.50 \mathrm{E}-06$ \\
\hline KEGG_PATHWAY & Phagosome & $\mathrm{RT}$ & 77 & 2.1 & $1.20 \mathrm{E}-05$ & $2.90 \mathrm{E}-04$ \\
\hline KEGG_PATHWAY & $\begin{array}{l}\text { Citrate cycle } \\
\text { (TCA cycle) }\end{array}$ & RT & 19 & 0.8 & $1.80 \mathrm{E}-07$ & $7.50 \mathrm{E}-06$ \\
\hline KEGG_PATHWAY & $\begin{array}{l}\text { Oxidative } \\
\text { phosphorylation }\end{array}$ & $\mathrm{RT}$ & 94 & 2.0 & $3.40 \mathrm{E}-07$ & $1.10 \mathrm{E}-05$ \\
\hline KEGG_PATHWAY & $\begin{array}{l}\text { Glycolysis/ } \\
\text { Gluconeogenesis }\end{array}$ & $\mathrm{RT}$ & 33 & 0.8 & $1.60 \mathrm{E}-02$ & $1.20 \mathrm{E}-01$ \\
\hline KEGG_PATHWAY & $\begin{array}{l}\text { Fatty acid } \\
\text { metabolism }\end{array}$ & RT & 29 & 0.8 & $1.90 \mathrm{E}-03$ & $2.20 \mathrm{E}-02$ \\
\hline KEGG_PATHWAY & Prion diseases & RT & 14 & 0.6 & $2.20 \mathrm{E}-03$ & $2.40 \mathrm{E}-02$ \\
\hline KEGG_PATHWAY & $\begin{array}{l}\text { Propanoate } \\
\text { metabolism }\end{array}$ & RT & 13 & 0.5 & $1.40 \mathrm{E}-03$ & $1.60 \mathrm{E}-02$ \\
\hline KEGG_PATHWAY & $\begin{array}{l}\text { Sulfur } \\
\text { metabolism }\end{array}$ & RT & 7 & 0.3 & $2.90 \mathrm{E}-03$ & $3.10 \mathrm{E}-02$ \\
\hline KEGG_PATHWAY & $\begin{array}{l}\text { Pyruvate } \\
\text { metabolism }\end{array}$ & RT & 15 & 0.6 & $5.30 \mathrm{E}-03$ & $4.90 \mathrm{E}-02$ \\
\hline KEGG_PATHWAY & $\begin{array}{l}\text { beta-Alanine } \\
\text { metabolism }\end{array}$ & RT & 11 & 0.5 & $3.10 \mathrm{E}-02$ & $2.00 \mathrm{E}-01$ \\
\hline KEGG_PATHWAY & $\begin{array}{l}\text { Butanoate } \\
\text { metabolism }\end{array}$ & RT & 10 & 0.4 & $3.30 \mathrm{E}-02$ & $2.00 \mathrm{E}-01$ \\
\hline KEGG_PATHWAY & $\begin{array}{l}\text { Tryptophan } \\
\text { metabolism }\end{array}$ & RT & 13 & 0.5 & $3.30 \mathrm{E}-02$ & $2.00 \mathrm{E}-01$ \\
\hline KEGG_PATHWAY & $\begin{array}{l}\text { Arginine } \\
\text { and proline } \\
\text { metabolism }\end{array}$ & $\mathrm{RT}$ & 15 & 0.6 & $4.00 \mathrm{E}-02$ & $2.10 \mathrm{E}-01$ \\
\hline KEGG_PATHWAY & $\begin{array}{l}\text { Metabolic } \\
\text { pathways }\end{array}$ & RT & 524 & 12.6 & $1.30 \mathrm{E}-12$ & $1.80 \mathrm{E}-10$ \\
\hline KEGG_PATHWAY & $\begin{array}{l}\text { Carbon } \\
\text { metabolism }\end{array}$ & RT & 75 & 2.2 & $3.80 \mathrm{E}-12$ & $3.70 \mathrm{E}-10$ \\
\hline KEGG_PATHWAY & $\begin{array}{l}\text { 2-Oxocarboxylic } \\
\text { acid metabolism }\end{array}$ & RT & 9 & 0.4 & $4.30 \mathrm{E}-03$ & $4.30 \mathrm{E}-02$ \\
\hline KEGG_PATHWAY & $\begin{array}{l}\text { Glutathione } \\
\text { metabolism }\end{array}$ & RT & 33 & 0.9 & $4.90 \mathrm{E}-05$ & $1.00 \mathrm{E}-03$ \\
\hline KEGG_PATHWAY & $\begin{array}{l}\text { Glyoxylate and } \\
\text { dicarboxylate } \\
\text { metabolism }\end{array}$ & RT & 15 & 0.6 & $4.20 \mathrm{E}-05$ & $9.40 \mathrm{E}-04$ \\
\hline KEGG_PATHWAY & $\begin{array}{l}\text { Porphyrin and } \\
\text { chlorophyll } \\
\text { metabolism }\end{array}$ & RT & 14 & 0.6 & $2.10 \mathrm{E}-02$ & $1.50 \mathrm{E}-01$ \\
\hline KEGG_PATHWAY & Ribosome & $\mathrm{RT}$ & 110 & 3.0 & $3.00 \mathrm{E}-20$ & $8.80 \mathrm{E}-18$ \\
\hline KEGG_PATHWAY & $\begin{array}{l}\text { Biosynthesis of } \\
\text { antibiotics }\end{array}$ & RT & 124 & 3.2 & $3.50 \mathrm{E}-11$ & $2.60 \mathrm{E}-09$ \\
\hline KEGG_PATHWAY & $\begin{array}{l}\text { Aminoacyl-tRNA } \\
\text { biosynthesis }\end{array}$ & RT & 24 & 1.0 & $4.30 \mathrm{E}-04$ & $6.60 \mathrm{E}-03$ \\
\hline
\end{tabular}




\begin{tabular}{|c|c|c|c|c|c|c|}
\hline Category & Term & RT & Count & $\%$ & P-value & Benjamini \\
\hline KEGG_PATHWAY & $\begin{array}{l}\text { Biosynthesis of } \\
\text { amino acids }\end{array}$ & RT & 41 & 1.0 & $1.10 \mathrm{E}-03$ & $1.50 \mathrm{E}-02$ \\
\hline KEGG_PATHWAY & $\begin{array}{l}\text { Terpenoid } \\
\text { backbone } \\
\text { biosynthesis }\end{array}$ & RT & 10 & 0.4 & $7.80 \mathrm{E}-03$ & $6.60 \mathrm{E}-02$ \\
\hline KEGG_PATHWAY & Proteasome & $\mathrm{RT}$ & 30 & 0.6 & $3.10 \mathrm{E}-02$ & $2.00 \mathrm{E}-01$ \\
\hline KEGG_PATHWAY & $\begin{array}{l}\text { Protein digestion } \\
\text { and absorption }\end{array}$ & RT & 24 & 1.0 & $2.30 \mathrm{E}-02$ & $1.60 \mathrm{E}-01$ \\
\hline KEGG_PATHWAY & $\begin{array}{l}\text { Fatty acid } \\
\text { degradation }\end{array}$ & RT & 27 & 0.7 & $5.30 \mathrm{E}-03$ & $5.00 \mathrm{E}-02$ \\
\hline KEGG_PATHWAY & $\begin{array}{l}\text { Protein } \\
\text { processing in } \\
\text { endoplasmic } \\
\text { reticulum }\end{array}$ & RT & 86 & 2.4 & $3.20 \mathrm{E}-07$ & $1.10 \mathrm{E}-05$ \\
\hline KEGG_PATHWAY & $\begin{array}{l}\text { PPAR signaling } \\
\text { pathway }\end{array}$ & RT & 20 & 0.8 & $1.60 \mathrm{E}-02$ & $1.20 \mathrm{E}-01$ \\
\hline KEGG_PATHWAY & $\begin{array}{l}\text { ECM-receptor } \\
\text { interaction }\end{array}$ & RT & 46 & 1.3 & $2.00 \mathrm{E}-04$ & $3.20 \mathrm{E}-03$ \\
\hline KEGG_PATHWAY & $\begin{array}{l}\text { Pentose } \\
\text { phosphate } \\
\text { pathway }\end{array}$ & $\mathrm{RT}$ & 11 & 0.5 & $1.90 \mathrm{E}-02$ & $1.40 \mathrm{E}-01$ \\
\hline KEGG_PATHWAY & Focal adhesion & RT & 88 & 2.3 & $1.30 \mathrm{E}-03$ & $1.70 \mathrm{E}-02$ \\
\hline KEGG_PATHWAY & Protein export & RT & 19 & 0.5 & $3.00 \mathrm{E}-03$ & $3.10 \mathrm{E}-02$ \\
\hline KEGG_PATHWAY & $\begin{array}{l}\text { Parkinson's } \\
\text { disease }\end{array}$ & RT & 97 & 2.1 & $1.20 \mathrm{E}-06$ & $3.30 \mathrm{E}-05$ \\
\hline KEGG_PATHWAY & $\begin{array}{l}\text { Alzheimer's } \\
\text { disease }\end{array}$ & RT & 99 & 2.3 & $3.60 \mathrm{E}-06$ & $9.40 \mathrm{E}-05$ \\
\hline KEGG_PATHWAY & $\begin{array}{l}\text { Huntington's } \\
\text { disease }\end{array}$ & RT & 101 & 2.3 & $5.30 \mathrm{E}-05$ & $1.00 \mathrm{E}-03$ \\
\hline KEGG_PATHWAY & Amoebiasis & RT & 36 & 1.5 & $5.60 \mathrm{E}-05$ & $1.00 \mathrm{E}-03$ \\
\hline KEGG_PATHWAY & $\begin{array}{l}\text { Complement } \\
\text { and coagulation } \\
\text { cascades }\end{array}$ & RT & 26 & 1.1 & $1.20 \mathrm{E}-04$ & $2.10 \mathrm{E}-03$ \\
\hline KEGG_PATHWAY & Viral myocarditis & RT & 21 & 0.9 & $9.10 \mathrm{E}-04$ & $1.30 \mathrm{E}-02$ \\
\hline KEGG_PATHWAY & $\begin{array}{l}\text { Cardiac muscle } \\
\text { contraction }\end{array}$ & RT & 25 & 1.0 & $1.30 \mathrm{E}-03$ & $1.60 \mathrm{E}-02$ \\
\hline KEGG_PATHWAY & $\begin{array}{l}\text { Staphylococcus } \\
\text { aureus infection }\end{array}$ & RT & 18 & 0.8 & $7.60 \mathrm{E}-03$ & $6.70 \mathrm{E}-02$ \\
\hline KEGG_PATHWAY & $\begin{array}{l}\text { Bacterial } \\
\text { invasion of } \\
\text { epithelial cells }\end{array}$ & RT & 38 & 1.0 & $1.10 \mathrm{E}-02$ & $9.00 \mathrm{E}-02$ \\
\hline KEGG_PATHWAY & $\begin{array}{l}\text { Vasopressin- } \\
\text { regulated water } \\
\text { reabsorption }\end{array}$ & $\mathrm{RT}$ & 15 & 0.6 & $1.30 \mathrm{E}-02$ & $1.10 \mathrm{E}-01$ \\
\hline KEGG_PATHWAY & $\begin{array}{l}\text { Arrhythmogenic } \\
\text { right ventricular } \\
\text { cardiomyopathy } \\
\text { (ARVC) }\end{array}$ & RT & 21 & 0.9 & $1.50 \mathrm{E}-02$ & $1.10 \mathrm{E}-01$ \\
\hline KEGG_PATHWAY & $\begin{array}{l}\text { Platelet } \\
\text { activation }\end{array}$ & RT & 58 & 1.3 & $3.40 \mathrm{E}-02$ & $2.00 \mathrm{E}-01$ \\
\hline
\end{tabular}


Mitochondrial Proteomic and Molecular Network Alterations in Human Ovarian Cancers DOI: http://dx.doi.org/10.5772/intechopen.86493

\begin{tabular}{lllcccc}
\hline Category & Term & RT & Count & $\%$ & P-value & Benjamini \\
\hline KEGG_PATHWAY & $\begin{array}{l}\text { Regulation } \\
\text { of actin } \\
\text { cytoskeleton }\end{array}$ & RT & 87 & 2.0 & $3.50 \mathrm{E}-02$ & $2.00 \mathrm{E}-01$ \\
\hline KEGG_PATHWAY & Legionellosis & RT & 16 & 0.7 & $3.70 \mathrm{E}-02$ & $2.10 \mathrm{E}-01$ \\
\hline KEGG_PATHWAY & Toxoplasmosis & RT & 29 & 1.2 & $4.50 \mathrm{E}-02$ & $2.30 \mathrm{E}-01$ \\
\hline KEGG_PATHWAY & $\begin{array}{l}\text { Systemic lupus } \\
\text { erythematosus }\end{array}$ & RT & 32 & 1.3 & $4.90 \mathrm{E}-02$ & $2.50 \mathrm{E}-01$ \\
\hline
\end{tabular}

Modified from Li et al. [15], with permission from Bioscientifica Ltd., copyright 2018.

Table 1.

52 statistically significant KEGG pathways enriched from 5115 proteins in ovarian cancers.

\begin{tabular}{|c|c|c|}
\hline Tern & Count & \\
\hline Ribosose & Ex: & 110 \\
\hline Metabolic pathways & E & 524 \\
\hline Carbon metabolisa & $E$ & 75 \\
\hline Biosynthesis of antibiotics & $=$ & 124 \\
\hline $\begin{array}{l}\text { Peroxisose } \\
\text { Pestes }\end{array}$ & ED & 53 \\
\hline Valine, leucine and isoleucine degradation & $E$ & 41 \\
\hline Citrate cycle (TCA cyele) & E & 19 \\
\hline Protein processing in endoplasale reticulua & E & 36 \\
\hline Oxidat ive phosphorylation & E & 94 \\
\hline Parkinson' s disease & E & 97 \\
\hline Alzheiner's disease & E & 99 \\
\hline Phazosone & E & 77 \\
\hline clyoxylate and dicarboxylate metabolisa & $E$ & 15 \\
\hline Glutathione metabolisa & E & 33 \\
\hline Hunt ington's disease & 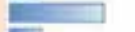 & 101 \\
\hline Amocbiasis & EI & 36 \\
\hline Complement and coagulation cascades & E & 26 \\
\hline ECM-receptor interaction & EI & 46 \\
\hline Aninoacy1-tReU biosynthesis & E & 24 \\
\hline Viral myocarditis & E. & 21 \\
\hline Biosynthesis of asino acids & $E$ & 41 \\
\hline Focal adbesion & $E$ & 88 \\
\hline Cardiac muscle contraction & E & 25 \\
\hline Propanoate metabolisa & E & 13 \\
\hline Fatty acid metabolias & E & 29 \\
\hline Prion diseases & ii & 14 \\
\hline Sulfur aetabolisa & 1 & 7 \\
\hline Protein export & [1] & 19 \\
\hline 2-0xocarboxylic acid metabolisa & 1 & 9 \\
\hline Fatty acid degradation & (4) & 27 \\
\hline Pyruvate metabolisa & [ & is \\
\hline Staphy lococcus aureus infection & [) & 18 \\
\hline Terpenoid backbone biosynthesis & [- & 10 \\
\hline Bacterial invasion of epithelial cells & $E$ & 38 \\
\hline Vasopressin-regulated water reabsorption & E & 15 \\
\hline Arrhy thaogenic right ventricular cardioayopathy (ARvC) & E & 21 \\
\hline PPAR signaling pathway & E. & 20 \\
\hline Glycolysis / Gluconeogenesis & EI & 33 \\
\hline Pentose phosphate pathray & I & 11 \\
\hline Porphyrin and chlorophy 11 metabolisa & E & 14 \\
\hline Protein digestion and absorption & [.] & 24 \\
\hline Proteasome & 드. & 30 \\
\hline beta-Alanine metabolisa & D & 11 \\
\hline Butanoate netabolisa & i & 10 \\
\hline Tryptophan metabolisa & [i & 13 \\
\hline Platelet activation & ED & 58 \\
\hline Rezulation of actin eytonkeleton & 0 & 87 \\
\hline Legionellosis & E & 16 \\
\hline Ly sosome & En & 52 \\
\hline Arginine and proline aetabolisa & E & 15 \\
\hline Toxoplasaosis & E] & 29 \\
\hline Systeaic lupus erytheaatosus & E & 32 \\
\hline
\end{tabular}

Figure 2.

52 statistically significant KEGG pathways enriched from 5115 proteins in ovarian cancers. Modified from Li et al. [15], with permission from Bioscientifica Ltd., copyright 2018.

control ovaries (Table 1 and Figure 2), including phagosome, peroxisome, valine, leucine and isoleucine degradation, lysosome, fatty acid metabolism, citrate cycle (TCA cycle), oxidative phosphorylation, glycolysis/gluconeogenesis, metabolic 


\begin{tabular}{|c|c|c|c|c|c|c|c|}
\hline $\begin{array}{l}\text { Accession } \\
\text { number }\end{array}$ & Protein name & $\begin{array}{l}\text { Gene } \\
\text { name }\end{array}$ & $\begin{array}{c}\text { Coverage } \\
(\%)\end{array}$ & $\begin{array}{l}\text { Unique } \\
\text { peptides }\end{array}$ & PSMs & $\begin{array}{l}\text { Ratio } \\
(\mathrm{T} / \mathrm{N})\end{array}$ & $\begin{array}{c}\text { t-test } \\
\text { p-value }\end{array}$ \\
\hline Q8IVP5 & $\begin{array}{l}\text { FUN14 domain- } \\
\text { containing } \\
\text { protein } 1\end{array}$ & FUNDC1 & 10.97 & 1 & 1 & 1.16 & $4.82 \mathrm{E}-2$ \\
\hline B4E164 & $\begin{array}{l}\text { cDNA } \\
\text { FLJ56613, } \\
\text { highly similar } \\
\text { to Serine/ } \\
\text { threonine- } \\
\text { protein kinase } \\
\text { TBK1 (EC } \\
\text { 2.7.11.1) }\end{array}$ & TBK1 & 2.42 & 1 & 1 & 1.25 & $1.12 \mathrm{E}-2$ \\
\hline 060313 & $\begin{array}{l}\text { Dynamin- } \\
\text { like } 120 \mathrm{kDa} \\
\text { protein, } \\
\text { mitochondrial }\end{array}$ & OPA1 & 51.15 & 44 & 130 & 1.19 & $3.72 \mathrm{E}-4$ \\
\hline Q99623 & Prohibitin-2 & PHB2 & 81.61 & 24 & 220 & 1.26 & $4.44 \mathrm{E}-4$ \\
\hline B4E3V2 & $\begin{array}{l}\text { cDNA } \\
\text { FLJ52854, } \\
\text { highly similar to } \\
\text { Sequestosome-1 }\end{array}$ & p62 & 10.47 & 1 & 1 & 1.10 & $1.96 \mathrm{E}-1$ \\
\hline H0YBC7 & $\begin{array}{l}\text { BCL2/ } \\
\text { adenovirus E1B } \\
19 \mathrm{kDa} \text { protein- } \\
\text { interacting } \\
\text { protein 3-like } \\
\text { (Fragment) }\end{array}$ & $\begin{array}{l}\text { BNIP3L } \\
\text { (NIX) }\end{array}$ & 9.19 & 1 & 2 & 0.77 & $2.31 \mathrm{E}-3$ \\
\hline A0A0S2Z5I6 & $\begin{array}{l}\text { Optineurin } \\
\text { isoform } 3\end{array}$ & OPTN & 7.94 & 2 & 2 & 0.62 & $1.01 \mathrm{E}-2$ \\
\hline E7EU96 & $\begin{array}{l}\text { Casein kinase II } \\
\text { subunit alpha }\end{array}$ & $\begin{array}{l}\text { CSNK2A1 } \\
(\mathrm{CK})\end{array}$ & 25.45 & 6 & 8 & 0.84 & $1.20 \mathrm{E}-2$ \\
\hline Q96HS1 & $\begin{array}{l}\text { Serine/ } \\
\text { threonine- } \\
\text { protein } \\
\text { phosphatase } \\
\text { PGAM5, } \\
\text { mitochondrial }\end{array}$ & PGAM5 & 32.53 & 10 & 37 & 1.49 & $3.32 \mathrm{E}-3$ \\
\hline B7Z737 & $\begin{array}{l}\text { cDNA } \\
\text { FLJ52784, } \\
\text { highly similar } \\
\text { to Bcl-2-like } 13 \\
\text { protein }\end{array}$ & Bcl2-L13 & 13.17 & 2 & 2 & 0.81 & $3.99 \mathrm{E}-2$ \\
\hline
\end{tabular}

PSMs = peptide sequence matches; $M W=$ molecular weight Ratio $(T / N)=$ ratio of tumors to normal controls. Reproduced from Li et al. [15], with permission from Bioscientifica Ltd., copyright 2018.

Table 2.

Mitophagy adaptors and regulatory molecules involved the identified proteins in ovarian cancer biological system.

pathways, carbon metabolism, glyoxylate and dicarboxylate metabolism, glutathione metabolism, propanoate metabolism, sulfur metabolism, 2-oxocarboxylic acid metabolism, pyruvate metabolism, porphyrin and chlorophyll metabolism, beta-alanine metabolism, butanoate metabolism, tryptophan metabolism, arginine and proline metabolism, ribosome, protein processing in endoplasmic reticulum, biosynthesis of amino acids, aminoacyl-tRNA biosynthesis, proteasome, protein 


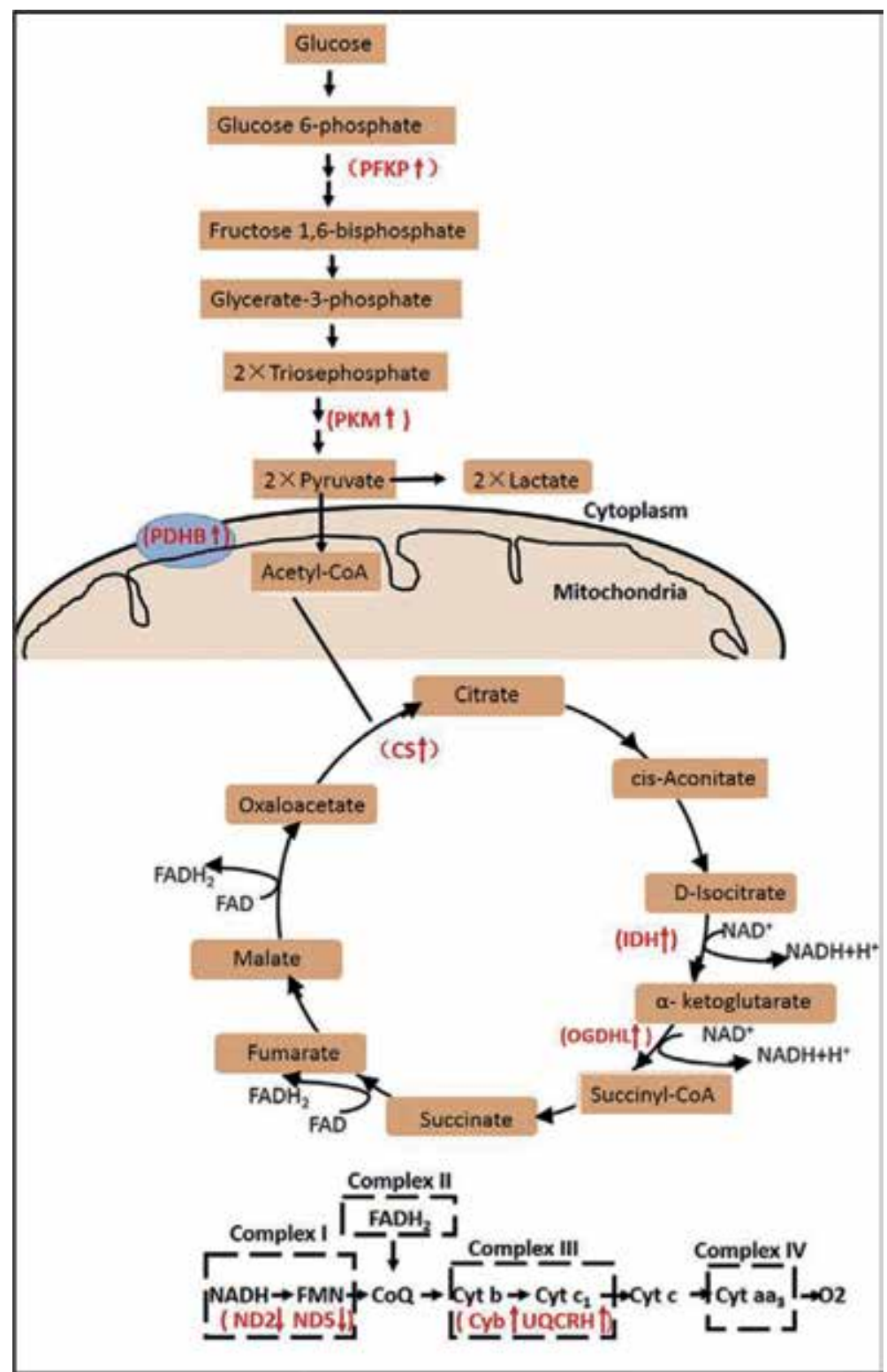

Figure 3.

Energy metabolism pathway changed in ovarian cancer. Reproduced from Li et al. [14], with permission from Elsevier Inc., copyright 2018.

digestion and absorption, ECM-receptor interaction, focal adhesion, protein export, signaling pathway, complement and coagulation cascades, platelet activation, PPAR pentose phosphate pathway, fatty acid degradation, vasopressinregulated water reabsorption, and regulation of actin cytoskeleton. Those pathway systems provided an overall molecular network changes in ovarian cancers, which might be important in ovarian cancer pathogenesis.

Among those altered pathway systems, especially interested is that mitophagy pathway and energy metabolism pathway were significantly changed in ovarian cancers compared to controls. The changed mitophagy pathway in ovarian cancer included phagosome, peroxisome, valine, leucine and isoleucine degradation, lysosome, and fatty acid metabolism pathways [15]. Mitophagy is to engulf any 


\begin{tabular}{|c|c|c|c|c|c|c|}
\hline Accession no. & Protein & $\begin{array}{l}\text { Unique } \\
\text { peptide }\end{array}$ & $\begin{array}{c}\text { Coverage } \\
(\%)\end{array}$ & PSMs & $\begin{array}{l}\text { Ratio } \\
(\mathrm{T} / \mathrm{N})\end{array}$ & $\begin{array}{l}\text { p value } \\
\text { ( } t \text { test })\end{array}$ \\
\hline Q01813 & $\begin{array}{l}\text { Phosphofructokinase, } \\
\text { platelet (PFKP) }\end{array}$ & & & & 1.90 & $2.28 \mathrm{E}-02$ \\
\hline P11177 & $\begin{array}{l}\text { Pyruvate } \\
\text { dehydrogenase E1 } \\
\text { component subunit } \\
\text { beta (PDHB) }\end{array}$ & 14 & 52.92 & 79 & 1.51 & $3.25 \mathrm{E}-03$ \\
\hline A0A024R5Z9 & $\begin{array}{l}\text { Pyruvate kinase } \\
(\mathrm{PKM})\end{array}$ & & & & 2.38 & $1.50 \mathrm{E}-04$ \\
\hline O43837 & $\begin{array}{l}\text { Isocitrate } \\
\text { dehydrogenase } \\
\text { [NAD] subunit beta } \\
\text { (IDH3B) }\end{array}$ & 13 & 41.56 & 43 & 1.75 & $8.69 \mathrm{E}-03$ \\
\hline B4DJV2 & Citrate synthase (CS) & 13 & 26.93 & 73 & 1.59 & $4.65 \mathrm{E}-03$ \\
\hline P50213 & $\begin{array}{l}\text { Isocitrate } \\
\text { dehydrogenase } \\
\text { [NAD] subunit alpha } \\
\text { (IDH3A) }\end{array}$ & 18 & 47.81 & 53 & 1.60 & $2.27 \mathrm{E}-02$ \\
\hline P48735 & $\begin{array}{l}\text { Isocitrate } \\
\text { dehydrogenase } \\
\text { [NADP] (IDH2) }\end{array}$ & 27 & 56.64 & 355 & 2.02 & $2.07 \mathrm{E}-03$ \\
\hline A0A0A0QN99 & $\begin{array}{l}\text { Cytochrome b } \\
\text { reductase } 1(\mathrm{CYB})\end{array}$ & 14 & 4.21 & 4 & 1.71 & $7.60 \mathrm{E}-03$ \\
\hline Q9ULD0 & $\begin{array}{l}\text { 2-oxoglutarate } \\
\text { dehydrogenase-like } \\
\text { (OGDHL) }\end{array}$ & 13 & 26.83 & 58 & 1.55 & $1.25 \mathrm{E}-03$ \\
\hline A0A096WB60 & $\begin{array}{l}\text { NADH-ubiquinone } \\
\text { oxidoreductase chain } \\
5 \text { (MT-ND5) }\end{array}$ & 1 & 5.14 & 6 & 0.38 & $3.34 \mathrm{E}-04$ \\
\hline P07919 & $\begin{array}{l}\text { Cytochrome b-c1 } \\
\text { complex subunit } 6 \\
\text { (QCR 6) }\end{array}$ & 5 & 51.65 & 18 & 1.59 & $1.63 \mathrm{E}-02$ \\
\hline А0A059T3A1 & $\begin{array}{l}\text { NADH-ubiquinone } \\
\text { oxidoreductase chain } \\
2 \text { (MT-ND2) }\end{array}$ & 1 & 4.61 & 2 & 0.38 & $6.03 \mathrm{E}-04$ \\
\hline P38919 & $\begin{array}{l}\text { Eukaryotic initiation } \\
\text { factor 4A-III } \\
\text { (EIF4AIII) }\end{array}$ & 4 & 11.92 & 9 & 0.71 & $1.48 \mathrm{E}-02$ \\
\hline
\end{tabular}

Modified from Li et al. [14], with permission from Elsevier Inc., copyright 2018.

Table 3.

Differentially expressed glycolysis/Kreb's cycle/mitochondrial respiratory chain/RNA binding proteins in EOC.

material in autophagosome, and subsequently fuses with lysosomes to release high-energy substance such as fatty acid and amino acid. Autophagosome also commonly contains mitochondria, proteins, or peroxisome. Mitophagy processes are involved in autophagy machinery, mitophagy adaptors, and regulatory molecules such as Bcl2-L12, p62, OPTN, prohibitin 2, OPA1, CK, PGAM5, BNIP3L(NIX), and FUNDC1 (Table 2). These findings were consistent with previous studies. The changed energy metabolism pathway in ovarian cancers included citrate cycle (TCA cycle), oxidative phosphorylation, and glycolysis (Figure 3) [14], and the important molecules were significantly changed in three energy metabolism pathways, including PFKM, PKM, PDHB, CS, and IDH2 (Table 3). It clearly demonstrated the Warburg and reverse-Warburg effects coexisted in ovarian cancers. 


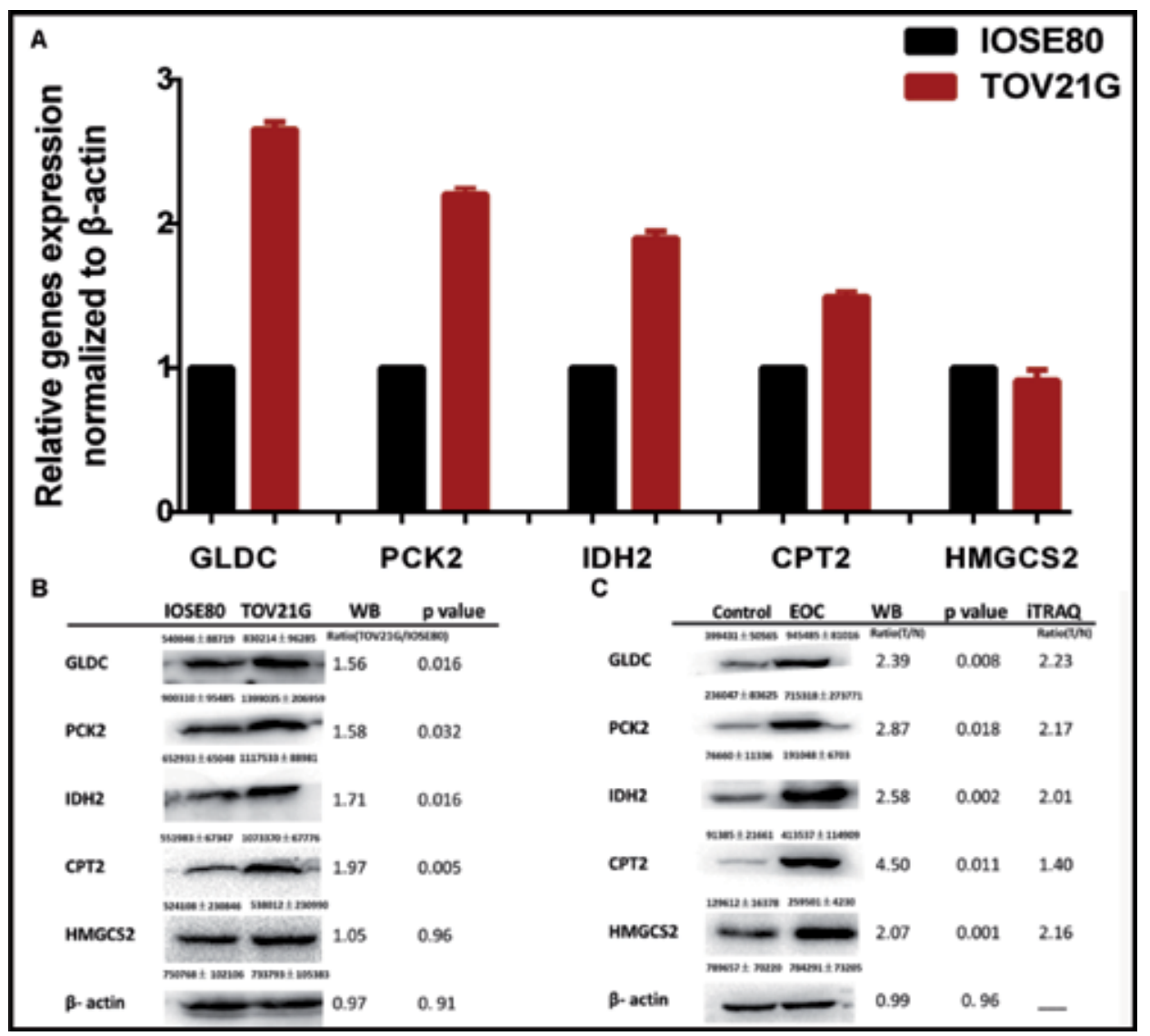

Figure 4 .

Validation of potential biomarkers (GLDC, PCK2, IDH2, CPT2 and HMGCS2) in ovarian cancer cell model with qRT-PCR $(A)$ and Western blot (B), and in human mitochondrial samples with Western blot $(C)$.

$\beta$-actin was used as internal standard. Reproduced from Li et al. [15], with permission from Bioscientifica Ltd., copyright 2018.

\subsection{Potential biomarkers for ovarian cancers}

Those 5115 mitochondrial proteins including $1198 \mathrm{mtDEPs}$ were the resource of potential biomarkers for ovarian cancers. For example, mtDEPs in mitophagy pathway and energy metabolism pathway might be effective biomarkers and therapeutic targets for ovarian cancer. Five mtDEPs, including GLDC, PCK2, and IDH2 in peroxisome pathway, CPT2 in fatty acid degradation pathway, and HMGCS2 in the valine, leucine and isoleucine degradation pathway were further validated by qRT-PCR and Western blot in ovarian cancer cells compared to normal control cells (Figure 4A and B), and by Western blot in the ovarian cancer tissue mitochondrial samples (Figure 4C). These results also confirmed the results of iTRAQ quantitative proteomics.

\section{Conclusions}

iTRAQ-labeled SCX-LC-MS/MS quantitative proteomics was an effective method to detect, identify, and quantify mitochondrial proteins and mtDEPs in mitochondrial samples prepared from human ovarian cancer and control ovary tissues. Totally 5115 mitochondrial proteins including $1198 \mathrm{mtDEPs}$ were identified in ovarian 
cancers, and 52 statistically significant pathways were identified to involve those mtDEPs. More interested is that this study found mitophagy pathway (phagosome, peroxisome, valine, leucine and isoleucine degradation, lysosome, and fatty acid metabolism), and energy metabolism pathways (citrate cycle, oxidative phosphorylation, and glycolysis) were significantly changed in ovarian cancers. The important molecules Bcl2-L12, p62, OPTN, prohibitin 2, OPA1, CK, PGAM5, BNIP3L(NIX), and FUNDC1 in mitophagy pathway, and PFKM, PKM, PDHB, CS, and IDH2 in energy metabolism pathways were significantly changed. It clearly demonstrated the changed mitophagy and energy metabolism pathways played important roles in ovarian cancers. These findings provide the large-scale proteomic variation profiles and molecular network alterations for ovarian cancer, which are the important scientific data to insight into the roles of mitochondrial dysfunction in ovarian cancer.

\section{Acknowledgements}

The authors acknowledge the financial supports from the Hunan Provincial Hundred Talent Plan (to X.Z.), National Natural Science Foundation of China (Grant no. 81572278 and 81272798 to X.Z.), China “863” Plan Project (Grant No. 2014AA020610-1 to X.Z.), the Hunan Provincial Natural Science Foundation of China (Grant No. 14JJ7008 to X.Z.), and the Xiangya Hospital Funds for Talent Introduction (to X.Z.).

\section{Conflict of interest}

We declare that we have no financial and personal relationships with other people or organizations.

\section{Author's contributions}

X.Z. conceived the concept, designed the manuscript, wrote and critically revised the manuscript, coordinated and was responsible for the correspondence work and financial support. N.L. participated in the literature analysis, data analysis, and prepared figures.

\section{Acronyms and abbreviations}

$\begin{array}{ll}\text { GO } & \text { gene ontology } \\ \text { iTRAQ } & \text { isobaric tags for relative and absolute quantification } \\ \text { KEGG } & \text { kyoto encyclopedia of genes and genomes } \\ \text { LC } & \text { liquid chromatography } \\ \text { MRPL41 } & \text { Bcl-2-interacting mitochondrial ribosomal protein L41 } \\ \text { MRPS23 } & \text { mitochondrial ribosomal protein S23 } \\ \text { MS/MS } & \text { tandem mass spectrometry } \\ \text { PSMs } & \text { peptide sequence matches } \\ \text { SCX } & \text { strong cation exchange } \\ \text { TMT } & \text { tandem mass tag } \\ \text { 2DGE } & \text { two-dimensional gel electrophoresis } \\ \text { 2D DIGE } & \text { two-dimensional difference in-gel electrophoresis } \\ \text { 2DLC } & \text { two-dimensional liquid chromatography }\end{array}$




\section{Author details}

Xianquan Zhan* and $\mathrm{Na} \mathrm{Li}$

Key Laboratory of Cancer Proteomics of Chinese Ministry of Health, Xiangya Hospital, Central South University, Changsha, China

*Address all correspondence to: yjzhan2011@gmail.com

\section{IntechOpen}

(c) 2019 The Author(s). Licensee IntechOpen. This chapter is distributed under the terms of the Creative Commons Attribution License (http://creativecommons.org/licenses/ by/3.0), which permits unrestricted use, distribution, and reproduction in any medium, provided the original work is properly cited. $(\mathrm{cc}) \mathrm{BY}$ 


\section{References}

[1] Deng P, Haynes CM. Mitochondrial dysfunction in cancer: Potential roles of ATF5 and the mitochondrial UPR. Seminars in Cancer Biology. 2017;47:43-49

[2] Georgieva E, Ivanova D, Zhelev Z, Bakalova R, Gulubova M, Aoki I. Mitochondrial dysfunction and redox imbalance as a diagnostic marker of "free radical diseases". Anticancer Research. 2017;37(10):5373-5381

[3] Kingnate C, Charoenkwan K, Kumfu S, Chattipakorn N, Chattipakorn SC. Possible roles of mitochondrial dynamics and the effects of pharmacological interventions in chemoresistant ovarian cancer. eBioMedicine. 2018;34:256-266

[4] Lim W, Ryu S, Bazer FW, Kim SM, Song G. Chrysin attenuates progression of ovarian cancer cells by regulating signaling cascades and mitochondrial dysfunction. Journal of Cellular Physiology. 2018;233(4):3129-3140

[5] Chowdhury SR, Ray U, Chatterjee BP, Roy SS. Targeted apoptosis in ovarian cancer cells through mitochondrial dysfunction in response to Sambucus nigra agglutinin. Cell Death \& Disease. 2017;8(5):e2762

[6] Salazar H, Merkow LP, Walter WS, Pardo M. Human ovarian neoplasms: Light and electron microscopic correlations. II. The clear cell tumor. Obstetrics and Gynecology. 1974;44(4):551-563

[7] Saitou M, Isonishi S, Hamada T, Kiyokawa T, Tachibana T, Ishikawa $\mathrm{H}$, et al. Mitochondrial ultrastructureassociated chemotherapy response in ovarian cancer. Oncology Reports. 2009;21(1):199-204

[8] Kim TW, Kim B, Kim JH, Kang S, Park SB, Jeong G, et al. Nuclear-encoded mitochondrial MTO1 and MRPL41 are regulated in an opposite epigenetic mode based on estrogen receptor status in breast cancer. BMC Cancer. 2013;13:502

[9] Pu M, Wang J, Huang Q, Zhao G, Xia C, Shang R, et al. High MRPS23 expression contributes to hepatocellular carcinoma proliferation and indicates poor survival outcomes. Tumor Biology. 2017;39:1393380537

[10] Sotgia F, Whitaker-Menezes D, Martinez-Outschoorn UE, Salem AF, Tsirigos A, Lamb R, et al. Mitochondria "fuel" breast cancer metabolism: Fifteen markers of mitochondrial biogenesis label epithelial cancer cells, but are excluded from adjacent stromal cells. Cell Cycle. 2012;11:4390-4401

[11] Ksiezakowska-Lakoma K, Kulczycka-Wojdala D, Kulig A, Baum M, Wilczynski JR. The presence of A5935G, G5949A, G6081A, G6267A, T9540C mutations in MT-CO1 and MT-CO3 genes and other variants of MT-CO1 and MT-CO3 gene fragments in the study population diagnosed with endometrial cancer. Ginekologia Polska. 2017;88:343-348

[12] Huhta H, Helminen O, Palomaki S, Kauppila JH, Saarnio J, Lehenkari PP, et al. Intratumoral lactate metabolism in Barrett's esophagus and adenocarcinoma. Oncotarget. 2017;8:22894-22902

[13] Michalak S, Rybacka-Mossakowska J, Gazdulska J, Golda-Gocka I, Ramlau R. The effect on cognition of mitochondrial respiratory system proteins in peripheral blood mononuclear cells in the course of lung cancer. Advances in Experimental Medicine and Biology. 2016;911:45-52

[14] Li N, Zhan X, Zhan X. The lncRNA SNHG3 regulates energy metabolism of ovarian cancer by an analysis of 
mitochondrial proteomes. Gynecologic Oncology. 2018;150:343-354

[15] Li N, Li H, Cao L, Zhan X. Quantitative analysis of the mitochondrial proteome in human ovarian carcinomas. Endocrine-Related Cancer. 2018;25:909-931

[16] Zhan X, Zhou T, Li N, Li H. The differentially mitochondrial proteomic dataset in human ovarian cancer relative to control tissues. Data in Brief. 2018;20:459-462

[17] Chen M, Huang H, He H, Ying W, Liu X, Dai Z, et al. Quantitative proteomic analysis of mitochondria from human ovarian cancer cells and their paclitaxel-resistant sublines. Cancer Science. 2015;106(8):1075-1083

[18] Chen X, Wei S, Ma Y, Lu J, Niu G, Xue Y, et al. Quantitative proteomics analysis identifies mitochondria as therapeutic targets of multidrugresistance in ovarian cancer. Theranostics. 2014;4(12):1164-1175

[19] Chappell NP, Teng PN, Hood BL, Wang G, Darcy KM, Hamilton CA, et al. Mitochondrial proteomic analysis of cisplatin resistance in ovarian cancer. Journal of Proteome Research. 2012;11(9):4605-4614

[20] Dai Z, Yin J, He H, Li W, Hou C, Qian X, et al. Mitochondrial comparative proteomics of human ovarian cancer cells and their platinumresistant sublines. Proteomics.

2010;10(21):3789-3799

[21] Tian Y, Tan AC, Sun X, Olson MT, Xie Z, Jinawath N, et al. Quantitative proteomic analysis of ovarian cancer cells identified mitochondrial proteins associated with paclitaxel resistance. Proteomics. Clinical Applications. 2009;3(11):1288-1295

[22] Young TW, Mei FC, Yang G, Thompson-Lanza JA, Liu J, Cheng X. Activation of antioxidant pathways in ras-mediated oncogenic transformation of human surface ovarian epithelial cells revealed by functional proteomics and mass spectrometry. Cancer Research. 2004;64(13):4577-4584

[23] Cheng T, Zhan X. Pattern recognition for predictive, preventive, and personalized medicine in cancer. The EPMA Journal. 2017;8:51-60

[24] Zhan X, Long Y, Zhan X, Mu Y. Consideration of statistical vs. biological significances for omics data-based pathway network analysis. Med One. 2017;2:e170002

[25] Hu R, Wang X, Zhan X. Multiparameter systematic strategies for predictive, preventive and personalised medicine in cancer. The EPMA Journal. 2013;4:2

[26] Gonzalez-Angulo AM, Iwamoto T, Liu S, Chen H, Do KA, Hortobagyi GN, et al. Gene expression, molecular class changes, and pathway analysis after neoadjuvant systemic therapy for breast cancer. Clinical Cancer Research. 2012;18:1109-1119

[27] Lu M, Zhan X. The crucial role of multiomic approach in cancer research and clinically relevant outcomes. The EPMA Journal. 2018;9(1):77-102

[28] Wang X, Guo T, Peng F, Long $\mathrm{Y}, \mathrm{Mu} \mathrm{Y}$, Yang $\mathrm{H}$, et al. Proteomic and functional profiles of a folliclestimulating hormone positive human nonfunctional pituitary adenoma. Electrophoresis. 2015;36:1289-1304

[29] Zhan X, Wang X, Long Y, Desiderio DM. Heterogeneity analysis of the proteomes in clinically nonfunctional pituitary adenomas. BMC Medical Genomics. 2014;7:69

[30] Liu J, Zhan X, Li M, Li G, Zhang P, Xiao Z, et al. Mitochondrial proteomics of nasopharyngeal carcinoma metastasis. BMC Medical Genomics. 2012;5:62 
[31] Karabudak AA, Hafner J, Shetty V, Chen S, Secord AA, Morse MA, et al. Autoantibody biomarkers identified by proteomics methods distinguish ovarian cancer from non-ovarian cancer with various CA-125 levels. Journal of Cancer Research and Clinical Oncology. 2013;139:1757-1770

[32] Nie S, Lo A, Zhu J, Wu J, Ruffin MT, Lubman DM. Isobaric proteinlevel labeling strategy for serum glycoprotein quantification analysis by liquid chromatography-tandem mass spectrometry. Analytical Chemistry. 2013;85:5353-5357

[33] Wang Z, Liu F, Ye S, Jiang P, Yu X, $\mathrm{Xu}$ J, et al. Plasma proteome profiling of high-altitude polycythemia using TMTbased quantitative proteomics approach. Journal of Proteomics. 2019;194:60-69

[34] Russell JD, Scalf M, Book AJ, Ladror DT, Vierstra RD, Smith LM, et al. Characterization and quantification of intact $26 \mathrm{~S}$ proteasome proteins by real-time measurement of intrinsic fluorescence prior to top-down mass spectrometry. PLoS ONE. 2013;8:e58157

[35] Merl J, Deeg CA, Swadzba ME, Ueffing M, Hauck SM. Identification of autoantigens in body fluids by combining pull-downs and organic precipitations of intact immune complexes with quantitative label-free mass spectrometry. Journal of Proteome Research. 2013;12:5656-5665

[36] Zhan X, Yang H, Peng F, Li J, Mu Y, Long $Y$, et al. How many proteins can be identified in a 2DE gel spot within an analysis of a complex human cancer tissue proteome? Electrophoresis. 2018;39(7):965-980

[37] Zhan X, Li N, Zhan X, Qian S. Revival of 2DE-LC/MS in proteomics and its potential for large-scale study of human proteoforms. Med One. 2018;3(5):e180008
[38] Zhan X, Long Y, Lu M. Exploration of variations in proteome and metabolome for predictive diagnostics and personalized treatment algorithms: Innovative approach and examples for potential clinical application. Journal of Proteomics. 2018;188:30-40

[39] Torre LA, Trabert B, DeSantis CE, Miller KD, Samimi G, Runowicz CD, et al. Ovarian cancer statistics 2018. CA: A Cancer Journal for Clinicians. 2018;68(4):284-296

[40] Pinsky PF, Miller EA, Zhu CS, Prorok PC. Overall mortality in men and women in the randomized prostate, lung, colorectal, and ovarian cancer screening trial. Journal of Medical Screening. 2019;2019:969141319839097 


\title{
Mitochondrial Dysfunction as a Key Event during Aging: From Synaptic Failure to Memory Loss
}

\author{
Claudia Jara, Angie K. Torres, Margrethe A. Olesen \\ and Cheril Tapia-Rojas
}

\begin{abstract}
Mitochondria are important cellular organelles with key regulatory functions in energy production, oxidative balance, and calcium homeostasis. This is especially important in the brain, since neurons require a large number of functional mitochondria to supply their high energy requirement, mainly for synaptic processes. A decrease in the activity and quality of mitochondria in the brain, particularly in the hippocampus, is associated with normal aging and a large number of neurodegenerative diseases compromising memory function. Although synaptic and cognitive dysfunction is multifactorial, growing evidence demonstrates that mitochondria play a key role in these processes and suggests that maintaining mitochondrial function could prevent these age-dependent alterations. In this chapter, we will discuss the hippocampal mitochondrial dysfunction present in aging and how these defects promote age-associated synaptic damage and cognitive impairment. We will summarize evidence that shows how neurodegeneration can be accelerated or attenuated during aging by modulating mitochondrial function.
\end{abstract}

Keywords: aging, mitochondria, oxidative stress, synapses, memory

\section{Introduction}

Aging is an extensively studied process, identifying a growing interest in how and why cognitive processes are affected from a neurobiological approach [1]. Aging is a multifactorial biological process, characterized by deterioration of physiological and cellular functions including brain function [2], where age is the main risk factor for the development of pathologies such as cancer, diabetes, cardiovascular disorders, and neurodegenerative diseases [3]. Cognitive deterioration occurs during aging, where reasoning, attention, and memory, among other processes, decrease gradually with the age [4]. Cellular senescence and alterations to mitochondria and in proteolytic systems are considered hallmarks of aging [3], where one of the most studied is the mitochondria [5]. In fact, mitochondrial dysfunction has been directly associated with the aging phenotype and the majority of diseases that lead to cognitive damage.

Over the last decades, a great interest has arisen regarding mitochondrial structure and function due to its relation with the aging brain [5]. Mitochondria are organelles essential for energy production, whose size is usually $0.5-1 \mu \mathrm{m}$, composed 
by two membranes, forming the intermembranous space and the mitochondrial matrix [6]. The outer membrane contains many copies of the transport protein porin (or voltage-dependent anion-selective channels (VDAC)), which allows the passage of molecules with a maximum weight of $5 \mathrm{KDalton}(\mathrm{KDa})$, and the inner membrane forms numerous invaginations, tubular structures, called cristae [6]. Mitochondria are capable of remodeling their architecture through fission and fusion processes, allowing morphological adaptation to different situations [6]. Fission is essential for mitochondrial duplication and is necessary for mitophagy, allowing dysfunctional mitochondrial sections to be recycled. Fusion allows mitochondria to interconnect, allowing damaged mitochondria to maintain their function. However, fission-fusion processes are interrupted during aging, generating damaged mitochondria [7].

Mitochondria have a small circular genome called mtDNA, which encodes 22 tRNAs, 2 mitochondrial rRNAs, and 13 subunits of the electron transport chain (ETC) [8]. mtDNA can be damaged by exposure to reactive oxygen species (ROS), chemical carcinogens, and ionizing radiation affecting the mitochondrial function; changes are also observed during aging [9]. The internal mitochondrial membrane contains the ETC, responsible for generating ATP. ETC is formed by five protein complexes; complex I (NADH dehydrogenase) receives electrons of NADH which pass through the ETC via oxidation-reduction reactions forming an electrochemical gradient that allows the formation of ATP. In addition, $\mathrm{FADH}_{2}$ donates its electrons to complex II (succinate dehydrogenase) performing the same action for ATP generation but at lower production levels [10]. As a secondary product, the ETC forms ROS, specifically by complexes I and III, but its production is controlled by antioxidant enzymes [11]. Therefore, in normal conditions ROS production is moderate, providing certain physiological roles [11]; however, during aging ROS accumulation causes biological damage known as "oxidative stress" [12].

In the past, mitochondria have always been highlighted for its role in ATP production; however, another key function is to maintain intracellular calcium homeostasis [13]. The outer mitochondrial membrane is permeable to ions and $\sim 5 \mathrm{KDa}$ metabolites because its lipid bilayer has transmembrane proteins that form the mitochondrial permeability transition pore (mPTP). mPTP opening and closing dynamics regulates the concentration of calcium [13]. However, in conditions of high calcium concentrations, permanent mPTP opening generates massive transport of ions and small molecules $<1.5 \mathrm{KDa}$ through the membrane, causing increased ROS production, inhibition of the ETC, and mitochondrial swelling, which finally results in the release of pro-apoptotic factors and cell death [14].

In this chapter we will discuss the mitochondrial alterations observed in the brain during aging, focusing on mitochondrial functions including redox balance, bioenergetics, and calcium homeostasis, and its implications in the aging process. In addition, we will discuss the contribution of mitochondrial dysfunction to synaptic failure and cognitive impairment. Finally, we will summarize potential treatments that have been proposed to prevent or attenuate the loss of mitochondrial function that could be used as potential antiaging treatment.

\section{Oxidative stress: the main characteristic of normal aging}

Aging is a complex process that involves both intrinsic and extrinsic factors [3]. Several researches showed that the reduction of synaptic function during aging could be related to increased oxidative stress and mitochondrial dysfunction $[15,16]$. The latter involves decreased production of energy and redox balance, activation of nitric oxide synthase, and an abundant generation of free radicals; meanwhile increased ROS production impairs neuronal function at advanced ages [17]. 
Mitochondria have a pivotal role in ROS production; they are the main organelle producer of species such as hydrogen peroxide $\left(\mathrm{H}_{2} \mathrm{O}_{2}\right)$, superoxide anion $\left(\mathrm{O}^{2-}\right)$, and hydroxyl radicals $\left(\mathrm{OH}^{-}\right)$[18]. ROS comprise all molecules derived from oxygen, can exist independently, and contain one or more unpaired electrons in their orbitals [19]. Normally, mitochondria generate ROS as a result of adequate function of the ETC by complexes I and III in OXPHOS to produce ATP. Likewise, electrons that escape mitochondrial ETC can reduce oxygen to form $\mathrm{O}^{2-}$ [20]. Additionally, $\mathrm{H}_{2} \mathrm{O}_{2}$ is more stable than $\mathrm{O}^{2-}$ and can diffuse freely through the membranes to the cytosol or nucleus, causing oxidative damage to many cellular compartments [21].

The mitochondrial ROS produced in normal conditions have important physiological roles in maintaining cell homeostasis, participate as signaling molecules, and are also related to the regulation of cell survival [22]. In contrast, excessive ROS production promotes cellular damage [23]. For example, recent evidence suggests that higher mitochondrion-derived ROS result in enhanced formation of $A \beta$, an effect that is prevented with the use of antioxidants that rescue mitochondrial function in cellular and animal models of Alzheimer's disease (AD) [24]. This suggests that higher ROS generation mediated by mitochondria is involved in early stages of age-associated diseases and during aging [25].

Cells maintain a balance between free radicals by the action of antioxidants molecules, which neutralize or remove them [22]. Cells are equipped with a variety of defense mechanisms to remove ROS, including antioxidant enzymes that facilitate antioxidant reactions and decompose ROS [26]. Among the antioxidant enzymes are glutathione reductase (GR), glutathione peroxidase (GPx), and catalase (CAT). In addition, superoxide dismutases (SODs), such as copper-zinc-superoxide dismutase (CuZnSOD) and manganese superoxide dismutase (MnSOD), help the dismutation of superoxide radicals to generate $\mathrm{H} 2 \mathrm{O} 2$, which is further removed by CAT and GPx enzymes [26]. Altogether, these antioxidant defenses regulate the amount of ROS, preventing accumulation and oxidative stress [27].

Oxidative stress occurs when the antioxidant defense mechanisms are unable to neutralize free radicals in the cell. This imbalance between the production of oxidative molecules and the antioxidant defense leads to an accumulation of ROS, which oxidize and produce damage to lipids, proteins, and DNA molecules. Similarly, ROS could alter many cell compartments, for example, promoting peroxidation of lipid membranes and inactivation of enzymes by oxidation [28].

In oxidative stress conditions, the concentration of ROS increases transiently or chronically, altering the cellular metabolism and its regulation [23]. Interestingly, these elements are implicated in the aging process, the mitochondrial free radical theory of aging (MFRTA) being the most accepted theory to explain the age-associated degeneration [29]. This theory exposed by Harman proposes that mitochondria play a central role in aging and indicates that aging is the product of accumulated damage caused by mitochondrial ROS in the cells and tissues of organisms [30,31]. Nevertheless, this theory has also been questioned, since aging is a multifactorial biological process and not just the consequence of a unique factor [32]. Thus, the mitochondrial theory of aging is relevant since these organelles are energy sources for cells and coordinate important processes such as apoptosis. During aging, accumulation of mtDNA mutations is increased, the mitochondrial genes related to energy production become progressively less active, and the mitochondria are observed as fragmented, producing less energy [33]. The brain is particularly susceptible to oxidative damage being the most aerobically active organ in the body due to its high metabolism [34]. The brain is generally in a redox balance; however, the high production and accumulation of ROS accompanied by a reduction in the antioxidant defense system plays a key role in aging, causing damaging effects due to the large number of potential harmful intermediates that cause neuronal 
dysfunction $[3,35]$. In turn, increased oxygen radical-induced oxidative damage during aging leads to significant changes in brain mitochondrial function [29]. Therefore, oxidative stress is implicated in aging and a wide range of age-related pathologies, such as AD and Parkinson's disease (PD), among others [3, 16, 36].

In the aged brain, a reduction in normal antioxidant defense machineries is observed, which increases the brain's susceptibility to the harmful effects of oxidative molecules [27, 37]. In addition to this, mitochondrial dysfunction contributes to ROS overproduction. It is important to emphasize that a decrease in the activity of oxidative enzymes accompanied by excessive production of oxidant molecules during aging is the main toxic mechanism that explains the neurodegeneration observed at an advanced age $[27,37]$. Since mitochondria are the main source of ROS production, they are in turn more exposed to oxidative damage at a faster and stronger rate than other organelles and cell compartments [16]. Moreover, the mitochondrial antioxidant system is less active than the antioxidant systems of other organelles, a feature that increases with age [5]. These mitochondrial "defects" can greatly affect several cellular processes that contribute to the aging phenotype [38]. Therefore, age is an important risk factor that increases the susceptibility of mitochondria, making them more vulnerable to oxidative stress, resulting in a vicious cycle of mitochondrial dysfunction and more oxidative damage [5, 33]. Mitochondria should be considered as a key factor in the development of agerelated neurodegeneration, and therefore therapeutic strategies such as mitochondrial protectors or antioxidants that improve mitochondrial function could be used to prevent or delay aging.

\section{Bioenergetic failure during aging}

One of the main functions of mitochondria is energy production in the form of ATP through OXPHOS [39]. The main substrate of neurons is glucose. Through the glycolytic pathway, the cell generates only two ATP molecules per glucose molecule; however in this pathway two pyruvate molecules are produced. These molecules then enter the mitochondria to be oxidized in the tricarboxylic acid (TCA) cycle producing $\mathrm{NADH}$ and $\mathrm{FADH}_{2}$, which in turn enter the ETC to produce high amounts of ATP by OXPHOS [40]. Electrons from NADH and $\mathrm{FADH}_{2}$ are transferred through four complexes to molecular oxygen, pumping protons to the intermembrane space, which form a proton gradient that generates the mitochondrial membrane potential $(\Delta \psi \mathrm{m})$. This $\Delta \psi \mathrm{m}$ is fundamental for adequate mitochondrial function, mainly for ATP synthesis by the ATPase complex [39].

Due to the importance of mitochondrial energy production, failures in mitochondrial bioenergetics are related to several neurological diseases such as amyotrophic lateral sclerosis (ALS) [41] and several age-associated neurodegenerative disorders such as $\mathrm{AD}$ [42]. A mitochondrial failure can be caused by either a dysfunction in the OXPHOS complexes or by mutations in the mtDNA, which encodes for 13 proteins that makes the different subunits of the ETC complexes. Interestingly, mtDNA mutations produce a group of pathologies known as primary mitochondrial disorders, characterized by neurological alterations. Thus, neurodegeneration is often related to mitochondrial dysfunction as a primary or secondary target, mediating the pathogenic events [43]. Since the main energy source in brain cells is glucose oxidation, the energy obtained from the mitochondrial OXPHOS system is vital to fulfilling their high basal energy requirement, including maintenance of the membrane potential for the propagation of electric signals, reestablishment of the ion balance after the action potential $(\mathrm{Na}+/ \mathrm{K}+$ ATPase activity), vesicle recycling, and neurotransmitter release [44]. 
Therefore, a deficit in ATP production can lead to neuronal damage and finally cell death, producing diverse defects in brain functions as occurs during normal aging, considered an important risk to the development of neurodegenerative disease [45]. An example of this is the glutamate-glutamine cycle, an essential process for the release of glutamate from the presynaptic terminal. Glutamate uptake occurs in astrocytes, where it is converted to glutamine and then transferred back to glutamatergic neurons. For these processes to occur, the neuron requires ATP [46], as well as for the accumulation of glutamate in synaptic vesicles [47]. Therefore lower ATP levels will result in reduced glutamate release leading to decreased excitatory synapsis and consequently decreased synaptic plasticity as a result of altered longterm potentiation (LTP) and long-term depression (LTD) [48].

In addition, $\mathrm{AD}$ is a neurodegenerative pathology where mitochondrial deficiency is observed in oxidative phosphorylation, with defective OXPHOS enzymes [49]. Several studies showed decreased cytochrome c oxidase activity but an increase in mitochondrial mRNA for complex IV, which may be a compensatory response for the reduced cytochrome c oxidase activity $[50,51]$. Also, there is a decrease in NADH dehydrogenase expression and an increase in complex III mRNA in AD patients [51]. These defects in the OXPHOS complex impede correct ATP production and increase ROS production [52], which could generate damage to mitochondrial proteins, activate the $\mathrm{mPTP}$, and mutagenize the mtDNA, leading to defective OXPHOS. All these mitochondrial defects can ultimately contribute to the characteristic synapse loss in the neocortex and hippocampus of AD patients [53], which correlates with cognitive impairment and memory loss. Similarly, critical mitochondrial dysfunction has been associated with PD. Several mutations in proteins that can directly or indirectly regulate mitochondrial activity and morphology have been described. Examples of this are PTEN-induced kinase 1 (PINK1) which induced mitochondrial autophagy during stress [54] and protein deglycase (DJ-1) which is a multifunctional protein that reacts against anti-oxidative stress [55]. These two proteins are localized in the mitochondria, while parkin, another protein that degrades dysfunctional mitochondria, translocates to damaged mitochondria [54]. The first evidence that mitochondria could be related to PD was published by Langston et al. in 1983 where they showed that the mitochondrial complex I inhibitor, 1-methyl-4-phenyl-1,2,3,6-tetrahydropyridine (MPTP) can cause acute and irreversible parkinsonian symptoms in humans [56]. Later, other mitochondrial toxins such as rotenone, which induces similar symptoms to MPTP, were described, leading to the development of a rotenone rodent model of Parkinson's disease [57]. Other studies of postmortem tissue from PD patients showed defects in complex I, NADH dehydrogenase in the substantia nigra [58].

Interestingly, similar bioenergetic deficits present in neurodegenerative disease are also seen in normal aging. In this natural process, it is well known that a large number of mutations accumulate in the mtDNA in different tissues, such as the brain and the muscle, the tissues with most accumulation of mutations, possibly due to the higher energetic demand [59]. For example, in a study performed with humans between 49 and 92 years old, they showed an increase by $25 \%$ in the muscle fibers that exhibit abnormalities in mitochondrial ETC in 92-year-old individuals compared to 49 year olds [60]. Another study showed that a mouse with a deficiency for mitochondrial DNA polymerase $\gamma$ (POLG) had an impaired proofreading ability, accumulated mtDNA mutations, and presented a premature-aged phenotype (hair loss, graying, kyphosis, reduced survival percentage, loss of bone mass, etc.) at the age of 9 months [61]. These mutations can lead to mitochondrial dysfunction associated with a deficient respiratory chain and a decrease in ATP production [62]. There is evidence that the brain of aged mice (26 months old) contains mutations in protein-coding regions that result in significant changes 
in the complex I subunit ND5 and complex III subunit CytB [62]. These mutations may limit correct assembly of these complexes, which correlates with their decreased activity during aging [62]. Other studies also showed downregulation of several genes coding for mitochondrial proteins in heart tissue, which correlated with a significant decrease in the respiratory capacity of mitochondria to oxidize substrates [63]. In liver tissue, there is a decrease in the respiratory control ratio and in ADP/oxygen (an index of ATP synthesis efficiency) in senescence-accelerated mice (SAMP8) mitochondria [64], suggesting that at 18 months of age, there is insufficient ATP for normal cell metabolism, which may be due to a dysfunctional energy transfer mechanism.

In the brain, it is widely known that with aging there is a decrease in the electron transfer activity accompanied by a decrease mainly in complexes I and IV $[65,66]$. Several studies showed that complex IV activity is decreased in substantia nigra, hippocampal dentate gyrus, frontal cortex, and cerebellum during aging $[67,68]$. A study performed with aged CD1 Swiss mice showed that NADH-cytochrome c reductase (complexes I and III) activity is the most affected during aging, decreasing by $48 \%$ in old mice (18 months), while succinate-cytochrome c reductase activity (complexes II and III) remain unmodified with age, indicating selective impairment of NADH dehydrogenase activity (complex I) during normal aging [69]. Likewise, cytochrome oxidase (complex IV) activity is decreased by $13 \%$ in old animals [69]. Additionally, there is evidence of increased expression of mitochondrial genes for complexes I, III, IV, and V in 18-month-old mice in the hippocampus, medial prefrontal cortex, and striatum [70], suggesting a compensatory mechanism that could induce overproduction of ETC proteins. However, this increased mRNA expression is not sustained over time, since 24-month-old mice have decreased expression of ETC complexes [70].

Another parameter that is altered during aging is the $\Delta \psi \mathrm{m}$ due to increased $\mathrm{H}^{+}$ permeability of the inner mitochondrial membrane and a consequent failure in maintaining the $\mathrm{H}+$ electrochemical gradient [71]. There is evidence that there is a decrease in the membrane potential in the cortical and striatal mitochondria of 33-month-old rats [72]. In the same way, a study in primary cultures of glial cells from the brain of young (4-6 months) and old (26-29 months) mice shows a decay in the $\Delta \psi \mathrm{m}$ in astrocytes [73].

Thus, mitochondrial bioenergetic failure is a hallmark of different diseases including neurodegenerative disorders. Interestingly, these same patterns of decreased ATP production, OXPHOS failure, and depolarization of the mitochondrial membrane are seen during aging, a natural process of everybody's life. This makes the mitochondria an important player in all neurological degeneration related with aging, such as synaptic failure and cognitive impairment.

\section{Age-associated calcium dysregulation}

Calcium $\left(\mathrm{Ca}^{+2}\right)$ is an ion that participates in a wide variety of functions in the cells of organisms, being an intracellular regulator of many physiological processes [74]. Intracellular calcium signals participate in the regulation of a large number of processes, which include gene expression, cell cycle stages, control of muscle contraction, autophagy, and cell death, among other functions, being a second intracellular messenger [74, 75].

In the central nervous system (CNS), $\mathrm{Ca}^{+2}$ plays a very important role in the neuronal synapse, mainly promoting exocytosis of the synaptic vesicles in the presynaptic region, meanwhile in the postsynaptic site is important for regulating the morphology of dendritic spines and spinogenesis [76, 77]. Calcium homeostasis 
is fundamental for correct cellular function, and the mitochondria are structures important for maintaining the intracellular calcium concentrations [78]. They participate in the local regulation of cellular $\mathrm{Ca}^{+2}$ homeostasis, since it captures $\mathrm{Ca}^{+2}$ from the cytosol in response to ion fluxes through channels in both the inner and outer plasma membranes or by release of $\mathrm{Ca}^{+2}$ from the endoplasmic reticulum (ER) [79]. Thus, when the cytosolic concentration of calcium increases, mitochondria capture and accumulate large amounts of the ion in order to control intracellular concentrations. Therefore, for appropriate neuronal functioning, adequate parameters of intracellular calcium concentrations must be maintained [80]. Interestingly, aged brain neurons are incapable of regulating intracellular calcium, mainly due to dysfunctional mitochondria and increased oxidative stress $[78,81]$.

Mitochondrial dysfunction substantially contributes to biological aging [78]. In aging, oxidative stress affects mitochondrial function and, therefore, its role in $\mathrm{Ca}^{+2}$ homeostasis $[78,82]$. When calcium homeostasis is altered, it has a detrimental role on the aging brain and is also associated with the development of neurodegenerative diseases [83]. Several studies showed that an increase of the $\mathrm{Ca}^{+2}$ affects synaptic communication, neurotransmitter release, and signal transduction, all this generating excitotoxicity and neuronal loss [84]. In addition, these alterations could also contribute to memory impairment $[16,84]$.

In this way, since the aging is associated with a marked cognitive decline, the calcium imbalance hypothesis proposed by Khachaturian turns out to be well accepted $[85,86]$. This hypothesis proposes that changes in calcium regulation gradually modulate normal brain aging and, at the same time, increase their vulnerability to neurodegenerative diseases such as AD [87]. Calcium signaling depends of the transient elevation of its intracellular concentration. In brain cells, reduced regulation of calcium homeostasis is an early event during aging, altering multiple signaling pathways and affecting various molecular and cellular functions [88].

Due to their high buffering capacity, mitochondria are an essential component for maintaining calcium homeostasis, due to their involvement in the regulation of intracellular calcium signaling [89]. Also, other mitochondrial characteristics that facilitate its role in the regulation of calcium signaling is its structural plasticity produced by fusion and fission processes in the mitochondrial network, as well as its distribution within the neuron [90]. Aging affects mitochondrial dynamics leading to mitochondrial fragmentation and alterations to these functions [90]. Studies in mitochondria isolated from the cortex of aged animals exhibited more ROS production and mitochondrial swelling after increased $\mathrm{Ca}^{+2}$ loading than that of young animals [78]. Therefore, these findings suggest that the aging increased the sensitivity of the mitochondria to calcium overload, generating mitochondrial swelling [81]. Mitochondrial swelling results in the opening of the mPTP [91], and in aged animals, mPTP opening occurs prematurely, indicating reduced $\mathrm{Ca}^{+2}$ buffering during aging $[78,81]$.

The MPTP is a large nonselective channel located in the inner mitochondrial membrane and communicates the mitochondrial matrix directly with the cytoplasm [81]. Their opening is activated by $\mathrm{Ca}^{+2}$, phosphate, ROS, increased $\mathrm{pH}$, and magnesium $\left(\mathrm{Mg}^{+2}\right)$ [92]. Transitory opening of $\mathrm{mPTP}$ allows the release of excessive calcium ions that accumulate in the mitochondria, but prolonged opening leads to the movement of ions and small molecules generating depolarization of the mitochondrial membrane and in turn releasing pro-apoptotic factors, which results in a reduction of ATP and finally causes cell death $[81,91]$.

The structure of mPTP is not completely clear. Experimental approaches have distinguished several protein components such as VDAC, the adenine nucleotide translocase protein (ANT), and the mitochondrial matrix protein cyclophilin D (Cyp-D) [91]. Recent research incorporates the F1FO subunits of ATP synthase, a 
key enzyme of the OXPHOS complex, which participates in ATP production and maintenance of the membrane potential [91]. Interestingly, deregulation of this enzyme associated with aging has been reported, showing decreased expression of OSCP and in F1FO ATP synthase activity $[81,91]$. These changes have also been observed in imaged brains that present age-related neurodegenerative pathologies $[81,91]$. Cyp-D is a specific mitochondrial protein and generally considered to be a critical component of mPTP formation [91]. Several studies indicate that Cyp-D is the most important component facilitating $\mathrm{MPTP}$ formation, thus leading to decreased ATP production, increasing ROS generation, and eventually causing cell death $[81,91]$, although it is not yet completely clear how Cyp-D triggers mPTP formation [92]. The opening of mPTP dissipates $\Delta \psi \mathrm{m}$, uncoupling the mitochondria and causing swelling [91]. The expression of Cyp-D increases with age and is related to several age-associated neurological diseases such as AD [91, 93]. For example, Gauba et al. have reported that Cyp-D promotes the dysfunction of ATP synthase F1FO, in the mitochondria of aged brains, observing a significant increase in the expression of this protein with age [91]. In contrast, it has been observed that deletion of Cyp-D improves cognitive and mitochondrial functions in both aging and in neurodegenerative diseases $[91,93]$.
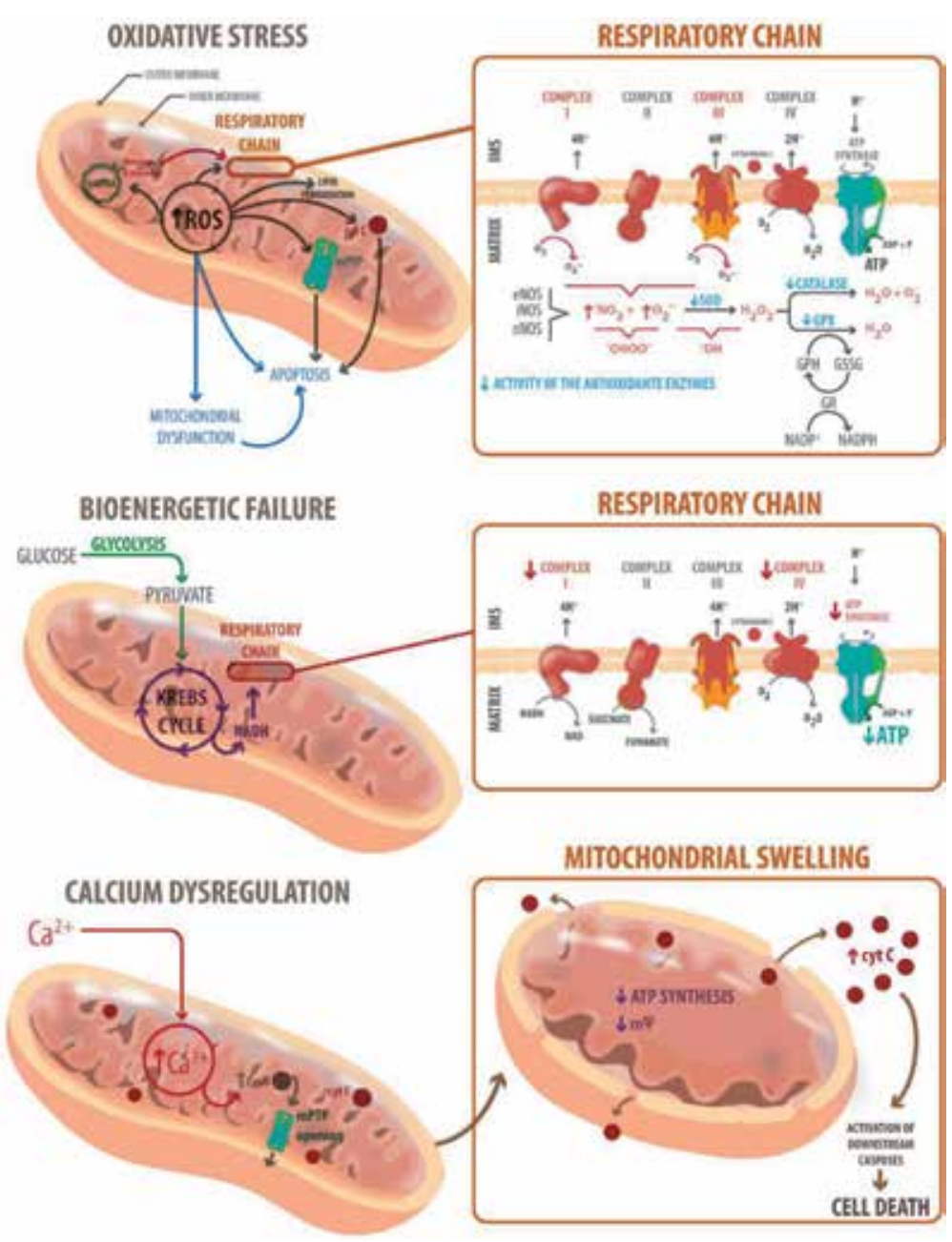

Figure 1.

The mitochondrial functions are impaired during aging. 
The increased life expectancy and the high incidence of neurodegenerative diseases require a better understanding of the aging processes and the mechanisms associated with it. Thus, comprehension of the interactions between calcium homeostasis and calcium-dependent processes during aging can help in the design of more effective therapeutic strategies. Maintaining calcium homeostasis and controlling the opening of mPTP are important factors that can be considered as a potential therapeutic objective to maintain the quality of life during aging and prevent mitochondrial damage and progressive cognitive deterioration associated with age that contribute to the development of neurodegenerative diseases.

Figure 1 is a schematic representation of the main mitochondrial functions affected during normal aging. It shows increased oxidative stress as a result of a REDOX imbalance due to decreased activity of antioxidant enzymes and increased reactive oxygen species. It also shows the characteristic bioenergetics failure, as a consequence of diminished OXPHOS functioning, specifically by decreased activity of complexes I and IV of the ETC, which lead to reduced ATP production and, finally, calcium dysregulation, which leads to mitochondrial swelling due to a permanent opening of the mitochondrial permeability transition pore.

\section{Mitochondrial dysfunction and cognitive impairment}

Synaptic plasticity in the adult nervous system is a response to changes in the environment and synaptic activity, involving dendritic spine growth or retraction and synaptogenesis, which are believed to be responsible for learning and memory [94]. In the hippocampus, one form of synapse plasticity is LTP, which produces a stronger transmission for consolidation of long-term memory [95]. For this process, neurons need to synthesize proteins de novo at the dendritic spines where different neurotrophic factors play a key role [96]. An impairment in this process leads to neurodegeneration, as a result of the initial loss of synaptic structure and function and finally cell death [96].

The previously described mitochondrial dysfunction could be an important factor in synapse loss associated with cognitive decline observed during aging and in neurodegenerative disease [97]. Since mitochondria are present in axonal terminals and dendrite spines playing a critical role in calcium flux, ROS homeostasis, and ATP production in the synapses, this organelle is a key element for neuronal plasticity [94]. In addition, mitochondrial transport to the synaptic regions is essential for the correct function of this neuronal network [98].

Multiple pathological conditions present cognitive impairment related with a mitochondrial dysfunction. For example, chronic kidney disease (CKD) patients with cognitive damage have increased oxidative stress and decreased antioxidant enzymes (SOD, CAT, GPx, and GSH levels in plasma) compared to CKD patients without cognitive impairment [99]. Also, patients with hypoxia, ischemia induced by a traumatic brain injury (TBI), and diabetes showed cognitive decline and different signs of mitochondrial impairment such as glutamate excitotoxicity, calcium overload, opening of mPTP (which dissipates the mitochondrial electrochemical gradient leading to cell death), and increased ROS levels [100-102]. Interestingly, pyramidal neurons in the cerebral cortex and hippocampus are more susceptible to this type of injury [103], suggesting that these cellular defects may affect mainly synaptic plasticity, learning, and memory.

In the context of neurodegenerative disease, mitochondrial impairment and oxidative stress are the target of $A \beta$ neurotoxicity, promoting cognitive impairment in $\mathrm{AD}$ [104]. The degree of cognitive impairment in $\mathrm{AD}$ has been related to the amount of $A \beta$ accumulated in mitochondria [105], resulting in a loss of the $\Delta \psi \mathrm{m}$ in 
synaptic regions and ultimately leading to the characteristic synaptic loss observed in $\mathrm{AD}$ [106]. It has been suggest that Cyp-D can interact with $\mathrm{A} \beta$ contributing to synaptic perturbations. A Cyp-D deficiency can notably improve synaptic function and therefore improve learning and memory in an AD mouse model [107]. It was recently proposed that tau protein can regulate synaptic activity, affecting mitochondrial function and axonal transport [108], and post-transductionally modified tau can induce mitochondrial damage, leading to synaptic dysfunction [109]. In fact, hyper-phosphorylated tau impairs mitochondrial respiratory chain function, increases ROS levels, decreases the activity of detoxifying enzymes, and produces $\Delta \psi \mathrm{m}$ dissipation [108]. Thus, the accumulation of tau can lead to synaptic deficits and cognitive impairment [110].

Interestingly, cognitive decline is not only characteristic of disease and injury, since cognitive impairment is also observed during aging. During normal aging, it is well established that there is a reduction in the surface area and cortical thickness, resulting in a volume loss in the whole brain, being the non-cortical regions, such as the hippocampus and striatum, more vulnerable to this age-related atrophy [111]. In this context, a study performed with Sprague-Dawley rats of 14, 18, 23, and 27 months of age showed changes in the volume of different brain parts using magnetic resonance imaging (MRI) [112]. In that study they showed enlargement of lateral ventricles and a decrease in the volume of the medial prefrontal cortex, hippocampus, and striatum in 27-month-old rats, which correlates with cognitive deficiency. Twenty-three- and twenty-seven-month-old rats have decreased recognition memory and decreased spatial learning and memory [112]. Another common symptom of aging is cognitive fatigue (CF) characterized by an increase in the facility of becoming tired, lack of energy, and failure to sustain attention when performing cognitively demanding tasks with a high mental effort [113]. There is evidence of a correlation between the decreased connectivity strength of the neuronal network established between the cortical and the striatum areas and a higher CF at an advanced age, suggesting that the cortical-striatal network plays a crucial role in the CF phenomenon [114].

In humans, similar cognitive decline is observed during aging, present as a deficit in episodic or declarative memory, spatial learning, working memory, and attention [115]. These processes are mainly dependent on an adequate function of the hippocampus. Structural and functional changes in the hippocampus are related to the severity and development of neurodegenerative disorders associated with cognitive decline. In fact, many of the cognitive deficits seen with aging can be replicated in animal models with bilateral hippocampal damage [116]. The connection between dentate gyrus (DG) and the CA3 area of the hippocampus is responsible for the formation of new memories, and this is naturally decreased in the aged brain [117], with different biochemical modifications that affect its ability to generate and consolidate LTP [117]. Diverse studies have shown that during aging, the autoassociative network of $\mathrm{CA} 3$ is strengthened, and the processing of new information coming in from the entorhinal cortex is weaker [118]. Thus, the stored information becomes dominant in contrast to the ability to encode new information [118]. Also, there is a decrease in gray matter volume, where age-related changes in the temporal lobe involve mainly changes in the hippocampus [4].

Also, different studies show high levels of tau in cerebrospinal fluid (CSF) during aging $[119,120]$. For example, the characteristic hearing loss (HL) present in aging influences neurodegeneration by promoting tau pathology in CSF [120], which produces cognitive impairment via synapsis dysfunction and neuronal loss [110]. Other studies evidence the age-related impairment of executive functions, verbal and nonverbal cognitive switching (independent of gender, education, and IQ), and the ability to focus attention and/or multitask [121, 122]. Studies have 
shown that during aging, there is a reduction in inhibitory mechanisms in the CA3, where short-term plasticity and LTP are compromised [123]. Interestingly, mitochondria play a central role in LTP, enhancing mitochondrial gene expression [124], satisfying the ATP demand by producing changes in mitochondrial energy production, and regulating calcium homeostasis by increasing calcium pump activity [125]. Also, there is evidence that mitochondrial dysfunction can lead to failure in connectivity of brain cortex producing cognitive impairment [126]. Thus, mitochondrial dysfunction during aging can be related with degeneration of synapses, triggering cell death.

In this mitochondrial context of aging, it is interesting that in brain regions highly associated with cognitive function, such as the hippocampus and cortex, there is a high amount of impaired mitochondria, with dysfunctional respiration, excessive ROS production, loss of $\Delta \psi \mathrm{m}$, and decreased cytochrome c oxidase activity. Meanwhile mitochondria are less affected in areas of the brain that are less involved in cognitive abilities [105]. Therefore, mitochondrial function is a key component in cognition. It allows proper information processing through the brain network, being an important player in synaptic transmission. Mitochondrial dysfunction generates deficits in synapsis that trigger cognitive impairment in

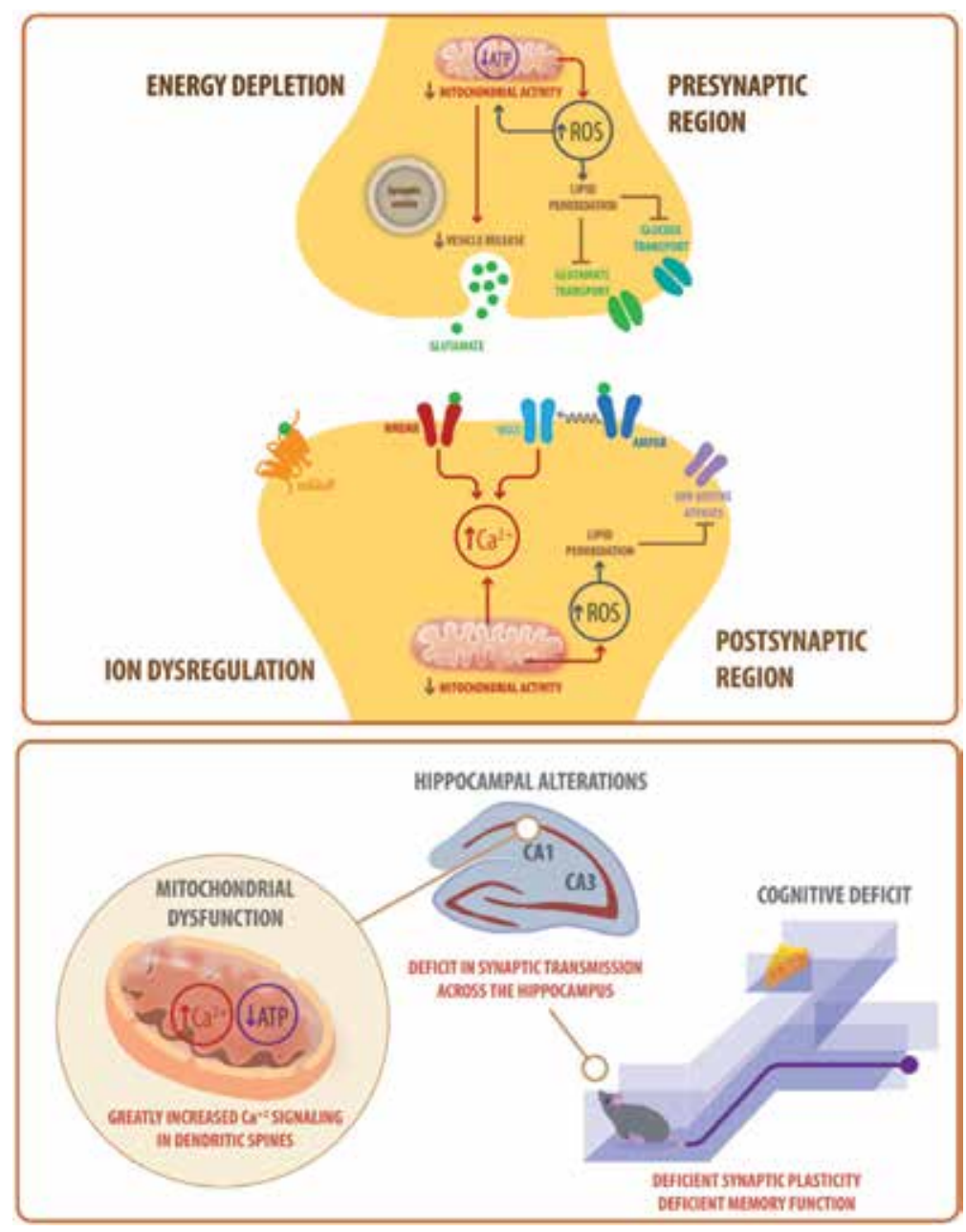

Figure 2.

A synaptic failure leads to cognitive impairment in aging. 
neurodegenerative disease but also in natural aging. Thus, the understanding of these processes may be critical in these times where the aged population is increasing; therefore, improving their quality of life is a priority.

Figure 2 above shows the synaptic effects of mitochondrial failure. In the presynaptic region, decreased mitochondrial activity diminishes ATP content, altering the exocytosis of synaptic vesicles. Also, increased ROS production induces lipid peroxidation, affecting glutamate and glucose transport. In the postsynaptic region, decreased mitochondrial activity disrupts calcium homeostasis, altering postsynaptic signaling. Besides, the increased ROS production and consequent lipid peroxidation impaired ion-motive ATPases. Figure 2 below schematizes that mitochondrial dysfunction at the CA1 of the hippocampus impaired synaptic transmission resulting in cognitive impairment.

\section{Mitochondrial therapies as an antiaging treatment}

Since mitochondrial dysfunction is a key event promoting aging, interventions that focus on maintaining or restoring the correct functioning of the mitochondria seem fundamental. For this purpose, two different experimental strategies could be used [127], physiological approaches or pharmacological approximations, which will be briefly summarized in this section.

From the physiological point of view, maintaining a lifestyle that includes recurrent physical exercise preserves mitochondrial function [127]. During aging a loss of age-associated muscle mass is directly related with decreased mitochondria-dependent metabolic capacity, as well as with reduced mitochondrial biogenesis [128]. Biogenesis of new mitochondria is regulated by the transcriptional coactivator peroxisome proliferator-activated receptor gamma coactivator 1-alpha (PGC-1 $\alpha$ ), which also regulates redox balance and energetic function [129]. Interestingly, PGC-1 $\alpha$ expression is decreased in aging reducing its signaling pathway and gene target [129], an effect that could be counteracted by exercise, demonstrating that exercise also increases mtDNA content in the muscle of aged rats [130]. In addition, exercise increases the expression of the CAT enzyme, reducing ROS levels [131]. Similarly, exercise promotes both fission and fusion events as indicated by upregulated levels of Fis1 and Mfn1 protein in the muscle tissue of old animals and by increased Mfn2 and Drp1 mRNA in the skeletal muscle of older women [132]. Finally, exercise could contribute to restoration of mitochondrial $\mathrm{Ca}^{+2}$ homeostasis, increasing the protein levels of mitochondrial $\mathrm{Ca}^{+2}$ uniporter (MCU) [132]. Thus, exercise during aging could promote the genesis of new mitochondria or could attenuate the mitochondrial dysfunction observed at an advanced age.

A second physiological approximation important for simulating mitochondrial function is caloric restriction, which has been demonstrated in different models that are able to reduce the age-related phenotype and to increase lifespan [133]. The beneficial effects of caloric restriction are directly associated with the bioenergetic defects observed in aging, activating ATP production through fatty acid metabolism [134]. Mechanistically, caloric restriction increases the activity of complexes I, III, and IV of the ETC, as well as MnSOD, which results in increased ATP and reduced ROS levels [135]. Likewise, caloric restriction enhances $\mathrm{Ca}^{+2}$ mitochondrial buffering, decreasing Cyp-D levels [135]. Therefore, regulating caloric ingestion is possible for maintaining mitochondrial activity during aging.

Mitochondrial function can also be regulated pharmacologically, for example, through the administration of polyphenols such as resveratrol, green tea, and red 
wine $[127,136]$. Specifically, they act by promoting mitochondrial OXPHOS and activating cellular antioxidant mechanisms [137]. Another possibility is the use of antioxidant compounds such as MitoQ, an electron scavenger that prevents the formation of mitochondrial free radicals [138]. Similarly, $\alpha$-tocopherol (MitoVitE), $\alpha$-phenyl-tert-butylnitrone (MitoPBN), the piperidine nitroxide MitoTEMPOL, the antioxidant SkQ1, and elamipretide (SS-31) enter and accumulate in the mitochondria preventing oxidative stress and preserving mitochondrial function $[139,140]$. The numerous studies probing the clinical efficacy of these compounds validate the importance of mitochondria in aging [139]. To promote the natural antioxidant effect in the cell, treatment with $\mathrm{N}$-acetylcysteine, vitamin, $\mathrm{C}$ and other physiological antioxidant molecules have also been shown to be effective as palliative treatment of senescence [141, 142].

It is also important to highlight the positive effects induced by the direct administration of fatty acids including omega- 3 fatty acid $\alpha$-linolenic acid, due to studies in vivo that have shown its capacity to extend lifespan [143]. This could be a consequence of increased $\beta$-oxidation, which results in higher mitochondrial energy production, by increasing mitochondrial biogenesis or by reducing oxidative stress [144]. Finally, we will mention the effects of Metformin, a drug commonly used for the treatment of type 2 diabetes. Metformin has a hypoglycemic effect in the plasma and promotes increased insulin sensibility by a mechanism that remains unclear [145]. However, favorable effects have been observed, where DNA damage and inflammation are prevented, impeding cellular damage by reducing ROS production [146].

Therefore, these approaches highlight the key role that mitochondrial function play during aging, where correct mitochondrial activity could extend lifespan, whereas metabolic alterations could compromise mitochondrial function, accelerating the aging phenotype.

\section{Future directions: importance of synaptic mitochondrial dysfunction in aging}

It is now known that the mitochondria have a fundamental role during the aging process. In neurons, the mitochondria are classified into two groups according to their localization, such as synaptic and non-synaptic mitochondria. Non-synaptic mitochondria are distributed throughout the cell body and in the neural prolongations, meanwhile synaptic mitochondria are exclusively found in synapses, both at the pre- and postsynaptic level [147]. Thus, it is not surprising that synaptic mitochondria, which have a higher energy requirement in order to sustain synaptic activity, present functional differences compared to non-synaptic mitochondria. For example, synaptic mitochondria have higher peroxide production than non-synaptic ones [148]. During aging, it seems that these differences are accentuated between these two mitochondrial populations. Aged cortical synaptic mitochondria present decreased oxidative capacity and higher susceptibility to calcium overload, in contrast to non-synaptic mitochondria that preserve their respiratory capacity [16]. Similarly, we observed that hippocampal synaptic mitochondria fail previous to non-synaptic mitochondria during aging and suffer premature mitochondrial swelling with age, contributing hippocampus-dependent memory loss (manuscript in preparation). Thus, maintaining adequate function of synaptic mitochondria seems to be the new challenge in order to attenuate the aging phenotype, reducing the synaptic and cognitive failure characteristics of older individuals. 


\section{Conclusions}

Taken together, the evidence presented in this chapter strongly suggests a close relationship between mitochondrial function and a wide range of processes associated with aging. In general, it is possible to propose an age-dependent decline observed in several organs such as the brain correlated with a loss of mitochondrial activity, generating a bioenergetic deficit and redox imbalance that promote oxidative stress. This promotes additional mitochondrial fail, affecting cellular calcium homeostasis, critical for neurons due to its important roles in the synapses. Thus, synaptic defects conduce to cognitive impairment. Finally, we propose that the synaptic mitochondria are a critical mitochondrial pool to preserve synaptic communication despite the passing of the years.

\section{Acknowledgements}

This work was supported by FONDECYT N¹1170546 and CONICYT PAI $\mathrm{N}^{\circ} 77170091$ to CTR.

\section{Author details}

Claudia Jara ${ }^{\dagger}$, Angie K. Torres ${ }^{\dagger}$, Margrethe A. Olesen and Cheril Tapia-Rojas* Laboratory of Neurobiology of Aging, Centro de Biología Celular y Biomedicina (CEBICEM), Facultad de Medicina y Ciencia, Universidad San Sebastián, Chile

*Address all correspondence to: cheril.tapia@uss.cl

$\uparrow$ Both authors contributed equally to this work.

IntechOpen

(C) 2019 The Author(s). Licensee IntechOpen. This chapter is distributed under the terms of the Creative Commons Attribution License (http://creativecommons.org/licenses/ by/3.0), which permits unrestricted use, distribution, and reproduction in any medium, provided the original work is properly cited. (cc) BY 


\section{References}

[1] Anderson ND, Craik FI. 50 years of cognitive aging theory. The Journals of Gerontology. Series B, Psychological Sciences and Social Sciences. 2017;72(1):1-6

[2] Lindenberger U et al. Agerelated decline in brain resources modulates genetic effects on cognitive functioning. Frontiers in Neuroscience. 2008;2(2):234-244

[3] Lopez-Otin C et al. The hallmarks of aging. Cell. 2013;153(6):1194-1217

[4] Harada CN, Natelson Love MC, Triebel KL. Normal cognitive aging. Clinics in Geriatric Medicine. 2013;29(4):737-752

[5] Bratic A, Larsson NG. The role of mitochondria in aging. The Journal of Clinical Investigation. 2013;123(3):951-957

[6] Lopez-Lluch G et al. Mitochondrial biogenesis and healthy aging. Experimental Gerontology. 2008;43(9):813-819

[7] Jendrach $\mathrm{M}$ et al. Morpho-dynamic changes of mitochondria during ageing of human endothelial cells. Mechanisms of Ageing and Development. 2005;126(6-7):813-821

[8] Falkenberg M, Larsson NG, Gustafsson CM. DNA replication and transcription in mammalian mitochondria. Annual Review of Biochemistry. 2007;76:679-699

[9] Trifunovic A et al. Premature ageing in mice expressing defective mitochondrial DNA polymerase. Nature. 2004;429(6990):417-423

[10] Manoj KM. Aerobic respiration: Criticism of the proton-centric explanation involving rotary adenosine triphosphate synthesis, chemiosmosis principle, proton pumps and electron transport chain. Biochemistry Insights. 2018;11:1178626418818442

[11] Valko $\mathrm{M}$ et al. Free radicals and antioxidants in normal physiological functions and human disease. The International Journal of Biochemistry \& Cell Biology. 2007;39(1):44-84

[12] Jacinto TA et al. Increased ROS production and DNA damage in monocytes are biomarkers of aging and atherosclerosis. Biological Research. 2018;51(1):33

[13] Gunter TE et al. Mitochondrial calcium transport: Mechanisms and functions. Cell Calcium. 2000;28(5-6):285-296

[14] Muller M et al. Mitochondria and calcium regulation as basis of neurodegeneration associated with aging. Frontiers in Neuroscience. 2018;12:470

[15] Oliver DMA, Reddy PH. Molecular basis of Alzheimer's disease: Focus on mitochondria. Journal of Alzheimer's Disease. Vol. Pre-press. 2019. pp. 1-22

[16] Lores-Arnaiz S et al. Brain cortex mitochondrial bioenergetics in synaptosomes and nonsynaptic mitochondria during aging. Neurochemical Research. 2016;41(1-2):353-363

[17] Campos PB, Paulsen BS, Rehen SK. Accelerating neuronal aging in in vitro model brain disorders: A focus on reactive oxygen species. Frontiers in Aging Neuroscience. 2014;6:292

[18] Murphy MP. How mitochondria produce reactive oxygen species. The Biochemical Journal. 2009;417(1):1-13

[19] Stuart JA et al. A midlife crisis for the mitochondrial free radical theory 
of aging. Longevity \& Healthspan. 2014;3(1):4

[20] Liu Y, Fiskum G, Schubert D. Generation of reactive oxygen species by the mitochondrial electron transport chain. Journal of Neurochemistry. 2002;80(5):780-787

[21] Lennicke $\mathrm{C}$ et al. Hydrogen peroxide - production, fate and role in redox signaling of tumor cells. Cell Communication and Signaling: CCS. 2015;13:39

[22] Sena LA, Chandel NS. Physiological roles of mitochondrial reactive oxygen species. Molecular Cell. 2012;48(2):158-167

[23] Wang $\mathrm{CH}$ et al. Oxidative stress response elicited by mitochondrial dysfunction: Implication in the pathophysiology of aging. Experimental Biology and Medicine (Maywood, N.J.). 2013;238(5):450-460

[24] Leuner K et al. Mitochondrionderived reactive oxygen species lead to enhanced amyloid beta formation. Antioxidants \& Redox Signaling. 2012;16(12):1421-1433

[25] Kudryavtseva AV et al. Mitochondrial dysfunction and oxidative stress in aging and cancer. Oncotarget. 2016;7(29):44879-44905

[26] Circu ML, Aw TY. Reactive oxygen species, cellular redox systems, and apoptosis. Free Radical Biology \& Medicine. 2010;48(6):749-762

[27] Jones DP et al. Redox analysis of human plasma allows separation of prooxidant events of aging from decline in antioxidant defenses. Free Radical Biology \& Medicine. 2002;33(9):1290-1300

[28] Espinosa-Diez C et al. Antioxidant responses and cellular adjustments to oxidative stress. Redox Biology. 2015;6:183-197
[29] Barja G. Updating the mitochondrial free radical theory of aging: An integrated view, key aspects, and confounding concepts. Antioxidants \& Redox Signaling. 2013;19(12):1420-1445

[30] Harman D. The free radical theory of aging: Effect of age on serum copper levels. Journal of Gerontology. 1965;20:151-153

[31] Bokov A, Chaudhuri A, Richardson A. The role of oxidative damage and stress in aging. Mechanisms of Ageing and Development. 2004;125(10-11):811-826

[32] Perez VI et al. Is the oxidative stress theory of aging dead? Biochimica et Biophysica Acta. 2009;1790(10):1005-1014

[33] Sun N, Youle RJ, Finkel T. The mitochondrial basis of aging. Molecular Cell. 2016;61(5):654-666

[34] Barbagallo M, Marotta F, Dominguez LJ. Oxidative stress in patients with Alzheimer's disease: Effect of extracts of fermented papaya powder. Mediators of Inflammation. 2015;2015:624801

[35] Deepashree S et al. Oxidative stress resistance as a factor in aging: Evidence from an extended longevity phenotype of Drosophila melanogaster. Biogerontology. 2019;20:497-513

[36] Reddy PH, Beal MF. Amyloid beta, mitochondrial dysfunction and synaptic damage: Implications for cognitive decline in aging and Alzheimer's disease. Trends in Molecular Medicine. 2008;14(2):45-53

[37] Ren X et al. Redox Signaling mediated by Thioredoxin and glutathione Systems in the Central Nervous System. Antioxidants \& Redox Signaling. 2017;27(13):989-1010

[38] Srivastava S. The mitochondrial basis of aging and age-related disorders. Genes (Basel). 2017;8(12):398 
[39] Papa S et al. The oxidative phosphorylation system in mammalian mitochondria. Advances in Experimental Medicine and Biology. 2012;942:3-37

[40] Lunt SY, Vander Heiden MG. Aerobic glycolysis: Meeting the metabolic requirements of cell proliferation. Annual Review of Cell and Developmental Biology. 2011;27:441-464

[41] Lu H et al. Current therapy of drugs in amyotrophic lateral sclerosis. Current Neuropharmacology. 2016;14(4):314-321

[42] Nunomura A et al. Oxidative damage is the earliest event in Alzheimer disease. Journal of Neuropathology and Experimental Neurology. 2001;60(8):759-767

[43] DiMauro S, Schon EA. Mitochondrial disorders in the nervous system. Annual Review of Neuroscience. 2008;31:91-123

[44] Rangaraju V, Calloway N, Ryan TA. Activity-driven local ATP synthesis is required for synaptic function. Cell. 2014;156(4):825-835

[45] Navarro A, Boveris A. Rat brain and liver mitochondria develop oxidative stress and lose enzymatic activities on aging. American Journal of Physiology. Regulatory, Integrative and Comparative Physiology. 2004;287(5):R1244-R1249

[46] Takeda K, Ueda T. Effective mechanism for synthesis of neurotransmitter glutamate and its loading into synaptic vesicles. Neurochemical Research. 2017;42(1):64-76

[47] Naito S, Ueda T. Characterization of glutamate uptake into synaptic vesicles. Journal of Neurochemistry. 1985;44(1):99-109
[48] Pittenger C, Bloch MH, Williams K. Glutamate abnormalities in obsessive compulsive disorder: Neurobiology, pathophysiology, and treatment. Pharmacology \& Therapeutics. 2011;132(3):314-332

[49] Yan MH, Wang X, Zhu X. Mitochondrial defects and oxidative stress in Alzheimer disease and Parkinson disease. Free Radical Biology \& Medicine. 2013;62:90-101

[50] Briston T, Hicks AR. Mitochondrial dysfunction and neurodegenerative proteinopathies: Mechanisms and prospects for therapeutic intervention. Biochemical Society Transactions. 2018;46(4):829-842

[51] Manczak M et al. Differential expression of oxidative phosphorylation genes in patients with Alzheimer's disease: Implications for early mitochondrial dysfunction and oxidative damage. Neuromolecular Medicine. 2004;5(2):147-162

[52] Kawamata H, Manfredi G. Proteinopathies and OXPHOS dysfunction in neurodegenerative diseases. The Journal of Cell Biology. 2017;216(12):3917-3929

[53] Terry RD et al. Physical basis of cognitive alterations in Alzheimer's disease: Synapse loss is the major correlate of cognitive impairment. Annals of Neurology. 1991;30(4):572-580

[54] Barodia SK, Creed RB, Goldberg MS. Parkin and PINK1 functions in oxidative stress and neurodegeneration. Brain Research Bulletin. 2017;133:51-59

[55] Ariga $\mathrm{H}$ et al. Neuroprotective function of DJ-1 in Parkinson's disease. Oxidative Medicine and Cellular Longevity. 2013;2013:683920

[56] Langston JW et al. Chronic parkinsonism in humans due to a 
product of meperidine-analog synthesis. Science. 1983;219(4587):979-980

[57] Cannon JR et al. A highly reproducible rotenone model of Parkinson's disease. Neurobiology of Disease. 2009;34(2):279-290

[58] Schapira AH et al. Mitochondrial complex I deficiency in Parkinson's disease. Journal of Neurochemistry. 1990;54(3):823-827

[59] Cortopassi GA et al. A pattern of accumulation of a somatic deletion of mitochondrial DNA in aging human tissues. Proceedings of the National Academy of Sciences of the United States of America. 1992;89(16):7370-7374

[60] Bua E et al. Mitochondrial DNA-deletion mutations accumulate intracellularly to detrimental levels in aged human skeletal muscle fibers. American Journal of Human Genetics. 2006;79(3):469-480

[61] Kujoth GC et al. Mitochondrial DNA mutations, oxidative stress, and apoptosis in mammalian aging. Science. 2005;309(5733):481-484

[62] Li $\mathrm{H}$ et al. Aging-associated mitochondrial DNA mutations alter oxidative phosphorylation machinery and cause mitochondrial dysfunctions. Biochimica et Biophysica Acta - Molecular Basis of Disease. 2017;1863(9):2266-2273

[63] Emelyanova L et al. Effect of aging on mitochondrial energetics in the human atria. The Journals of Gerontology. Series A, Biological Sciences and Medical Sciences. 2018;73(5):608-616

[64] Nakahara $\mathrm{H}$ et al. Mitochondrial dysfunction in the senescence accelerated mouse (SAM). Free Radical Biology \& Medicine. 1998;24(1):85-92
[65] Lenaz G et al. Mitochondrial complex I defects in aging. Molecular and Cellular Biochemistry. 1997;174(1-2):329-333

[66] Benzi G et al. The mitochondrial electron transfer alteration as a factor involved in the brain aging. Neurobiology of Aging. 1992;13(3):361-368

[67] Itoh K et al. Cytochrome c oxidase defects of the human substantia nigra in normal aging. Neurobiology of Aging. 1996;17(6):843-848

[68] Bertoni-Freddari C et al. Cytochrome oxidase activity in hippocampal synaptic mitochondria during aging: A quantitative cytochemical investigation. Annals of the New York Academy of Sciences. 2004;1019:33-36

[69] Navarro A et al. Behavioral dysfunction, brain oxidative stress, and impaired mitochondrial electron transfer in aging mice. American Journal of Physiology. Regulatory, Integrative and Comparative Physiology. 2002;282(4):R985-R992

[70] Manczak M et al. Time-course of mitochondrial gene expressions in mice brains: Implications for mitochondrial dysfunction, oxidative damage, and cytochrome $\mathrm{c}$ in aging. Journal of Neurochemistry. 2005;92(3):494-504

[71] Klohn PC et al. Early resistance to cell death and to onset of the mitochondrial permeability transition during hepatocarcinogenesis with 2-acetylaminofluorene. Proceedings of the National Academy of Sciences of the United States of America. 2003;100(17):10014-10019

[72] LaFrance R et al. Age-related changes in regional brain mitochondria from Fischer 344 rats. Aging Cell. 2005;4(3):139-145 
[73] Lin DT et al. Ca2+ signaling, mitochondria and sensitivity to oxidative stress in aging astrocytes. Neurobiology of Aging. 2007;28(1):99-111

[74] Frazier HN et al. Calcium's role as nuanced modulator of cellular physiology in the brain. Biochemical and Biophysical Research Communications. 2017;483(4):981-987

[75] Raza M et al. Aging is associated with elevated intracellular calcium levels and altered calcium homeostatic mechanisms in hippocampal neurons. Neuroscience Letters. 2007;418(1):77-81

[76] Mattson MP. Calcium and neurodegeneration. Aging Cell. 2007;6(3):337-350

[77] Korkotian E, Segal M. Release of calcium from stores alters the morphology of dendritic spines in cultured hippocampal neurons. Proceedings of the National Academy of Sciences of the United States of America. 1999;96(21):12068-12072

[78] Brown MR, Geddes JW, Sullivan PG. Brain region-specific, age-related, alterations in mitochondrial responses to elevated calcium. Journal of Bioenergetics and Biomembranes. 2004;36(4):401-406

[79] Decuypere JP et al. IP(3) receptors, mitochondria, and Ca Signaling: Implications for aging. Journal of Aging Research. 2011;2011:920178

[80] Bagur R, Hajnoczky G. Intracellular $\mathrm{Ca}(2+)$ sensing: Its role in calcium homeostasis and Signaling. Molecular Cell. 2017;66(6):780-788

[81] Panel M, Ghaleh B, Morin D. Mitochondria and aging: A role for the mitochondrial transition pore? Aging Cell. 2018;17:e12793
[82] Oh MM et al. Altered calcium metabolism in aging CA1 hippocampal pyramidal neurons. The Journal of Neuroscience. 2013;33(18):7905-7911

[83] Radzik T et al. Calcium Dyshomeostasis alters CCL5 Signaling in differentiated PC12 cells. BioMed Research International. 2019;2019:9616248

[84] Supnet C, Bezprozvanny I. The dysregulation of intracellular calcium in Alzheimer disease. Cell Calcium. 2010;47(2):183-189

[85] Khachaturian ZS. Hypothesis on the regulation of cytosol calcium concentration and the aging brain. Neurobiology of Aging. 1987;8(4):345-346

[86] Khachaturian ZS. The role of calcium regulation in brain aging: Reexamination of a hypothesis. Aging (Milano). 1989;1(1):17-34

[87] Khachaturian ZS. Calcium hypothesis of Alzheimer's disease and brain aging. Annals of the New York Academy of Sciences. 1994;747:1-11

[88] Betzer C, Jensen PH. Reduced cytosolic calcium as an early decisive cellular state in Parkinson's disease and Synucleinopathies. Frontiers in Neuroscience. 2018;12:819

[89] Du H et al. Early deficits in synaptic mitochondria in an Alzheimer's disease mouse model. Proceedings of the National Academy of Sciences of the United States of America. 2010;107(43):18670-18675

[90] Chauhan A, Vera J, Wolkenhauer O. The systems biology of mitochondrial fission and fusion and implications for disease and aging. Biogerontology. 2014;15(1):1-12

[91] Gauba E, Guo L, Du H. Cyclophilin D promotes brain mitochondrial F1FO 
ATP synthase dysfunction in aging mice. Journal of Alzheimer's Disease. 2017;55(4):1351-1362

[92] Kwong JQ, Molkentin JD. Physiological and pathological roles of the mitochondrial permeability transition pore in the heart. Cell Metabolism. 2015;21(2):206-214

[93] Du H et al. Cyclophilin D deficiency improves mitochondrial function and learning/memory in aging Alzheimer disease mouse model. Neurobiology of Aging. 2011;32(3):398-406

[94] Mattson MP. Mitochondrial regulation of neuronal plasticity. Neurochemical Research.

2007;32(4-5):707-715

[95] Bliss TV, Collingridge GL. A synaptic model of memory: Long-term potentiation in the hippocampus. Nature. 1993;361(6407):31-39

[96] Batool S et al. Synapse formation: From cellular and molecular mechanisms to neurodevelopmental and neurodegenerative disorders. Journal of Neurophysiology. 2019;121(4):1381-1397

[97] Cai Q, Tammineni P. Mitochondrial aspects of synaptic dysfunction in Alzheimer's disease. Journal of Alzheimer's Disease. 2017;57(4):1087-1103

[98] Mattson MP, Gleichmann M, Cheng A. Mitochondria in neuroplasticity and neurological disorders. Neuron. 2008;60(5):748-766

[99] Vinothkumar G et al. Abnormal amyloid beta42 expression and increased oxidative stress in plasma of CKD patients with cognitive dysfunction: A small scale case control study comparison with Alzheimer's disease. BBA Clinical. 2017;8:20-27

[100] Walker KR, Tesco G. Molecular mechanisms of cognitive dysfunction following traumatic brain injury. Frontiers in Aging Neuroscience. 2013;5:29

[101] Fujimoto K et al. Targeting cyclophilin D and the mitochondrial permeability transition enhances beta-cell survival and prevents diabetes in $\mathrm{Pdx} 1$ deficiency. Proceedings of the National Academy of Sciences of the United States of America. 2010;107(22):10214-10219

[102] Taddeo EP et al. Opening of the mitochondrial permeability transition pore links mitochondrial dysfunction to insulin resistance in skeletal muscle. Molecular Metabolism. 2014;3(2):124-134

[103] Gozal D, Daniel JM, Dohanich GP. Behavioral and anatomical correlates of chronic episodic hypoxia during sleep in the rat. The Journal of Neuroscience. 2001;21(7):2442-2450

[104] Butterfield DA. Beta-amyloidassociated free radical oxidative stress and neurotoxicity: Implications for Alzheimer's disease. Chemical Research in Toxicology. 1997;10(5):495-506

[105] Dragicevic N et al. Mitochondrial amyloid-beta levels are associated with the extent of mitochondrial dysfunction in different brain regions and the degree of cognitive impairment in Alzheimer's transgenic mice. Journal of Alzheimer's Disease. 2010; 20(Suppl 2):S535-S550

[106] Mattson MP, Partin J, Begley JG. Amyloid beta-peptide induces apoptosis-related events in synapses and dendrites. Brain Research. 1998;807(1-2):167-176

[107] Du H et al. Cyclophilin D deficiency attenuates mitochondrial and neuronal perturbation and ameliorates learning and memory in Alzheimer's disease. Nature Medicine. 2008;14(10):1097-1105 
[108] Eckert A et al. March separate, strike together-role of phosphorylated TAU in mitochondrial dysfunction in Alzheimer's disease. Biochimica et Biophysica Acta. 2014;1842(8):1258-1266

[109] Cheng Y, Bai F. The Association of tau with Mitochondrial Dysfunction in Alzheimer's disease. Frontiers in Neuroscience. 2018;12:163

[110] Di J et al. Abnormal tau induces cognitive impairment through two different mechanisms: Synaptic dysfunction and neuronal loss. Scientific Reports. 2016;6:20833

[111] Lemaitre $\mathrm{H}$ et al. Normal agerelated brain morphometric changes: Nonuniformity across cortical thickness, surface area and gray matter volume? Neurobiology of Aging. 2012;33(3):617 e1-617 e9

[112] Hamezah HS et al. Volumetric changes in the aging rat brain and its impact on cognitive and locomotor functions. Experimental Gerontology. 2017;99:69-79

[113] Leavitt VM, DeLuca J. Central fatigue: Issues related to cognition, mood and behavior, and psychiatric diagnoses. PM \& R: The Journal of Injury, Function, and Rehabilitation. 2010;2(5):332-337

[114] Ren P et al. Cognitive fatigue and cortical-striatal network in old age. Aging (Albany NY). 2019;11:2312-2326

[115] Kausler DH. Learning and Memory in Normal Aging. San Diego, CA, US: Academic Press; 1994

[116] Bettio LEB, Rajendran L, Gil-Mohapel J. The effects of aging in the hippocampus and cognitive decline. Neuroscience and Biobehavioral Reviews. 2017;79:66-86

[117] Yassa MA et al. Age-related memory deficits linked to circuit-specific disruptions in the hippocampus. Proceedings of the National Academy of Sciences of the United States of America. 2011;108(21):8873-8878

[118] Wilson IA et al. Neurocognitive aging: Prior memories hinder new hippocampal encoding. Trends in Neurosciences. 2006;29(12):662-670

[119] Blomberg $\mathrm{M}$ et al. Cerebrospinal fluid tau levels increase with age in healthy individuals. Dementia and Geriatric Cognitive Disorders. 2001;12(2):127-132

[120] Xu W et al. Age-related hearing loss accelerates cerebrospinal fluid tau levels and brain atrophy: A longitudinal study. Aging (Albany NY). 2019;11:3156-3169

[121] Wecker NS et al. Mental flexibility: Age effects on switching. Neuropsychology. 2005;19(3):345-352

[122] Darowski ES et al. Age-related differences in cognition: The role of distraction control. Neuropsychology. 2008;22(5):638-644

[123] Villanueva-Castillo C et al. Agingrelated impairments of hippocampal mossy fibers synapses on CA3 pyramidal cells. Neurobiology of Aging. 2017;49:119-137

[124] Williams JM et al. Synaptic activitydependent modulation of mitochondrial gene expression in the rat hippocampus. Brain Research. Molecular Brain Research. 1998;60(1):50-56

[125] Stanton PK, Schanne FA. Hippocampal long-term potentiation increases mitochondrial calcium pump activity in rat. Brain Research. 1986;382(1):185-188

[126] Fernandez A et al. Mitochondrial dysfunction leads to cortical underconnectivity and cognitive impairment. Neuron. 2019;102:1127-1142 
[127] Madreiter-Sokolowski CT et al. Targeting mitochondria to counteract age-related cellular dysfunction. Genes (Basel). 2018;9(3):165

[128] Joseph AM, Adhihetty PJ, Leeuwenburgh C. Beneficial effects of exercise on age-related mitochondrial dysfunction and oxidative stress in skeletal muscle. The Journal of Physiology. 2016;594(18):5105-5123

[129] Anderson R, Prolla T. PGC-1alpha in aging and anti-aging interventions. Biochimica et Biophysica Acta. 2009;1790(10):1059-1066

[130] Kang C et al. Exercise training attenuates aging-associated mitochondrial dysfunction in rat skeletal muscle: Role of PGC1alpha. Experimental Gerontology. 2013;48(11):1343-1350

[131] Gioscia-Ryan RA et al. Voluntary aerobic exercise increases arterial resilience and mitochondrial health with aging in mice. Aging (Albany NY). 2016;8(11):2897-2914

[132] Zampieri S et al. Physical exercise in aging human skeletal muscle increases mitochondrial calcium uniporter expression levels and affects mitochondria dynamics. Physiological Reports. 2016;4(24):e13005

[133] Lopez-Lluch G, Navas P. Calorie restriction as an intervention in ageing. The Journal of Physiology. 2016;594(8):2043-2060

[134] Bruss MD et al. Calorie restriction increases fatty acid synthesis and whole body fat oxidation rates. American Journal of Physiology. Endocrinology and Metabolism. 2010;298(1):E108-E116

[135] Amigo I et al. Caloric restriction increases brain mitochondrial calcium retention capacity and protects against excitotoxicity. Aging Cell. 2017;16(1):73-81
[136] Baur JA et al. Resveratrol improves health and survival of mice on a high-calorie diet. Nature. 2006;444(7117):337-342

[137] Sandoval-Acuna C, Ferreira J, Speisky H. Polyphenols and mitochondria: An update on their increasingly emerging ROS-scavenging independent actions. Archives of Biochemistry and Biophysics. 2014;559:75-90

[138] Smith RA, Murphy MP. Animal and human studies with the mitochondriatargeted antioxidant MitoQ. Annals of the New York Academy of Sciences. 2010;1201:96-103

[139] El-Hattab AW et al. Therapies for mitochondrial diseases and current clinical trials. Molecular Genetics and Metabolism. 2017;122(3):1-9

[140] Smith RA, Murphy MP. Mitochondria-targeted antioxidants as therapies. Discovery Medicine. 2011;11(57):106-114

[141] Monacelli F et al. Vitamin C, aging and Alzheimer's disease. Nutrients. 2017;9(7):670

[142] Brack C, Bechter-Thuring E, Labuhn $\mathrm{M}$. N-acetylcysteine slows down ageing and increases the life span of Drosophila melanogaster. Cellular and Molecular Life Sciences. 1997;53(11-12):960-966

[143] Champigny CM et al. Omega-3 Monoacylglyceride effects on longevity, mitochondrial metabolism and oxidative stress: Insights from drosophila melanogaster. Marine Drugs. 2018;16(11):453

[144] Afshordel S et al. Omega-3 polyunsaturated fatty acids improve mitochondrial dysfunction in brain aging--impact of Bcl-2 and NPD-1 like metabolites. Prostaglandins, Leukotrienes, and Essential Fatty Acids. 2015;92:23-31 
Mitochondrial Dysfunction as a Key Event during Aging: From Synaptic Failure to Memory Loss DOI: http://dx.doi.org/10.5772/intechopen.88445

[145] Barzilai N et al. Metformin as a tool to target aging. Cell Metabolism. 2016;23(6):1060-1065

[146] Karnewar S et al. Metformin regulates mitochondrial biogenesis and senescence through AMPK mediated H3K79 methylation: Relevance in age-associated vascular dysfunction. Biochimica et Biophysica ActaMolecular Basis of Disease. 2018; 1864(4 Pt A):1115-1128

[147] Ly CV, Verstreken P. Mitochondria at the synapse. The Neuroscientist. 2006;12(4):291-299

[148] Borras C et al. Mitochondria from females exhibit higher antioxidant gene expression and lower oxidative damage than males. Free Radical Biology \& Medicine. 2003;34(5):546-552 



\title{
Coenzyme $\mathrm{Q}_{10}$ and L-Carnitine Disturbances in Children with Mitochondrial Diseases
}

\author{
Ekaterina A. Nikolaeva, Ilgar S. Mamedov \\ and Irina V. Zolkina
}

\begin{abstract}
Coenzyme Q10 (CoQ10) and L-carnitine are very important biologically active compounds involved in energy metabolism. L-carnitine and coenzyme Q10 disturbances in mitochondrial diseases require the correction. Patients and methods: The levels of coenzyme Q10 and L-carnitine (total carnitine, free carnitine, and acylcarnitines) were determined in children with mitochondrial diseases ( 25 children and 16 children, respectively). High-performance liquid chromatography with UV detection (chromatograph Shimadzu Nexera LC-30) and chromatography-mass spectrometry (Agilent 6410 QQQ, USA) were used. As an additional parameter of possible coenzyme Q10 and carnitine insufficiency, the coenzyme Q10/cholesterol ratio and acylcarnitines/free carnitine ratio were calculated. Results: A significantly low ratio of coenzyme Q10/cholesterol in children with mitochondrial diseases was revealed $-0.10 \pm 0.01$ vs. $0.19 \pm 0.01$ in the control group $(\mathrm{p}<0.001)$. A lower absolute level of coenzyme Q10 and tendency toward a more pronounced decrease in the Q10/cholesterol ratio in older patients (6-16 years) were shown. The free carnitine blood level was within the normal range and averaged at $29.8 \pm 2.6 \mu \mathrm{mol} / \mathrm{l}$; however, the level was lower than that in the control group $(44 \pm 5.2 \mu \mathrm{mol} / \mathrm{l}$, $\mathrm{p}<0.05)$. A pronounced significant increase in the acylcarnitines/free carnitine ratio was determined $-1.5 \pm 0.05$ (the normal range $<0.6$ ).
\end{abstract}

Keywords: children, mitochondrial diseases, coenzyme Q10, carnitine, treatment

\section{Introduction}

Mitochondrial diseases are a large heterogeneous group of pathological conditions caused by genetically determined defects in the mitochondria's structure and function in the release of the energy of organic substances and its accumulation in the form of macroergic phosphate compounds by the generation of adenosine triphosphate [1]. These disorders can be due to mutations in mitochondrial DNA or due to mutations in nuclear DNA. Some mitochondrial diseases are rare. However, in general, mitochondrial encephalopathy is the most common neurometabolic disorder [2]. Defects in the respiratory chain and oxidative phosphorylation are the basis of the pathogenesis of these severe diseases.

Mitochondrial diseases have a wide range of clinical presentations with a generally poor prognosis: failure to thrive, encephalopathy, respiratory insufficiency, 
hypotonia, ataxia, seizures, cardiac involvement, hepatopathy and nephropathy, sensorineural hearing loss, retinopathy, lesions of the basal ganglia, and others. The common laboratory signs are lactic acidosis, hypo- or hyperglycemia (diabetes), elevated creatine kinase and aminotransferases, and urine organic acid/amino acid abnormalities [3].

Current therapies are frequently inefficient and mostly palliative. The treatment strategy for mitochondrial diseases is to improve the efficiency of biological processes in the respiratory chain and oxidative phosphorylation. Patients are prescribed complex treatment, including drugs that affect different stages of energy metabolism. This treatment approach shows a higher positive effect than monotherapy [4]. Coenzyme Q10 and L-carnitine are very important biologically active substances involved in energy metabolism. So, coenzyme Q10 and L-carnitine are often recommended for the treatment of mitochondrial diseases [5]. However, some authors acknowledge the lack of rationale behind these recommendations since the data from randomized clinical trials are still lacking.

\section{Functions of $\mathrm{CoQ} 10$ and its biological role}

Coenzyme Q10 is the most common ubiquinone in the human body. Its structure contains a quinoid ring and 10 isoprenyl groups. Coenzyme Q10 is structurally similar to vitamins E and K. Coenzyme Q10 exists in oxidized (ubiquinone) and reduced (ubiquinol) forms and is known to be a constituent of the biological membranes [6]. Coenzyme Q10 is one of the main components of the electron transport chain of mitochondria. In the form of ubiquinone, it acts as an electron transporter from Complex I and Complex II to Complex III. In this process, the formation of the reduced form-ubiquinol-occurs. Ubiquinol is a powerful antioxidant, which has a protective effect on biological membranes, regulates their permeability, inhibits peroxidation of plasma lipoproteins, and provides a recovery of tocopherol activity $[6,7]$. According to the recent data, coenzyme Q10 is reported to be involved in the regulation of some gene expression and inflammatory mediators, in particular, by influencing the transcription factor NFkappaB1; its participation in DNA replication and repair was shown $[8,9]$.

In mammals, the largest amount of coenzyme Q10 is found in the heart and skeletal muscles. In the peripheral blood, coenzyme Q10 is bound to lipoproteins, and its level is positively correlated with total cholesterol $[10,11]$.

Most of the body's daily coenzyme Q10 requirement is derived from endogenous synthesis; small amounts of coenzyme Q10 are obtained from foods such as meat, fish, and nuts. Biosynthesis is a multi-step process, taking place on the inner mitochondrial membrane. Vitamins B2, B3, B6, B12, and C and folic and pantothenic acids are known to participate in the coenzyme Q10 biosynthetic pathway under the control of a dozen genes. The intensity of biosynthesis declines substantially with age $[12,13]$.

\section{Coenzyme Q10 deficiency in disorders: the possibility of diagnosis}

Primary coenzyme Q10 deficiency is due to a defect in its biosynthesis. These diseases form a separate group of mitochondrial diseases and are associated with mutations in multiple genes including PDSS1, PDSS2, CoQ2, CoQ6, CoQ9, and ADCK3. These diseases are characterized by a decrease in the level of coenzyme Q10 in tissues and in fibroblasts whereas the blood levels can be normal $[11,14,15]$. Secondary coenzyme deficiency with low plasma and tissue coenzyme Q10 levels 
can occur in patients taking anticancer agents and statins. The hypocholesterolemic effect of statins is due to the inhibition of 3-hydroxy-3-methylglutaryl-COA reductase and a disruption of the synthesis of mevalonic acid, which is one of the precursors of not only cholesterol but also ubiquinone. Approximately a half of patients receiving statins show a decrease in coenzyme Q10 in the muscle tissue; myalgia and myoglobinuria may also be observed $[16,17]$.

Secondary coenzyme Q10 deficiency and low levels of coenzyme Q10 in plasma and tissues are found in certain diseases of older age (Parkinson's and Alzheimer's disease, atherosclerosis, diabetes mellitus, etc.) $[13,18,19]$, in some hereditary diseases, including inborn errors of metabolism - mevalonic aciduria, phenylketonuria, glutaric acidemia II, ataxia-oculomotor apraxia 1, and cardiofaciocutaneous syndrome $[11,20]$. Coenzyme Q10 deficiency in mevalonic aciduria and in phenylketonuria can be explained by insufficient cholesterol production: the decrease in the activity of mevalonate kinase and the inhibition of 3-hydroxy-3-methylglutarylCOA reductase with high levels of phenylalanine, respectively. In phenylketonuria, ubiquinone deficiency may well be exogenous due to dietary restrictions such as avoidance of animal products [10].

A decrease in coenzyme Q10 was reported in the peripheral blood and muscles in some (20-40\%) patients with mitochondrial pathology associated with mutations and depletion of mitochondrial DNA [21, 22]. Of interest, in children with myopathy due to other causes, there were no changes in the content of coenzyme Q10 in the muscles, except for the patients with Duchenne muscular dystrophy [23].

The coenzyme Q10 deficiency can be detected in biological fluids (plasma or serum), fibroblasts, and muscle tissue. However, the blood level of coenzyme Q10 is not considered as a reliable indicator of its state in the body. There is no clear correlation between the levels of ubiquinone in plasma and muscle tissue. This parameter is influenced by the lipid intake from foods and the blood levels of cholesterol and low-density lipoproteins $[7,10,11]$. Therefore, the ratio of coenzyme Q10 to cholesterol and low-density lipoproteins is proposed for clinical use. Apparently, the measurement of coenzyme Q10 in the peripheral blood mononuclear cells appears to be a promising detection method.

\section{Low blood level of coenzyme Q10 as a diagnostic marker of mitochondrial encephalomyopathy and the rationale for therapy}

In the Research and Clinical Institute of Pediatrics, an examination of 16 children (group 1) aged $1-16$ years (average age $8.3 \pm 1.5$ years) with mitochondrial diseases was performed.

In nine children, the disease was caused by deletions or point mutations of mitochondrial DNA: Kearns-Sayre syndrome (common deletion of mitochondrial DNA) in three; mitochondrial encephalomyopathy with pyramidal-extrapyramidal syndrome (MTND1 mutation) in two; mitochondrial encephalomyopathy with cardiomyopathy (MTTK mutations) in two; mitochondrial myopathy, encephalopathy, lactic acidosis, and stroke-like episodes (MTTL1 mutation) in 1; and maternal inherited Leigh syndrome (MTND3 mutation) in 1.

Seven children were diagnosed with mitochondrial diseases of nuclear origin: leukoencephalopathy with brain stem and spinal cord involvement and lactate elevation (DARS2 mutations) in four and Leigh syndrome (SURF1 mutations) in three.

The comparison group (group 2) consisted of 13 children with neurodegenerative diseases aged $1-15$ years (mean age $6.4 \pm 1.3$ y): 6 children with neuronal ceroid 
lipofuscinosis 2 (TPP1 mutations), 2 with sialidosis type 2 (NEU1 mutations), and 5 with progressive ataxia not genetically confirmed. The control group (group 3) consisted of 29 healthy children aged 1-16 years (mean age $7.4 \pm 0.8$ y) who underwent a routine examination at the health center (an informed consent of the parents was obtained) [24]. The ratio of boys:girls is $16: 13$. There was no statistically significant difference in the average age between the three groups.

A detailed work-up of the patients of the first two groups included clinical (pedigree, neurological, cardiological, and other examinations) examination and biochemical tests. In all children, the plasma level of coenzyme Q10 was determined by high-performance liquid chromatography with UV detection (chromatograph Shimadzu Nexera LC-30). The blood cholesterol level was determined photometrically (analyzer Konelab Prime 60i), followed by the calculation of the coenzyme Q10/cholesterol ratio. The DNA diagnosis of diseases was carried out in the laboratory of inborn errors of metabolism of Research Centre for Medical Genetics (Moscow, Russia).

Statistical data processing was carried out by methods of variation statistics and correlation analysis (Statistica, Excel 7.0). Student's t-test was used to assess the statistical significance of the data, and the differences were considered statistically significant at $\mathrm{p}<0.05$.

The blood levels of coenzyme Q10 in children with mitochondrial diseases (group 1) were $0.56 \pm 0.05 \mu \mathrm{mol} / \mathrm{l}$ (Table 1) and did not differ from that in the control group but was significantly lower $(\mathrm{p}<0.01)$ than that in children with neurodegenerative diseases (group 2). The blood level of coenzyme Q10 in children with neurodegenerative diseases was $1.53 \pm 0.23 \mu \mathrm{mol} / \mathrm{l}$ and significantly exceeded that in healthy children $(\mathrm{p}<0.01)$.

The blood cholesterol level in patients of the first and second groups was significantly higher than that in healthy children $(\mathrm{p}<0.01)$. The ratio of coenzyme Q10/cholesterol was severely impaired compared with that in healthy children (see

Table 1). This parameter was significantly decreased in patients with mitochondrial diseases $(0.10 \pm 0.01$ vs. $0.19 \pm 0.01, \mathrm{p}<0.001)$ but increased in those with neurodegenerative diseases $(0.31 \pm 0.04, \mathrm{p}<0.002)$.

For the subgroup analysis, children aged $1-5$ and 6-16 years were analyzed separately within each group (Table 2). In healthy children (group 3), there were no age-related differences.

In the group of older patients with mitochondrial diseases, the blood level of coenzyme Q10 was significantly lower than that in the younger subgroup $(\mathrm{p}<0.05)$ and was significantly different from its level in children in the second

\begin{tabular}{|c|c|c|c|}
\hline \multirow{2}{*}{$\begin{array}{l}\text { Groups of } \\
\text { children }\end{array}$} & \multicolumn{3}{|c|}{ Levels in the blood } \\
\hline & Coenzyme Q10, $\mu \mathrm{mol} / 1$ & $\begin{array}{c}\text { Cholesterol, } \\
\mu \mathrm{mol} / \mathbf{l}\end{array}$ & Coenzyme Q10/cholesterol \\
\hline Group 1, $\mathrm{n}=16$ & $0.56 \pm 0.05$ & $5.7 \pm 0.32$ & $0.10 \pm 0.01$ \\
\hline Group 2, n = 13 & $1.53 \pm 0.23$ & $4.8 \pm 0.31$ & $0.31 \pm 0.04$ \\
\hline Group 3, n = 29 & $0.67 \pm 0.04$ & $3.5 \pm 0.12$ & $0.19 \pm 0.01$ \\
\hline $\mathrm{p}$ & $\begin{array}{l}{ }^{1-2} p<0.001 \\
{ }^{2-3} p<0.001\end{array}$ & $\begin{array}{l}{ }^{1-3} p<0.001 \\
{ }^{2-3} p<0.001\end{array}$ & $\begin{array}{l}{ }^{1-2} p<0.001 \\
{ }^{1-3} p<0.001 \\
{ }^{2-3} p<0.002\end{array}$ \\
\hline
\end{tabular}

${ }^{1-2} p,{ }^{1-3} p$, and ${ }^{2-3} p$ - significance of differences between groups (1-2, 1-3, and 1-3)

Table 1.

Coenzyme $Q 10$ and cholesterol levels $(M \pm m)$ in the blood of the examined children. 


\begin{tabular}{|c|c|c|c|}
\hline \multirow[t]{2}{*}{ Groups of children } & \multicolumn{3}{|c|}{ Levels in the blood } \\
\hline & $\begin{array}{c}\text { Coenzyme Q10, } \\
\mu \mathrm{mol} / \mathrm{l}\end{array}$ & $\begin{array}{c}\text { Cholesterol, } \\
\mu \mathrm{mol} / 1\end{array}$ & $\begin{array}{c}\text { Coenzyme Q10/ } \\
\text { cholesterol }\end{array}$ \\
\hline \multicolumn{4}{|l|}{ Group 1, n = 16} \\
\hline Age $1-5$ years, $n=6$ & $0.73 \pm 0.15^{*}$ & $\begin{array}{c}6.4 \pm 0.81 \\
{ }^{1-2} p<0.05 \\
{ }^{1-3} p<0.001\end{array}$ & $\begin{array}{c}0.12 \pm 0.03 \\
{ }^{1-2} p<0.001 \\
{ }^{1-3}<0.05\end{array}$ \\
\hline Age $6-16$ years, $n=10$ & $\begin{array}{c}0.47 \pm 0.04 \\
{ }^{1-2} p<0.001 \\
{ }^{1-3} p<0.05\end{array}$ & $\begin{array}{c}5.5 \pm 0.38 \\
{ }^{1-3} p<0.001\end{array}$ & $\begin{array}{l}0.09 \pm 0.01 \\
1-2 p<0.001 \\
{ }^{1-3} p<0.001\end{array}$ \\
\hline \multicolumn{4}{|l|}{ Group 2, n = 13} \\
\hline Age $1-5$ years, $n=7$ & $\begin{array}{c}1.18 \pm 0.26 \\
{ }^{2-3} p<0.001\end{array}$ & $\begin{array}{r}4.4 \pm 0.44 \\
{ }^{2-3} p<0.05\end{array}$ & $\begin{array}{l}0.26 \pm 0.03 \\
{ }^{2-3} p<005\end{array}$ \\
\hline Age $6-16$ years, $n=6$ & $\begin{array}{c}1.93 \pm 0.37 \\
{ }^{2-3} p<0.001\end{array}$ & $\begin{array}{c}5.3 \pm 0.38 \\
{ }^{2-3} p<0.001\end{array}$ & $\begin{array}{l}0.37 \pm 0.07 \\
{ }^{2-3} p<0.05\end{array}$ \\
\hline \multicolumn{4}{|l|}{ Group 3, n = 29} \\
\hline Age $1-5$ years, $n=15$ & $0.64 \pm 0.04$ & $3.5 \pm 0.16$ & $0.19 \pm 0.02$ \\
\hline Age 6-16 years, $n=14$ & $0.69 \pm 0.07$ & $3.6 \pm 0.18$ & $0.20 \pm 0.02$ \\
\hline
\end{tabular}

*Significant difference from the older age subgroup; $p<0.05 .{ }^{1-2} p,{ }^{1-3} p$, and ${ }^{2-3} p-$ significance of differences between groups (1-2, 1-3, and 1-3)

Table 2.

Coenzyme Q10 and cholesterol levels $(M \pm m)$ in the blood in children of different age subgroups.

$(\mathrm{p}<0.001)$ and third $(\mathrm{p}<0.05)$ groups of the same age. In addition, older patients (6-16 years) tend to have lower cholesterol levels and lower coenzyme Q10/cholesterol ratios than younger patients (1-5 years). In the group of children with mitochondrial encephalomyopathies, there was a negative correlation between the blood level of coenzyme Q10 and cholesterol and the patient's age $(\mathrm{r}=-0.54$ and $\mathrm{r}=-0.48$, respectively; $\mathrm{p}<0.05)$. There were no differences in the studied parameters between children with mitochondrial diseases caused by mutations of mitochondrial $(n=9)$ and nuclear $(n=6)$ DNA. By age, these subgroups were not different.

In the group of children with neurodegenerative diseases, the opposite tendency was observed toward higher rates of coenzyme Q10, cholesterol, and their ratios in patients of the older subgroup (see Table 2); unreliability of differences seems to be associated with a small number of patients. A positive correlation between the blood levels of coenzyme Q10 and cholesterol ( $r=0.66 ; \mathrm{p}<0.05)$ was established. These parameters correlated positively with the age of the patients $(r=0.37$ and $\mathrm{r}=0.41$, respectively; $\mathrm{p}<0.05$ ).

To sum up, our study demonstrated that the average level of coenzyme Q10 in patients with mitochondrial diseases did not differ from that in healthy children. However, these patients had a higher cholesterol level and, as a result, a reduced ratio of coenzyme Q10/cholesterol. In patients of the older subgroup (6-16 years), the changes were more pronounced: significantly lower levels of coenzyme Q10 and a tendency toward a lower Q10/cholesterol ratio than the younger subgroup (1-5 years).

In children with neurodegenerative diseases (not caused by primary mitochondrial dysfunction), the level of cholesterol (as well as in the first group) was higher than that in healthy children. Other test results differed considerably from those in patients with mitochondrial pathology. High blood level of coenzyme Q10 and an 
increase in the coenzyme Q10/cholesterol ratio were revealed, and these changes increased with age.

Due to a small sample size, the obtained data were considered as preliminary. Nevertheless, our results revealed a coenzyme Q10 deficiency in children with mitochondrial diseases and emphasized the difference in the pathogenesis of primary mitochondrial diseases and neurodegenerative diseases of non-mitochondrial origin. In both patient groups, the age-related aggravation of these changes was noted to correspond to a progressive disease course. The similarity of clinical manifestations underlies the difficulties in the differential diagnosis between mitochondrial encephalomyopathies and neurodegenerative diseases. The detection of the plasma coenzyme Q10 level can be helpful in the differential diagnosis between these conditions.

In addition, a low coenzyme Q10/cholesterol ratio and a tendency toward a decrease in the coenzyme Q10 levels with age suggest its insufficiency in patients with progressive mitochondrial encephalomyopathy. This provides a rationale for the use of coenzyme Q10 in the treatment of patients with mitochondrial diseases.

\section{Functions of carnitine and its biological role}

Carnitine ( $\beta$-hydroxy- $\gamma$-trimethylaminobutyric acid) is a low molecular weight compound, which is crucial for energy metabolism in the human body. As an L-stereoisomer, carnitine is present in various tissues. Endogenous carnitine formation occurs in the liver, kidney, and brain cells through the transformation of the amino acids lysine and methionine, with a glycine involvement. Vitamins C, B6, and $\mathrm{B} 3$ and iron ions are the cofactors for carnitine biosynthesis. The biosynthesis steps are under the control of mitochondrial enzymes (trimethyl-lysine deoxygenase, 3-OH-trimethyl-lysine aldolase, 4-trimethylaminobutanal dehydrogenase, butyrobetaine dioxygenase) [25]. However, biosynthesis provides only a part of carnitine daily requirements, and the main source of its intake is animal foods including red meat, fish, and dairy products. Carnitine absorption in the gastrointestinal tract, tubular reabsorption, and delivery to the tissue are provided by transport proteins, with OCTN2 being the main carnitine transporter. Carnitine is transported to the skeletal muscles and myocardium - these tissues contain the main reserves of carnitine, due to their high activity of lipid metabolism [26]. The importance of carnitine for the body is evidenced by its almost complete reabsorption in the renal tubules.

Studies have established the value of carnitine for the processes of biological oxidation and maintenance of mitochondrial functions in the human body. Carnitine is crucial in conditions of a high energy consumption. These conditions such as intercurrent diseases, increased physical activity, starvation, etc. are characterized by increased catabolism. After depletion of carbohydrate reserves, lipids become the main sources of the ATP synthesis in the body.

One of the main vital functions of carnitine is bioenergetics. Carnitine is involved in lipid catabolism, providing its initial stages - an activation and a transfer of long-chain fatty acids from the cytoplasm through the outer and inner mitochondrial membranes to the mitochondrial matrix, thereby making them available for subsequent $\beta$-oxidation to form acetyl-CoA. In addition, fatty acid oxidation is the main pathway of ketogenesis, and ketone bodies are an additional energy substrate for peripheral tissues and the brain [26, 27].

The effect of carnitine on fat metabolism occurs through its participation in the cytoplasmic synthesis of fatty acids. Carnitine provides the reverse transfer of acetyl groups of mitochondrial acetyl-CoA through the mitochondrial membrane into the cytoplasm. 
An important function of carnitine is due to its ability to bind acyl radicals. Thus, carnitine regulates tissue energy metabolism, affecting the ratio of acyl$\mathrm{CoA} /$ free $\mathrm{CoA}$ in the mitochondria. Likewise, the detoxifying role of carnitine is achieved through binding of organic acid derivatives (intermediates in oxidative processes) and its excretion from the cell. These organic acid derivatives, accumulating in the mitochondria and cytoplasm, have an adverse effect, by inhibiting the enzyme activity.

Carnitine appears to play an important role in the permeability of mitochondrial membranes. The protective impact of carnitine relies on the prevention of a negative membranotropic action of toxic agents, inhibitors of complexes of a mitochondrial respiratory chain (3-nitropropionic acid, methylphenylpyridine, and others), and inducers of apoptosis (long-chain fatty acid radicals). Carnitine supplementation in experimental animals prevents these disorders or significantly reduces their severity and prevents a degenerative damage to the nervous tissue [28-31].

In addition, a favorable impact of carnitine on the cytokine production and on vascular endothelium was revealed. Carnitine is capable of restoring endothelial function and preventing of vascular remodeling caused by a decrease in nitric oxide production $[25,32,33]$. Apparently, the carnitine functions require further research.

\section{Carnitine deficiency in diseases}

There are primary and secondary carnitine deficiencies. The primary deficiency is due to an autosomal recessive defect of the gene SLC22A5, which is expressed in the skeletal muscles, heart, and kidneys. The gene SLC22A5 encodes a transport protein OCTN2, the sodium-dependent organic cation transporter. The genetic defect disrupts the transport of carnitine into the tissues and reabsorption in the renal tubules. The clinical manifestations of the disease include cardiomyopathy, skeletal myopathy, fatty liver, and kidney dystrophy [34].

The causes of secondary carnitine deficiency are diverse and associated with an interruption of endogenous synthesis and disturbance of absorption from food and of retention in the body, as well as with an increased excretion through the kidneys or gastrointestinal tract [35]. The activity of endogenous carnitine biosynthesis depends on the function of the liver and kidneys. Biosynthesis decreases with malnutrition due to a protein deficiency. Carnitine removal is enhanced in stress, intercurrent diseases, and impaired renal tubular function. Low blood carnitine level is determined in children with epilepsy treated with valproate, in patients with heart failure, and in patients on hemodialysis [36-38].

Secondary insufficiency occurs in inborn errors of metabolism. In particular, secondary carnitine insufficiency is characteristic for a large group of hereditary diseases of organic and fatty acid metabolism. In these diseases, low levels of carnitine in the peripheral blood and tissues result from the accumulation of acylcarnitines and their enhanced renal excretion [34, 39].

\section{The carnitine insufficiency in children with mitochondrial encephalomyopathies}

Some patients with mitochondrial diseases (about one-fourth patients) were reported to have a decrease in carnitine levels in the peripheral blood [40, 41]. Our study was designed to diagnose and treat carnitine insufficiency in patients with mitochondrial diseases; to achieve this, we analyzed the clinical parameters and 
laboratory findings of 40 children aged 2-15 years: 25 with mitochondrial encephalomyopathies (group 1) and 15 with congenital myopathies (group 2). Group 1 consisted of 10 children with Kearns-Sayre syndrome (common deletion of mitochondrial DNA); 2 with mitochondrial myopathy, encephalopathy, lactic acidosis, and stroke-like episodes (MTTL1 mutation); 1 with myoclonic epilepsy associated with ragged-red fibers (MTTK mutation); 5 with leukoencephalopathy with brain stem and spinal cord involvement and lactate elevation (DARS2 mutations); 1 with Barth syndrome (TAZ mutation); 3 with Leigh syndrome (SURF1 mutations); and 3 with POLG-related diseases (mitochondrial recessive ataxia syndrome in 2 and autosomal recessive progressive external ophthalmoplegia in 1). Group 2 consisted of 10 children with central core disease and 5 with minicore myopathy. The control group included 10 children without mitochondrial diseases or congenital myopathies, who attended the clinic.

The clinical examination included pedigree, neurological, cardiological, and other examinations. In all children, acid-base balance of the blood and the level of lactic and pyruvic acids were determined. The level of L-carnitine-total carnitine, free carnitine ( $\mathrm{C} 0)$, and acylcarnitines (AC) —in dry blood spots was measured by chromatography-mass spectrometry (Agilent 6410 QQQ, USA). As an additional parameter of a possible carnitine insufficiency, the ratio AC/C0 was calculated. The DNA diagnosis of mitochondrial diseases was carried out in the laboratory of inborn errors of metabolism of the Research Centre for Medical Genetics (Moscow, Russia). Structural myopathy was diagnosed using a morphological study of muscle tissue (light and electronic microscopy, histochemical methods).

Statistical data processing was carried out by methods of variation statistics and correlation analysis (Statistica, Excel 7.0). Student's t-test was used to assess the statistical significance of the data, and the differences were considered statistically significant at $\mathrm{p}<0.05$.

In children with mitochondrial diseases, the clinical presentations of the nervous and muscular system involvement prevailed: fast fatigability, low exercise tolerance, muscle weakness and hypotension, and a development delay. Severe psychomotor retardation was noted in three children with Leigh syndrome. Most patients had ataxia, ophthalmoplegia, headaches and vomiting, and heart damage (atrioventricular blockade, cardiomyopathy). Some patients had a short stature, seizures, retinitis pigmentosa, a hearing loss, and an impaired liver function with a moderate increase in blood aspartate and alanine aminotransferase.

Compensated metabolic acidosis was detected in 12 of 25 children. Elevated blood lactate levels were noted within the range $2.9-6.7 \mathrm{mmol} / \mathrm{l}$ in 20 children (the normal range 1.0-1.7 mmol/l). In 11 patients, the pyruvate level was elevated (0.19-0.39 mmol/l, norm 0.09-0.12 $\mu \mathrm{mol} / \mathrm{l})$.

In children with mitochondrial diseases, the total carnitine blood levels (Figure 1) ranged from 39.1 to $95.3 \mu \mathrm{mol} / \mathrm{l}$, averaging $(\mathrm{M} \pm \mathrm{m}) 75.8 \pm 6.2 \mu \mathrm{mol} / \mathrm{l}$ (in the control group-from 41.1 to $119.9 \mu \mathrm{mol} / \mathrm{l} ; 73.7 \pm 9.7 \mu \mathrm{mol} / \mathrm{l}$ ). There was a negative correlation between the total carnitine and lactate in the peripheral blood of patients with mitochondrial diseases $(\mathrm{r}=-0.65 ; \mathrm{p}<0.05)$.

The free carnitine blood level was within the normal range $(19-60 \mu \mathrm{mol} / \mathrm{l})$ and averaged at $29.8 \pm 2.6 \mu \mathrm{mol} / \mathrm{l}$; however, the level was lower than that in the control group $(44 \pm 5.2 \mu \mathrm{mol} / \mathrm{l}, \mathrm{p}<0.05)$. In six patients, the free carnitine blood level was at the lower limit of the normal range, not exceeding $25 \mu \mathrm{mol} / \mathrm{l}$.

The average acylcarnitine level was $44.5 \pm 3.7 \mu \mathrm{mol} / \mathrm{l}$ (see Figure 1); $87 \%$ of acylcarnitines were represented by acetylcarnitine (C2). Acetylcarnitine level was $38.7 \pm 3.9 \mu \mathrm{mol} / \mathrm{l}$ (higher than that in control group; $\mathrm{p}<0.05$ ); its level in four children went beyond the limit of the normal range $(56.3,60.2,64.5,65.7 \mu \mathrm{mol} / \mathrm{l}$ at a rate of up to $50 \mu \mathrm{mol} / \mathrm{l})$. 


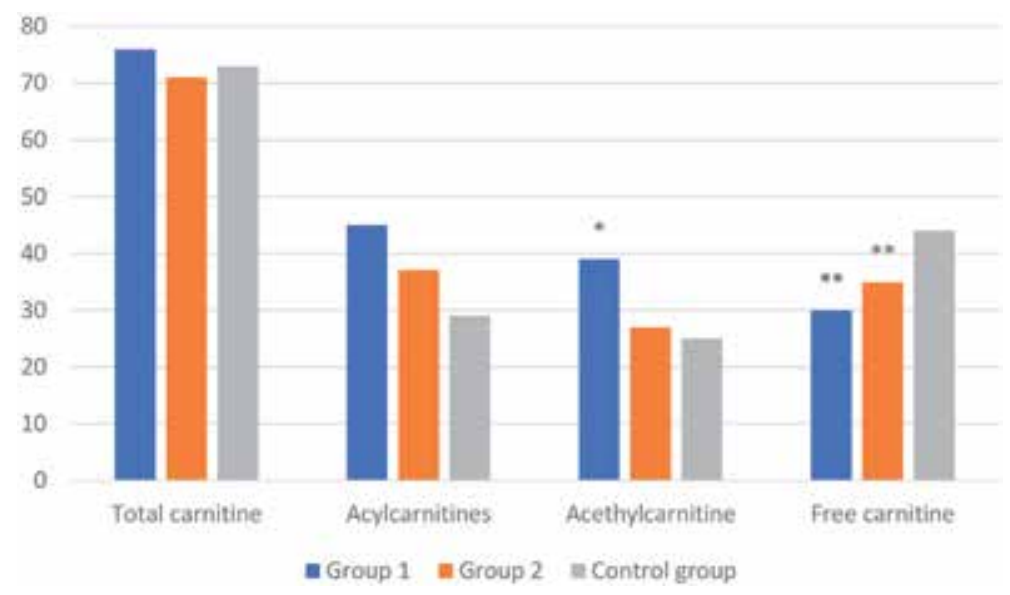

Figure 1.

Comparison of carnitine levels ( $\mu \mathrm{mol} / \mathrm{l}$ ) in dry blood spots in children of three groups. ${ }^{*}$ significant difference $(p<0.05)$ with groups 2 and $3 .{ }^{* *}$ significant difference $(p<0.05)$ with group 3.

About a half (13) of the patients had elevated levels of other acylcarnitines: methylmalonyl-(C4DC), tiglyl-(C5: 1), glutaryl-(C5DC), hydroxybutyryl-(C4OH), hydroxyisovaleryl-( $\mathrm{C} 5 \mathrm{OH})$, and hexanoyl-(C6); there was an increase in the blood levels of alanine, glycine, and leucine. These metabolic changes are likely to be associated with the activation of ketogenesis, an impaired metabolism of lactate and pyruvate in mitochondrial diseases.

On average, the proportion of free carnitine was merely $39 \%$ of the total blood carnitine (the normal range is $70-80 \%$ ). The proportion of acylcarnitines was $61 \%$, significantly exceeding that of healthy subjects (20-30\%).

The ratio of acylcarnitines and free carnitine $\mathrm{AC} / \mathrm{C} 0$ was markedly increased to $1.3-1.8$, reaching an average of $1.5 \pm 0.05$ (the normal range $<0.6$ ). The increase in this ratio suggests the relative insufficiency of free carnitine and confirms the accumulation of esterified forms in the total carnitine pool.

In the patients with congenital myopathies, the clinical presentations predominantly included myopathic manifestations, impaired motor development, and increased fatigue. Moderately elevated blood lactate levels were found in eight children (1.9-2.8 $\mathrm{mmol} / \mathrm{l}$, the normal range $1.0-1.7 \mathrm{mmol} / \mathrm{l})$. In 10 patients, the pyruvate level was increased $(0.17-0.5 \mathrm{mmol} / \mathrm{l}$, norm $0.09-0.12 \mathrm{mmol} / \mathrm{l})$.

The total carnitine blood levels in children ranged from 46.7 to $106.1 \mu \mathrm{mol} / \mathrm{l}$, averaging at $(\mathrm{M} \pm \mathrm{m}) 71.4 \pm 3.5 \mu \mathrm{mol} / \mathrm{l}$. There was no difference in total carnitine level between the patients with congenital myopathies and the control group.

The mean free carnitine level of $35.0 \pm 1.9 \mu \mathrm{mol} / \mathrm{l}$ was within the normal range, but it was lower than that in the control group $(\mathrm{p}<0.05)$. In two children with structural myopathy, free carnitine level was at the lower limit of the normal range.

The mean level of acylcarnitines was normal $(36.9 \pm 2.4 \mu \mathrm{mol} / \mathrm{l})$. Likewise, the level of acetylcarnitine is not elevated. Of note, levels of other acylcarnitines were moderately elevated in three patients.

The proportion of free carnitine in the total carnitine was reduced-49\% (the normal range $70-80 \%$ ). The proportion of the esterified forms accounted for $51 \%$ of the total carnitine, which significantly exceeded the corresponding values of healthy individuals (20-30\%). The ratio of acylcarnitines and free carnitine AC/C0 was increased to $0.9-1.7$, averaging at $1.1 \pm 0.08$ (norm $<0.6$ ), which was consistent with carnitine insufficiency. In the control group of conditionally healthy children, 
the ratio of $\mathrm{AC} / \mathrm{C} 0$ was $0.66 \pm 0.03$ and was significantly different from that in groups 1 and $2(\mathrm{p}<0.01)$.

The comparison of the carnitine parameters in patients with mitochondrial encephalomyopathies and congenital myopathies showed that in mitochondrial diseases, carnitine deficiency was more pronounced. Although the levels of acylcarnitines, free and total carnitine, were not significantly different, in the group of children with mitochondrial diseases, there was a tendency for an accumulation of bound carnitine and a lower level of free carnitine. Additionally, an acetylcarnitine level was significantly higher, and the impairment of total carnitine composition was more pronounced in children with mitochondrial diseases than in those with congenital myopathies. This was confirmed by a higher ratio of AC/C0 (1.5 \pm 0.05 vs. $1.1 \pm 0.08 ; \mathrm{p}<0.01)$.

The detection of carnitine deficiency underscores the need for L-carnitine therapy. L-carnitine per os in a dose of $30-50 \mathrm{mg} / \mathrm{kg} /$ day (depending on age) was included in the complex of energy treatment (coenzyme Q10, succinates, vitamin B) of patients with mitochondrial diseases. Within 1 year, three courses of therapy (for 2 months) were prescribed with a period off treatment for 1-2 months.

After 10-12 months of a follow-up of 18 children, a distinct improvement in one third of the patients was demonstrated: a reduction of fatigue, an improvement of exercise tolerance, and a reduction in the frequency of headache and nausea attacks. In one half cases, a stabilization with minimal positive dynamics was observed. These 15 children showed a decrease in the blood lactate level to $1.4-2.3 \mathrm{mmol} / \mathrm{l}$. At the same time, in three children with Leigh syndrome, despite the treatment, a moderate progression of the disease with a persistent lacticidemia was observed.

The total carnitine remained at the same level $(70.5 \pm 5.1 \mu \mathrm{mol} / \mathrm{l})$; a tendency ( $\mathrm{p}>0.05)$ toward an increase in the free carnitine level $(36.2 \pm 2.9 \mu \mathrm{mol} / \mathrm{l})$ and a decrease in the acylcarnitine level $(34.3 \pm 4.1 \mu \mathrm{mol} / \mathrm{l})$, including acetylcarnitine, was noted. A significant improvement in the $\mathrm{AC} / \mathrm{C} 0$ ratio was revealed-a decrease to 0.9 ( $\mathrm{p}<0.001)$; the proportion of free carnitine in total carnitine increased significantly to $52 \%(\mathrm{p}<0.01)$. In general, the data indicate favorable changes: a reduction in carnitine deficiency, an improvement of its function, and a reduction in ketogenesis and in the severity of lactate metabolism disorders.

\section{Conclusion}

Coenzyme Q10 and carnitine are important components of energy metabolism that are involved in many biological processes in the human body. Our data suggest that there is an insufficiency of these compounds in patients with mitochondrial diseases. Our studies have not revealed the severe deficiency of these substances, while the evidence for a relative insufficiency were found. According to our laboratory data, coenzyme Q10 deficiency is manifested by a significantly low ratio of coenzyme Q10/cholesterol. Lower absolute level of coenzyme Q10 and tendency toward a more pronounced decrease in the Q10/cholesterol ratio in older patients (6-16 years), in our opinion, are consistent with the progressive course of mitochondrial pathology.

Carnitine deficiency is manifested by a tendency toward a decrease in the free carnitine blood level, a pronounced decrease in its proportion in total carnitine, and a significant increase in the ratio of bound and free carnitines.

The coenzyme Q10 and free carnitine insufficiency certainly adversely affects the course of the disease. The causes for these disorders remain unclear. Perhaps, defective mitochondria are not able to provide adequate biosynthesis of coenzyme Q10. Depletion of free carnitine is likely to occur as a result of the activation of 
conjugation of acyl radicals, which accumulate in the disorders of respiratory chain and oxidative phosphorylation.

Given a crucial role of carnitine and coenzyme in mitochondrial energy processes, the insufficiency of these compounds should be treated. Clinical heterogeneity of mitochondrial diseases justifies further research in homogeneous patient groups in order to develop evidence-based recommendations and ensure higher treatment efficacy. Furthermore, a moderate carnitine deficiency in congenital structural myopathies provides indications for carnitine supplementation.

\section{Author details}

Ekaterina A. Nikolaeva* ${ }^{1 *}$ Ilgar S. Mamedov² and Irina V. Zolkina²

1 Research and Clinical Institute of Pediatrics named after Yuri Veltischev, Pirogov Russian National Research Medical University, Russian Ministry of Health, Moscow, Russian Federation

2 LLC “Laboratory of Chromatographic Systems”, Moscow, Russian Federation

*Address all correspondence to: kate_nikolaeva09@mail.ru

\section{IntechOpen}

(C) 2019 The Author(s). Licensee IntechOpen. This chapter is distributed under the terms of the Creative Commons Attribution License (http://creativecommons.org/licenses/ by/3.0), which permits unrestricted use, distribution, and reproduction in any medium, provided the original work is properly cited. (cc) BY 


\section{References}

[1] Tucker EJ, Compton AG, Thorburn DR. Recent advances in the genetics of mitochondrial encephalopathies. Current Neurology and Neuroscience Reports. 2010;10(4):277-285

[2] Debray FG, Lambert M, Chevalier I, Robitaille Y, Decarie JC, Shoubridge EA, et al. Long-term outcome and clinical spectrum of 73 pediatric patients with mitochondrial diseases. Pediatrics. 2007;119(4):722-733

[3] Kanungo S, Morton J, Neelakantan M, Ching K, Saeedian J, Goldstein A. Mitochondrial disorders. Annals of Translational Medicine. 2018;6(24):475

[4] Parikh S, Goldstein A, Koenig MK, Scaglia F, Enns GM, Saneto R, et al. Diagnosis and management of mitochondrial disease: A consensus statement from the mitochondrial medicine society. Genetics in Medicine. 2015;17(9):689-701

[5] El-Hattab AW, Zarante AM, Almannai M, Scaglia F. Therapies for mitochondrial diseases and current clinical trials. Molecular Genetics and Metabolism. 2017;122(3):1-9

[6] Crane FL. Biochemical functions of coenzyme Q10. Journal of the American College of Nutrition. 2001;20(6):591-598

[7] Molyneux SL, Yong JM, Florkowski CM, Lever M, George PM. Coenzyme Q10: Is there a clinical role and a case for measurement? Clinical Biochemist Reviews. 2008;29:71-82

[8] Schmelzer C, Lindner I, Rimbach G, Niklowitz P, Menke T, Döring F. Functions of coenzyme Q10 in inflammation and gene expression. BioFactors. 2008;32(1-4):179-183

[9] Zhai J, Bo Y, Lu Y, Liu C, Zhang L. Effects of coenzyme Q10 on markers of inflammation: A systematic review and meta-analysis. PLoS ONE. 2017;12:e170172

[10] Hargreaves IP. Coenzyme Q10 in phenylketonuria and mevalonic aciduria. Mitochondrion. 2007;7(Suppl. 1):S175-S180

[11] Emmanuele V, López LC, Berardo A, Naini A, Tadesse S, Wen B, et al. Heterogeneity of coenzyme Q10 deficiency: Patient study and literature review. Archives of Neurology. 2012;69(8):978-983

[12] Quinzii CM, López LC, Von-Moltke J, Naini A, Krishna S, Schuelke M, et al. Respiratory chain dysfunction and oxidative stress correlate with severity of primary CoQ10 deficiency. The FASEB Journal. 2008;22(6):1874-1885

[13] Hernández-Camacho JD, Bernier M, López-Lluch G, Navas P. Coenzyme Q10 supplementation in aging and disease.

Frontiers in Physiology. 2018;9:44

[14] DiMauro S, Quinzii C, Hirano M. Mutations in coenzyme Q10 biosynthetic genes. The Journal of Clinical Investigation. 2007;117(3):587-589

[15] Malicdan MCV, Vilboux T, Ben-Zeev B, Guo J, Eliyahu A, PodeShakked B, et al. A novel inborn error of the coenzyme Q10 biosynthesis pathway: Cerebellar ataxia and static encephalomyopathy due to COQ5 C-Methyltransferase deficiency. Human Mutation. 2018;39(1):69-79

[16] Lamperti C, Naini AB, Lucchini V, Prelle A, Bresolin N, Moggio M, et al. Muscle coenzyme Q10 level in statin-related myopathy. Archives of Neurology. 2005;62:1709-1712

[17] Qu H, Guo M, Chai H, Wang W, Gao Z, Shi D. Effects of coenzyme Q10 on 
statin-induced myopathy: An updated meta-analysis of randomized controlled trials. Journal of the American Heart Association. 2018;7(19):e009835

[18] DiNicolantonio JJ, Bhutani J, McCarty MF, O’Keefe JH. Coenzyme Q10 for the treatment of heart failure: A review of the literature. Open Heart. 2015;2(1):e000326

[19] Mantle D, Hargreaves I. Coenzyme Q10 and degenerative disorders affecting longevity: An overview. Antioxidants (Basel). 2019;8(2):44

[20] Nikolaeva EA, Mamedov IS. Deficiency of coenzyme Q10 in children: Clinical and genetic variants, diagnosis and treatment. Rossiyskiy Vestnik Perinatologii i Pediatrii (Russian Bulletin of Perinatology and Pediatrics). 2012;57(2):77-83. (In Russ.)

[21] Sacconi S, Trevisson E, Salviati L, Aymé S, Rigal O, Redondo AG, et al. Coenzyme Q10 is frequently reduced in muscle of patients with mitochondrial myopathy. Neuromuscular Disorders. 2010;20:44-48

[22] Montero R, Grazina M, LópezGallardo E, Montoya J, Briones P, Navarro-Sastre A, et al. Artuch R; coenzyme $Q_{10}$ deficiency study group. Coenzyme $Q_{10}$ deficiency in mitochondrial DNA depletion syndromes. Mitochondrion. 2013;13(4):337-341

[23] Miles L, Miles MV, Tang PH, Horn PS, Wong BL, DeGrauw TJ, et al. Muscle coenzyme Q: A potential test for mitochondrial activity and redox status. Pediatric Neurology. 2005;32(5):318-324

[24] Nikolaeva EA, Kharabadze MN, Zolkina IV, Kulagina TE, Vasina TN, Stavtseva SN, et al. Diagnostic value of blood coenzyme Q10 levels in children with mitochondrial diseases. Rossiyskiy Vestnik Perinatologii i Pediatrii (Russian
Bulletin of Perinatology and Pediatrics). 2015;60 (5):71-75. (In Russ.)

[25] Sharma S, Black SM. Carnitine homeostasis, mitochondrial function, and cardiovascular disease. Drug Discovery Today: Disease Mechanisms. 2009;6(1-4):e31-e39

[26] Das AM, Steuerwald U, Illsinger S. Inborn errors of energy metabolism associated with myopathies. Journal of Biomedicine \& Biotechnology. 2010;2010:340849

[27] Houten SM, Wanders RJA. A general introduction to the biochemistry of mitochondrial fatty acid $\beta$-oxidation. Journal of Inherited Metabolic Disease. 2010;33(5):469-477

[28] Wang C, Sadovova N, Ali HK, Duhart HM, Fu X, Zou X, et al.

L-carnitine protects neurons from 1-methyl-4-phenylpyridiniuminduced neuronal apoptosis in rat forebrain culture. Neuroscience. 2007;144(1):46-55

[29] Oyanagi E, Yano H, Kato Y, Fujita H, Utsumi K, Sasaki J. L-Carnitine suppresses oleic acid-induced membrane permeability transition of mitochondria. Cell Biochemistry and Function. 2008;26(7):778-786

[30] Zou X, Sadovova N, Patterson TA, Divine RL, Hotchkiss CE, Ali SF, et al. The effects of L-carnitine on the combination of, inhalation anestheticinduced developmental, neuronal apoptosis in the rat frontal cortex. Neuroscience. 2008;151(4):1053-1065

[31] Sue YM, Chou HC, Chang CC, Yang NJ, Chou Y, Juan SH. L-carnitine protects against carboplatin-mediated renal injury: AMPK- and PPAR $\alpha$ dependent inactivation of NFAT3. PLoS One. 2014;9(8):e104079

[32] Bueno R, Alvarez de Sotomayor M, Perez-Guerrero C, Gomez-Amores L, 
Vazquez CM, Herrera MD. L-carnitine and propionyl-L-carnitine improve endothelial dysfunction in spontaneously hypertensive rats: Different participation of NO and COX-products. Life Sciences. 2005;77(17):2082-2097

[33] Yousefinejad A, Siassi F, Javanbakht MH, Mohammadi H, Ghaedi E, Zarei $M$, et al. Effect of Genistein and L-carnitine and their combination on lipid profile and inflammatory cytokines in experimental Nephrotic syndrome. Reports of Biochemistry and Molecular Biology. 2018;7(1):1-8

[34] Longo N, Frigeni M, Pasquali M. Carnitine transport and fatty acid oxidation. Biochimica et Biophysica Acta. 2016;1863(10):2422-2435

[35] Buist NR. Historical perspective on clinical trials of Carnitine in children and adults. Annals of Nutrition \& Metabolism. 2016;68(Suppl 3):1-4

[36] Adeva-Andany MM, CalvoCastro I, Fernández-Fernández C, Donapetry-García C, Pedre-Piñeiro AM. Significance of l-carnitine for human health. IUBMB Life. 2017;69(8):578-594

[37] El Mously S, Abdel Ghaffar H, Magdy R, Hamza S, Mansour M. Carnitine deficiency in epileptic children treated with a diversity of anti-epileptic regimens. Egyptian Journal of Neurology, Psychiatry and Neurosurgery. 2018;54(1):37

[38] Moreira da Silva Guimarães S, de Souza Cruz WM, de Souza Weigert G, Scalco FB, Colafranceschi AS, Ribeiro MG, et al. Decompensated chronic heart failure reduces plasma L-carnitine. Archives of Medical Research. 2018;49(4):278-281

[39] Mamedov I, Zolkina I, Nikolaeva E, Glagovsky P, Sukhorukov V. Carnitine insufficiency in children with inborn errors of metabolism: Prevalence and treatment efficacy. Journal of Pediatric Endocrinology \& Metabolism. 2015;28(11-12):1299-1304

[40] Pancrudo J, Shanske S, Coku J, Lu J, Mardach R, Akman O, et al. Mitochondrial myopathy associated with a novel mutation in mtDNA. Neuromuscular Disorders. 2007;17(8):651-654

[41] Haas RH, Chir B, Parikh S, Saneto RP, Wolf NI, Darin N, et al. The In-depth evaluation of suspected mitochondrial disease. Molecular Genetics and Metabolism. 2008;94(1):16-37 



\section{Edited by Stavros Baloyannis}

The mitochondrion is a unique and ubiquitous organelle that contains its own genome, encoding essential proteins that are major components of the respiratory chain and energy production system. Mitochondria play a dominant role in the life and function of eukaryotic cells including neurons and glia, as their survival and activity depend

upon mitochondrial energy production and supply. Besides energy production, mitochondria also play a vital role in calcium homeostasis and may induce apoptosis by excitotoxicity. Mitochondrial dysfunction is related to common neurological diseases, such as Parkinson's disease, Alzheimer's disease, Friedreich's ataxia, Huntington's disease, and Multiple Sclerosis. An efficient treatment of mitochondrial dysfunction would open new horizons in the therapeutic perspectives of a substantial number of inflammatory and degenerative neurological disorders. 